\title{
AN ATTEMPTED TRANSINFECTION OF WOLBACHIA IN THE WESTERN HONEY BEE (APIS MELLIFERA)
}

\author{
A thesis \\ submitted in partial fulfillment for the requirements \\ for the degree of Master of Science in Ecology and Biodiversity
}

March 2018

\section{Jessica Francis Elizabeth Jane Russell}

School of Biological Sciences,

Victoria University of Wellington,

New Zealand

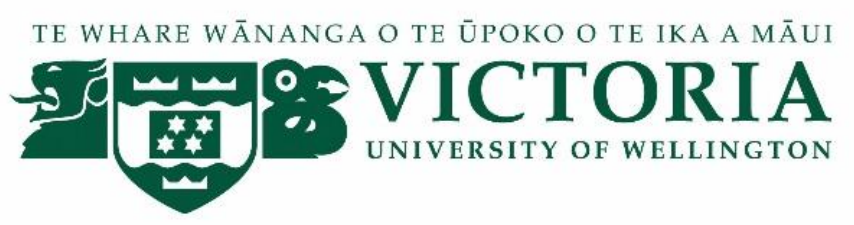


Wolbachia, an intracellular endosymbiont found in up to $60 \%$ of arthropods, has been celebrated for its highly varied host-phenotype interactions. These effects are diverse, ranging from reproductive manipulations to obligate mutualisms and facultative symbiosis. These facultative effects include increased resistance to, and reduction in the ability to vector, a number of RNA viruses in insects. Artificial transinfection to mediate human vector-borne diseases such as Dengue fever and Zika virus in Aedes mosquitoes has had considerable success globally. However, using Wolbachia to mediate zoonotic disease directly in threatened species has not been examined. The Western honey bee (Apis mellifera) has shown significant global population declines across the US and Europe, suffering from a diverse range of pathogens, including viral RNA and parasite vector networks. Wolbachia infection in honey bees has only been detected once and its effects have not been investigated. Here, I present the first attempted transinfection of Wolbachia in the Western honey bee using established transinfection protocols.

The natural, but rarely found, Wolbachia infection reported in A. mellifera was examined against a robust phylogeny of all existing Wolbachia supergroups, a feat that has not been updated in the literature since 2015. I discovered Wolbachia infection in Ancistrocerus gazella, the European tube wasp, where it has never been observed. I isolated the natural Wolbachia strain hosted by Drosophila melanogaster (wMel ) and more than 1200 individuals from a range of honey bee life stages (from eggs to adults) were used as potential Wolbachia recipients using sound microinjection protocols. Additionally, I present a novel transinfection avenue utilizing artificial insemination and honey bee breeding using Wolbachia-inoculated drone semen.

When no individuals were successfully infected with Wolbachia in $F_{0}$ or $F_{1}$, I investigated the expression of several antimicrobial peptides to characterize the immune response in young larvae to Wolbachia microinjection. There was a significant upregulation of apidaecin when injected with live Wolbachia, but not heat-treated bacteria, which has never been reported in host immune response to Wolbachia previously. The findings presented in this study highlight the importance of Wolbachia strain selection, immune response to Wolbachia, and the potential requirement for cell line culture in future transinfection attempts into A. mellifera. These findings will help inform future transinfection attempts, which are encouraged. 


\title{
ACKNOWELDGEMENTS
}

\author{
The busy bee has no time for sorrow. \\ - William Blake
}

They say it takes a village to raise a child, and although this thesis isn't a child, it threw enough tantrums to convince one otherwise. So, I therefore have a small village of people to thank.

Firstly, thank you to my supervisor Professor Phil Lester, for putting your faith in me to undertake this project, for your support and patience, and for putting up with the ever constant "Hi Phil!" in the hallways. Thank you for bringing me down to Earth when I got a bit overwhelmed, for always being so knowledgeable and for maintaining your sense of humour even when I wasn't funny. To the members of the Ants, Bees and Wasp group, thank you for your incredible intelligence and for inspiring me with your amazing research. I feel blessed to be working so closely with people who are going to be published in Science and Nature. Thank you to James Baty, who has taught me everything I know in the lab and is always willing to take time to answer questions and to Alexandra Sebastien for teaching me what a PCR was. Evan, I give you an extra shout out for re-sparking my enthusiasm when I started to feel 100\% over it, for loving what you do so much, and for being the most efficient person I've ever met. Antoine, you make my heart sing.

Thank you to Peter Dearden and his wonderful team down at Otago University for allowing me to use their facilities and for not laughing at my crazy ideas. Thank you to Gemma for your wonderful (and somewhat twisted) sense of humour towards wasps, and to Mackenzie for allowing me to share my experience in feeling terrible for hurting bees. To Otto Hyink, thank you for your honey bee expertise and for enabling the logistics of the artificial insemination experiment as well as providing nucs. Many thanks to Frans Laas of Better Bees for giving up his time to inseminate those lovely queens. Thank you to Emily Remnant, who seems to be the only person in the world as excited about Wolbachia as I am.

Closer to home, thank you to Chris Thorn for being fly supply queen and working around my everconstant logistical struggles with nothing but a smile. Thank you to Mike Jackson for your humour and willingness to help. Additionally, Frank Lindsay, my heart goes out to you for your endless knowledge of and passion for bees - thank you for supplying those first eggs that sparked my excitement.

To my friends and support crew, I love you endlessly and I need to thank you for keeping me sane when nothing was working. To Matt, for always being there, and always being down for a whinge, a laugh, and coffee in the tearoom (a.k.a keeping me sane); to Roald for being as obsessed with birds as I am with 
bees and for being the best desk buddy a girl could ask for - thank you for your R expertise and for sharing my love of CorelDraw; Kate, for always reminding me to keep my work/life balance in check; Matire, for your reality checks and good humour; Brianna, for board games, getting me outside, and giggles; Marni, for your loving heart and endless and unwavering support; and Louise for being such an encouraging little spirit all the way in up Auckland. I also thank my Nana Biff for being so curious about my studies and for (still) thinking I'm studying to become a beekeeper; and to Granddad and Uncle Borris, who are always around in one way or another.

More than anyone, I would like to thank the rock in my life, my mama, Julie, for having endless faith in me, and bringing everything back into perspective. Through your own struggles over the last year you still manage to have the answers, whether about university, personal mishaps or to tell me where my planets are. You always know exactly what to say and I will never be able to thank you enough for it. I hope I've made you as proud as you make me.

Last, but certainly not least, I would like to thank the bees, particularly those who had to lose their lives for this thesis. I'm sorry for being such an atrocious beekeeper, but I want you to know I acknowledged every sting and tone change. Thank you for trusting me and I'm deeply sorry some of you had to die for this study. I promise it was with the best of intentions. 


\section{TABLE OF CONTENTS}

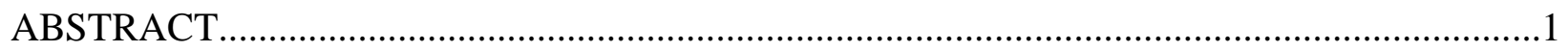

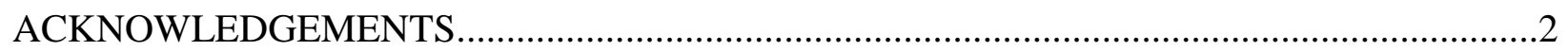

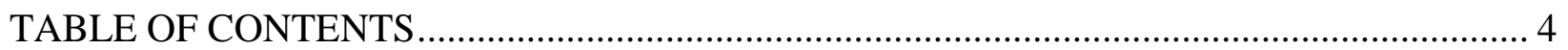

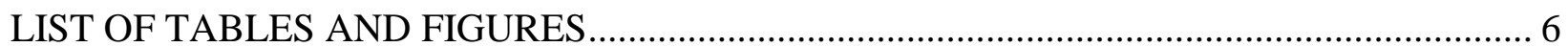

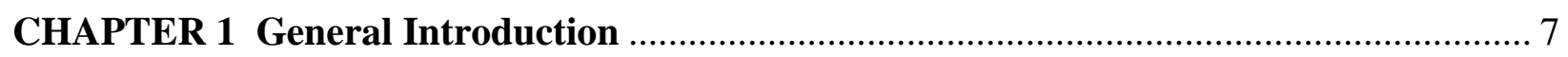

The importance of the honey bee ...................................................................................... 7

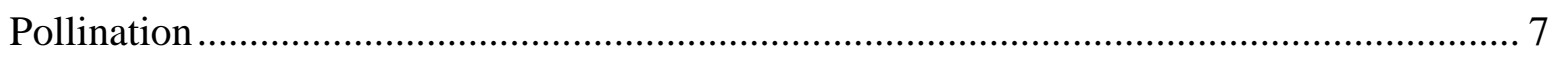

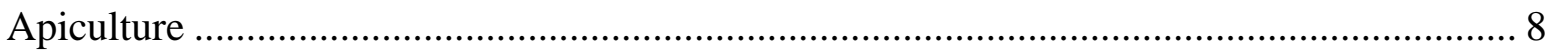

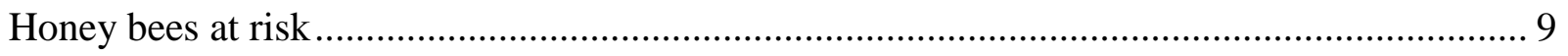

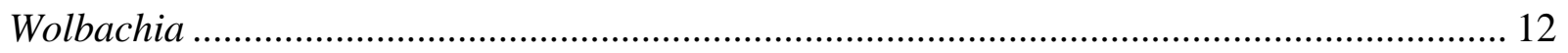

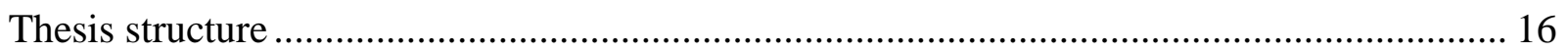

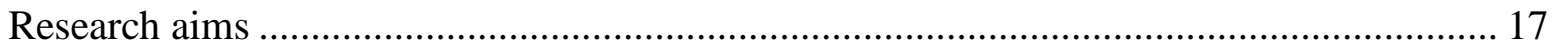

CHAPTER 2 Wolbachia transinfection viability in pre-pupated Apis mellifera .................. 18

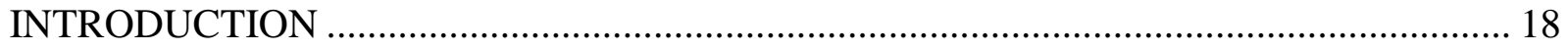

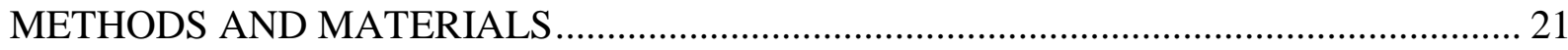

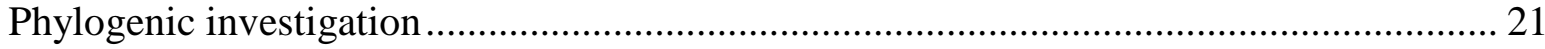

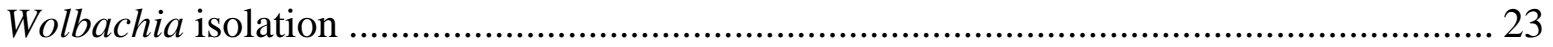

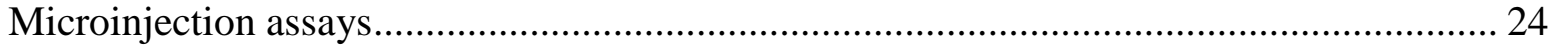

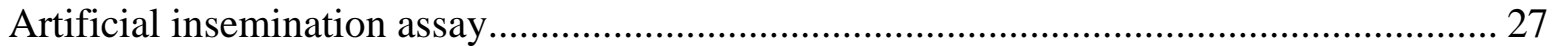

Deformed Wing Virus infection and survival assay .................................................... 28

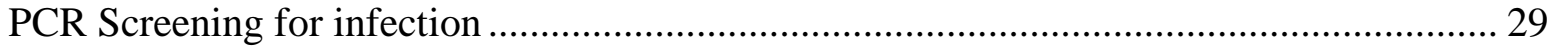

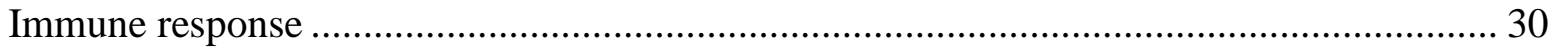

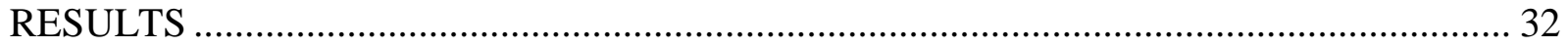

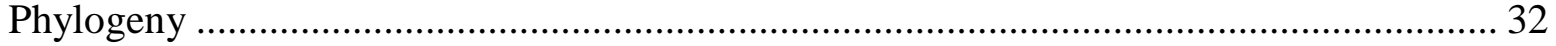

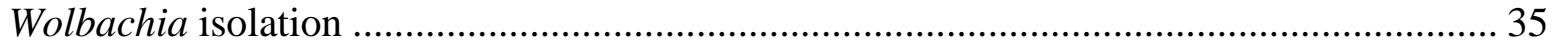

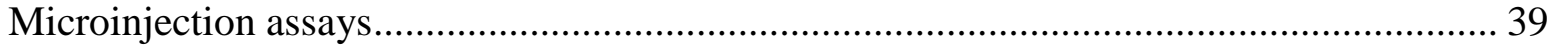

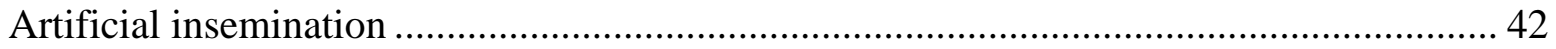

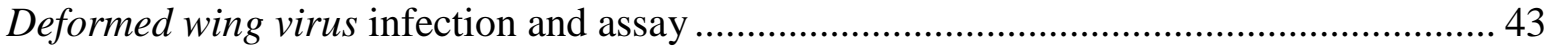

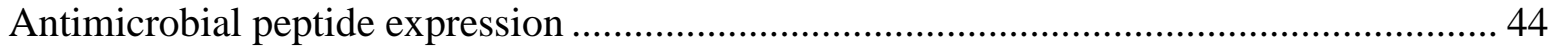




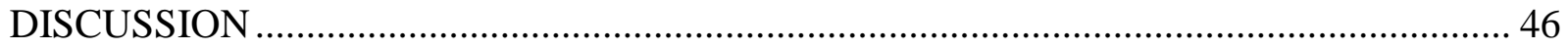

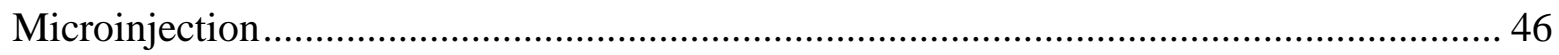

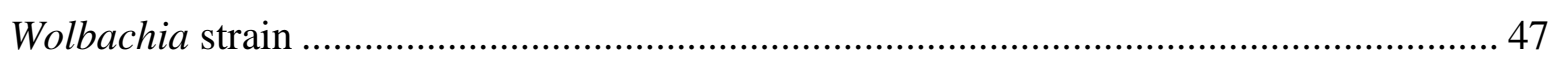

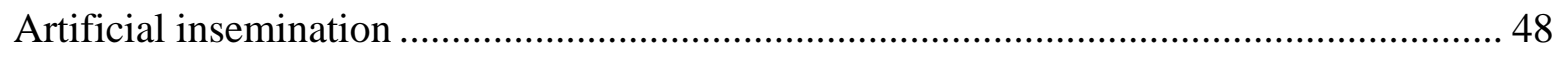

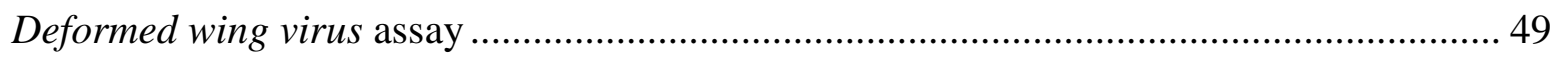

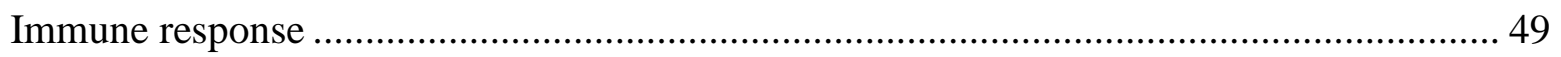

CHAPTER 3 Conclusions and future reccommendations ................................................ 52

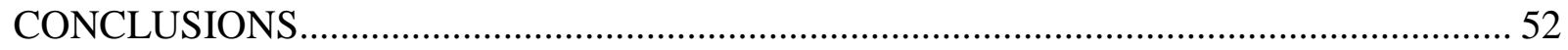

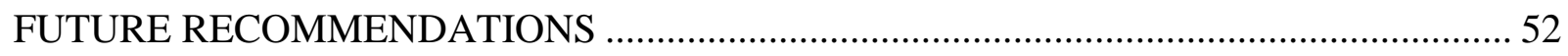

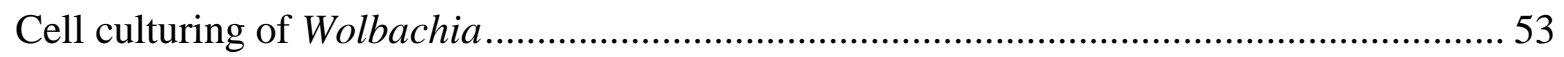

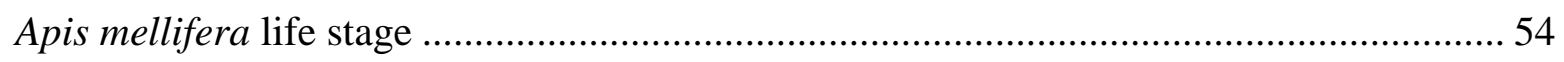

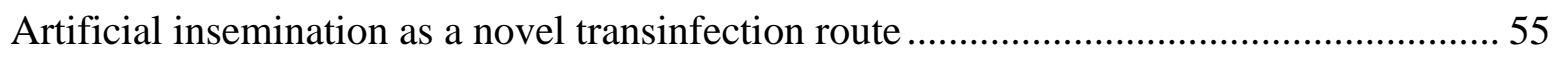

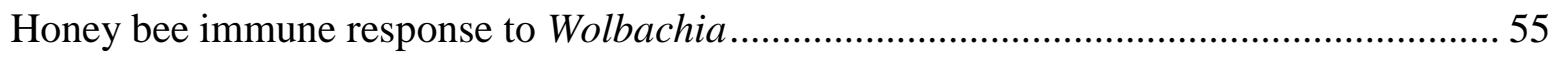

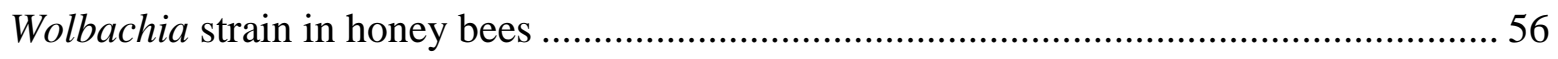

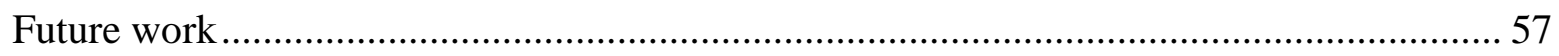

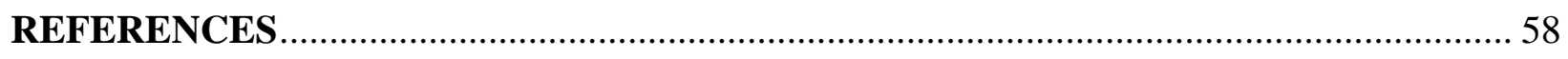

APPENDIX 1 Protocol for the rearing of Apis mellifera larvae from eggs to pupation....... 80

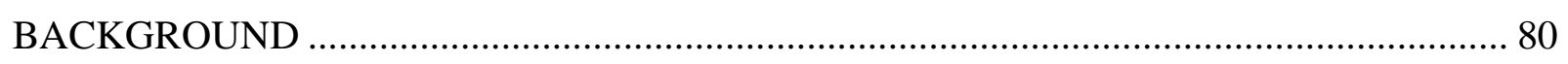

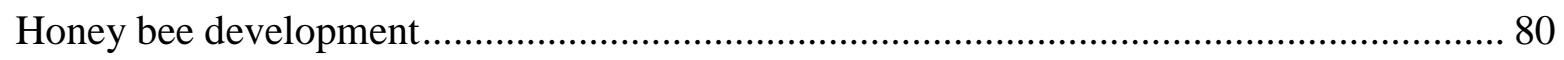

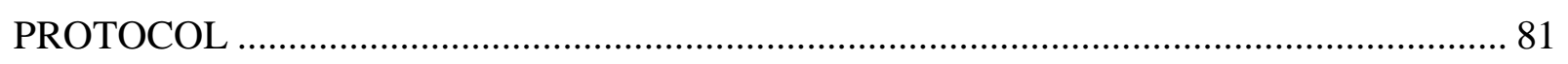

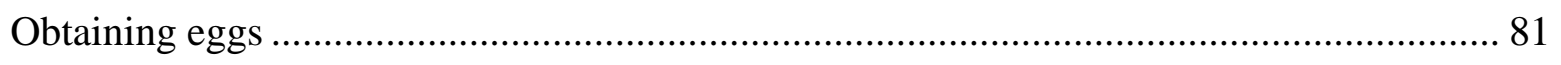

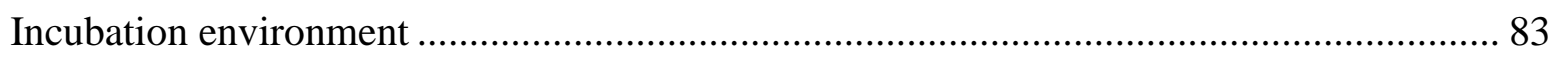

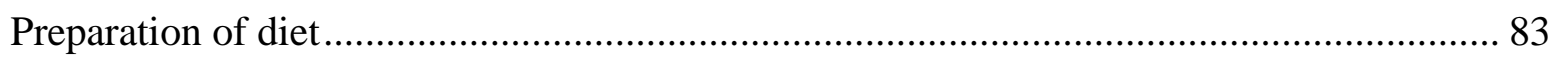

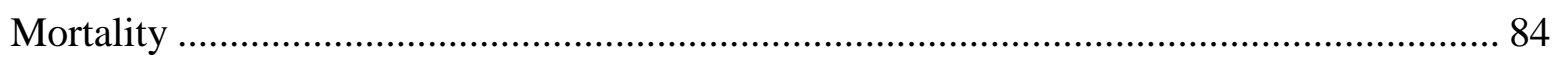

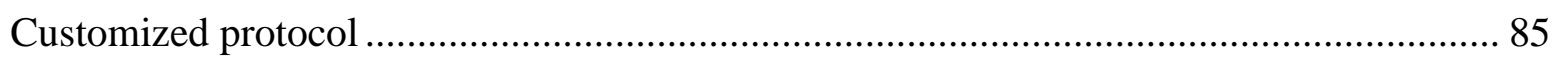

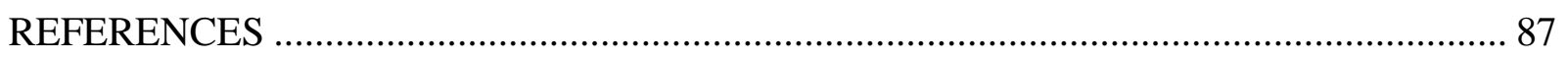

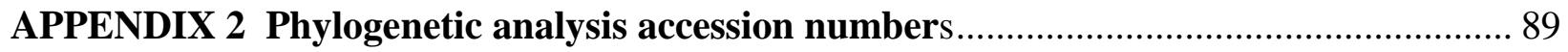

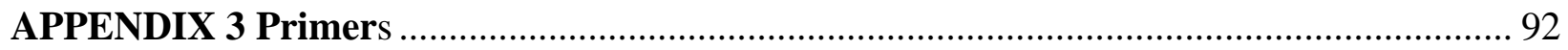




\section{LIST OF TABLES AND FIGURES}

Figure 1 Overview of the microinjection process. .26

Table 1 Information on candidate honey bee antimicrobial peptides abaecin, apidaecin, hymenoptaecin

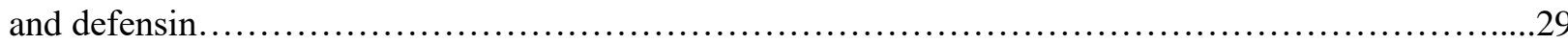

Figure 2 Concatenated Bayesian phylogenic tree of Wolbachia infections in 57 host taxa with Wolbachia-

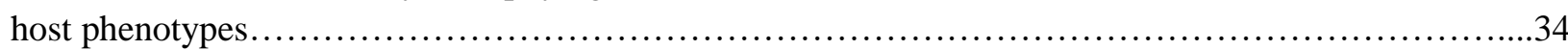

Table 3 Information on supergroup groupings and Wolbachia-host phenotypes for taxa analysed in Figure 2 .

Figure 3A) Maximum likelyhood phylogeny of the native Wolbachia strain found in the Victoria University of Wellington wildtype Drosophila melanogaster colonies against a number of international D. melanogaster strains, including wMel. B) Maximum likelihood phylogeny to place Ancisterocerus gazella within the wider Wolbachia supergroup complex using the chaperonin gene groEL

Figure 4 A)Wolbachia in a Drosophila melangaster egg stained with SYTO11 dye. B) Wolbachia cells in semen used for the artficial insemination stained with SYTO11 dye. C) Visualized PCR products of Wolbachia surface protein (wsp) from Victoria University's Drosophila melanogaster colonies of varying body parts and eggs. D) Fifth instar A. mellifera larvae injected with Phosphate-buffered saline (PBS) and inert green dye to show injection location between the 5-6 body segment.

Figure 5 A) Proportion of Apis mellifera individuals of varying life stages (egg, young larvae, older larvae, and pupae) alive after 72 hours post micro-injection with either Wolbachia or control phosphatebuffered saline (PBS). B) Kaplein-Meyer survival graph of cumulative survival of all life stages (eggs, young larvae, older larvae, and pupae) post microinjection with Wolbachia or PBS controls.

Figure 6 Kaplain Meyer survival curves of pre-pupated Apis mellifera microinjected with either Wolbachia or phosphate-buffered saline (control).

Table 3 Pairwise comparisons between survival curves of pre-pupated Apis mellifera microinjected with either Wolbachia or phosphate-buffered saline (control). Each value is comparing the survival curve between life stage as per Figure 6

Figure 7 Visualised PCR products of the $w s p$ gene from progeny of queen bees artificially inseminated with Wolbachia-inoculated semen....

Figure 8 A) Summary PCR visualisation of all wsp products over all the entire study. B) A. mellifera queen during artificial insemination.

Figure 9 Kaplein-Meyer survival curve of bees injected with Deformed wing virus and suspected to be infected with Wolbachia and controls

Figure 10 Mean relative antimicrobial expression in first instar Apis mellifera larvae following microinjection with Wolbachia or Wolbachia heat-treated for 30 minutes at $85^{\circ} \mathrm{C}$ over 48 hours.........44 Appendix Figure 1 Honey bee (Apis mellifera) developmental stages per caste.

Appendix Figure 2 Honey bee eggs and larvae laid in-situ to exemplify egg laying is not chronological by cell within the comb and so larvae found is not ordered by age.

Appendix Figure 3 A) honey bee egg removed from comb using a size 0 paint brush. B) Visual difference between alive and dead larvae. 


\section{CHAPTER 1}

\section{General Introduction}

\section{THE IMPORTANCE OF THE HONEY BEE}

\section{Pollination}

Pollination is one of the most ecologically and economically important ecosystem services on Earth (Klein, et al., 2007; Potts, et al., 2010). Eighty-seven percent of angiosperm plants (approximately 308,000 species) depend, at least in part, on animal pollination for sexual reproduction (Ollerton, et al., 2011). Three-quarters of leading food crops, occupying 33-35\% of all agricultural land in the world, benefit from animal pollination. Of the 107 global leading food crops, 85\% rely on animal pollination (Williams, 1994; Gallai, et al., 2009) and the annual market value of the 5-8\% of global food production directly linked with pollination services is estimated between US\$235 billion and US\$577 billion worldwide (Lautenbach, et al., 2012). Most pollinators of agricultural importance are insects, particularly the hymenopteran Apidae which are the most abundant and diverse pollinators, with over 20,000 species worldwide (Neff \& Simpson, 1993; Klein, et al., 2007; Michener, 2007; Kleijn, et al., 2015).

Of these insects, the Western honey bee (Apis mellifera Linnaeus, and its subspecies) is thought to be the most important, with their management being the basis of global food security (Klein, et al., 2007). Of the leading 107 global crops, 91 of the leading global food crop commodities are dependent on them, generating over US\$215 billion annually (Le Conte \& Navajas, 2008; vanEnglesdorp \& Meixner, 2010). Without honey bees, the yield of these crop species have been estimated to be reduced by up to 96\% (Potts et al., 2010), with an associated significant reduction in seed set and recruitment (Klein, et al., 2007). The honey bee is now considered by some to be the "most important productive livestock" (Stoic, et al., 2016) and, due to its high pollination efficiency, is the primary choice of agricultural pollinator worldwide (Le Conte \& Navajas, 2008; Klein, et al., 2007).

Pollinator-dependent agriculture has seen a $300 \%$ rise in line with globalized communities and human population growth over the last 50 years (Aizen \& Harder, 2009). However, the rapid increase in agricultural production greatly exceeds that of the global stock of domesticated honey bees, which have only steadily risen by 45\% since 1961 (Aizen \& Harder, 2009). Long-term declines in bee populations in Europe and the United States, which are areas with some of the largest food consumption in the world, has 
rung alarm bells regarding the pollination deficit that continues to grow in these areas. An evaluation by Gillai et al. (2009) concluded that in the event of a loss of insect pollination in highly populated areas, particularly in the US and Europe, the human consumption of fruit, vegetable, and stimulant crops (such as coffee) would exceed global production by up to 50\%. Less densely populated areas would also be heavily impacted, including vegetable deficits throughout Africa and Oceania, and a shortfall of fruit to North America and West Africa. This scenario is particularly pertinent areas that produce more than their fair share of produce for export, such as East Asia, where the loss of honey bees would result in an overall deficit in fruit production of $26 \%$, which would represent a considerable loss since the region produces $20 \%$ of global fruit output (Gillai, et al., 2009).

The human health implications resulting from honey bee losses through crop production reductions would be substantial, particularly in developing countries (Ellis, et al., 2015). Up to 56\% of all people in Zambia, Uganda, Mozambique, and Bangladesh would be at risk of vitamin A, calcium, folate, iron, and zinc deficiencies in scenarios where honey bees and other pollinators are eliminated (Ellis, et al., 2015). Vitamin A deficiency causes an estimated 800,000 deaths worldwide in women and children currently, and roughly doubles the risk of death from common conditions such as measles, diarrhea, and malaria, and increases the risk of maternal mortality four-fold (Rice et al., 2004). Honey bee decline would, therefore, not only directly reduce food production, but would indirectly increase disease frequency, particularly in countries with limited medical resources. Additionally, the disappearance of bees will impact the $87.5 \%$ of wild angiosperms that are reliant on animal pollination, thus impacting plant diversity worldwide (Kevan \& Phillips, 2001; Klein, 2007; Ollerton, et al., 2011).

\section{Apiculture}

Despite the slow increase in global honey bee stocks for pollination, apiculture is a commercial growth industry, with rapid global increases in natural honey export profit value averaging $10 \%$ profit growth between 2011 and 2015 (UN Comtrade Database, 2016). In 2015, the total global honey trade exceeded US $\$ 4.56$ billion from over 140 countries (UN Comtrade Database, 2016), which is a fourfold increase from 2007. Producers of raw honey vary in quantity and quality. China is the world's largest mass producer with over 144,7586 tonnes exported in 2015, with an average wholesale value of US\$1.99/kg. In the same year New Zealand produced an entire order of magnitude less honey for export but had the highest export value by over US\$7.7/kg worldwide. New Zealand currently exports raw honey products for an average of US\$20/kg and up to US\$80/kg for wholesale honey (MPI NZ, 2015). High-value honey exports have driven a boom in New Zealand apiculture industries where exports are successful (MPI NZ, 2016, 2017).

In New Zealand, the growth in global apiculture is exemplified, with exports increasing from US\$25 million to $\$ 200$ million per annum and with an increase in price $/ \mathrm{kg}$ of $\$ 6.25 / \mathrm{kg}$ to $\$ 18.71 / \mathrm{kg}$ between 2011 
and 2016 (UN Comtrade Database, 2016). The drive in honey profits has promoted the increase of registered beekeeping enterprises. In New Zealand alone the number of registered apiaries almost doubled between 2010 and 2015, with an increase of approximately 200,000 registered hives in the same period. Manuka honey, produced from nectar of the New Zealand native Manuka plant, Leptospermum scoparium, has soared in popularity throughout global markets due to its antibacterial properties and proposed health benefits (Saikaly \& Khachemoune, 2017). Today, New Zealand is the world's third-largest honey producer by value, but only $16^{\text {th }}$ in the world by volume, highlighting the premium international prices of Manuka honey, that makes up the majority of the country's apiculture economy (MPI NZ, 2016).

The increased global demand for honey has led to increased hive densities in areas of high value, such as in Manuka scrubland. This increase in density has been suggested to malnourishment of honey bees due to inadequate floral resources (Decourtye, et al., 2010), fighting and robbing between hives, and the increased spread of pathogens. The combination of high density hive placement and the periodic movement of hives, often to follow seasonal crop pollination, has led to the widespread distribution of honey bee diseases (Berthoud, et al., 2010). Malnourishment, particularly of dietary protein (pollen), can lead to a range of problems for bees, such as insufficient essential amino acids needed for the synthesis of peptides in immune pathways (Grimble, 2001; Schmid-Hempel, 2005). Further, a lack of carbohydrates (nectar and honey) leads to reduced foraging in bees and energy-deficiency for metabolic processes related to immune response, causing increased vulnerability to microsporidian infection and disease (Schmid-Hempel, 2005).

\section{HONEY BEES AT RISK}

Western honey bees are vulnerable to, and are suffering from, a diverse range of pathogens and parasites. These range from bacterial and fungal infection, trypanosome protozoans, and DNA and RNA viruses (Cox-Foster, et al., 2007; Evans, et al., 2011). Extreme cases of honey bee loss has previously been seen in colony collapse disorder (CCD). Colony collapse disorder is a phenomenon wherein substantial honey bee hive losses in the US and Europe between 2005-2012 were ascribed to the sudden disappearance of adult worker bees despite the lack of evidence of dead workers near the hive, with adequate food and brood stores (vanEngelsdorp, et al., 2010). Multiple stressors appear responsible for CCD, with networks of pathogens being the main suspect, including the parasitic Varroa mite (Varroa destructor) and viruses it vectors (Schroeder \& Martin, 2012; Cornman, et al., 2012). Of these viruses Deformed wing virus (DWV), that appears to be mutualistic with Varroa, is considered to be the most likely candidate for the majority of global honey bee colony loss worldwide over the last 50 years (Van Englesdorp, et al., 2009; Nazzi et al., 2012; Schroeder \& Martin, 2012). 
Varroa-vectored DWV plays an important role in 'parasitic mite syndrome' which causes Varroainduced colony collapse, evidenced by field observation and through modelling approaches (Hung, et al., 1995, 1996; Martin, 2001). This syndrome describes the symptoms of an overt DWV outbreak at colony level, where fast brood turnover in spring can compensate for DWV-related bee losses until brood rearing slows in the autumn when virus epidemic accelerates, and the excessive loss of working bees causes the hive numbers to drop rapidly, and ultimately die (de Miranda \& Genersch, 2010). The movement and distribution of the Varroa mite has been followed with elevated colony losses throughout the Northern Hemisphere (Neumann \& Carreck, 2010). These losses included approximately $40 \%$ in the USA up to 53\% and $85 \%$ losses in Europe and the Middle East, respectively and considerable losses throughout Japan and Taiwan compared to pre-Varroa levels (Crailsheim, et al., 2009; Gutierrez, 2009; Haddad et al., 2009; Soroker, et al., 2009; vanEnglesdorp, et al., 2009, 2010). Currently, the only viable methods to control these mites are chemicals and pesticides, and alternative miticides (De Miranda \& Genersch, 2010, Ziegelmann, et al., 2017). However, mites quickly develop pesticide resistance and mite-killing pesticide residues have been found in honey, reducing sale value and exporter reputation (Johnson et al., 2010).

Insect sociality has a direct impact on disease transfer for insect colonies (Evans, et al., 2006). For example, in honey bee colonies thousands of individuals interact in close quarters in densities unparalleled in vertebrate groups. Combined with a homeostatic hive environment and presence of high-sugar food resources, bees are attractive targets for disease agents (Schmid-Hempel, 1998; Evans, et al., 2006). Bees have therefore developed "social immunity" strategies to combat many diseases, including grooming, hive hygiene and other behavioural traits to reduce the densities and impact of pathogen microsporidians and parasitic mites (Evans \& Spivak, 2010). Social hygiene behaviours are very prominent in bees, particularly allogrooming, which is characterised by worker bees' detection of infected larvae and its removal and disposal from among healthy brood (eggs and larvae) (Spivak \& Reuter, 2001). Additionally, autogrooming exists, wherein bees will remove foreign pathogens, such as tracheal mites, from themselves (Evan \& Spivak, 2010). However, these social behaviours are less effective when the bees are naïve to the pathogen, as is the case with the Western honey bee and its interactions with Varroa mite. Where the Eastern honey bee (Apis cerana) has evolved with $V$. destructor, it elicits effective allogrooming strategies to keep mite levels below a threshold level (Evans \& Spivak, 2010) and prevents high levels of Varroa-vectored disease. However, as the mite is novel to the Western honey bee, these bees have not evolved such grooming behaviours and it is unable to remove the parasite (Rath \& Drescher, 1990).

Breeding programs targeting Varroa-resistant bees exist, prioritizing stocks with desirable behavioural phenotypes, in particular bees that are able to detect, uncap and remove diseased brood (Spivak $\&$ Reuter, 2001). Auto-grooming, wherein the mites may be injured or killed (Ruttner \& Hanel, 1992) or a promotion of behaviours of workers to attack free roaming mites (evidenced by dead mites on hive floors 
with damage caused by bee mandibles is desirable (Fries, et al., 1996; Rinderer, et al., 2010). Indeed, attempts by apiarists at breeding brood that are unattractive to Varroa parasitism are currently being undertaken, as is selecting for unattractive larval food and comb properties (Nazzi, et al., 2001). Ultimately, however, it is unlikely that these approaches will make Western honey bees completely resistant to Varroa but they may eventually keep infestations to manageable levels as in A. cerana hives, (Peng, et al., 1987; Rinderer, et al., 2010).

\section{Insect immune system}

Individually, the honey bee immune system provides some degree of defense against pathogens (CasteelsJossen, et al., 1994; Evans, 2004). Like most insects, honey bees are protected by a layer of antimicrobial secretion on the exoskeleton, and by a gut environment that is hostile to many potential pathogens (Evans, 2006). If pathogens move past the gut, the epithelium and peritrophic membrane lining the digestive tract are often sufficient to prevent further progress (DeGrandi-Hoffman \& Chen, 2015). However, the Western honey bee's naivety to Varroa is illustrated by the mite's method of transmitting disease by piercing the bee's exoskeleton to get directly into the haemolyph, thereby bypassing the rigorous gut protection (BowenWalker \& Gunn, 2001). When this barrier is breached, the pathogen is met by an cellular and humoral immune defense system that shares many parallels to the innate immune system found in vertebrates (Hoffman, 2003; Beutler, 2004; Evans, et al., 2006). The activation of the innate immune system relies of the recognition on highly conserved structural motifs on the surface of pathogens, which are not found on the host by pattern recognition receptor proteins (Brutscher \& Flenniken, 2015; DeGrandi-Hoffman \& Chen, 2015). Individual pathways within the honey bee immune system deal, with some cross-talk, with different pathogens. These pathways include the Jak/STAT and RNA interference (RNAi) pathways, both of which deal with only with viruses; the immune deficiency (Imd) pathway that processes virus particles and gram-negative bacteria; and the Toll pathway that is typically activated by fungi, gram positive bacteria and virulence factors (Evans, et al., 2006). Ultimately, these cascades regulate the transcription of target genes encoding effector molecules, including the rapid and transient synthesis of antimicrobial peptides (Hoffman \& Reichhart, 1996).

Antimicrobial peptides (AMPs) are an important component of the humeral immune system (Giuliani, et al., 2007; Danihlik, et al., 2015) and over 200 have been described in insects (Li, et al., 2012). AMPs are secreted by insect fat bodies and hemocytes, and are secreted in response to microbial infection and septic wounding (Turner, 1994; Evans, et al., 2006; Laughton, et al., 2011). Most AMPs are classed as catatonic or amphipathic peptides, which allow them to interact with and disrupt negatively charged lipid membranes containing lipopolysaccharides, often found in microbes. AMPs interact with their target microbes in a number of ways, including the interaction of peptides resulting in the formation of channels 
which enable the leakage of small ions and essential metabolites (Danihlik, et al., 2015). In some cases, this process allows the penetration of large molecules like peptides and small proteins with fatal effects for the target bacteria (Hancock, 1997; Shen, et al., 2010). Additionally, AMPs can interact directly with inner proteins, DNA, RNA or microbial cell compartments in their target (Maróti, et al., 2011). For instance, proline-rich peptides are able to pass through plasmatic membrane and bind to bacterial heat shock proteins and interact with chaperonins without lytic effect to the prokaryotic membrane (Otvos, et al., 2000; Kragol, et al., 2001; Scocchi, et al., 2009).

The insect microbiome is extensive and is a mixture of beneficial, pathenogenic and neutral resident bacteria (Engel, et al., 2012). In the case of internal symbionts, the insect immune system, while protecting its host from invading micro-organisms must also support this diverse microbiota that can contribute to various host functions, including immune function (Douglas, 2011). In the case of infection with endosymbionts, the host immune system function is challenged by distinct and conflicting selection pressures (Feldhaar \& Gross, 2008, 2009). In the case of obligate symbionts, the host immune system may adapt via reduction, inhibiting the detection of specific bacterial species (Douglas, 2011). However, facultative or parasitic symbionts have not co-evolved with their host, and two alternative explanations exist for the lack of host detection: (i) the symbiont is being recognized as part of the host; (ii) lack of immune response is due to a mechanism of the symbiont evading immunity or causing the silencing of elicitors of immunity (Hurst, et al., 2003). Honey bees host a number of these naturally occurring facultative endosymbionts, including in the genera Arensophononus, Spiroplasma and Rickettsia (Yanez, et al., 2016).

\section{WOLBACHIA}

Not all microbes are pathogenic. In fact, gut microbiota is now considered to play a vital role in protecting hosts from infection (Sekirov, et al., 2010; Cryan \& Dinan, 2012). For example, in humans, female vaginal microbes can provide resistance to sexually transmitted pathogens, such as HIV (Pyles et al, 2014). New treatments for human gastrointestinal disorders include fecal transplants to move bacterial microbiota from one human to another in order to fight disease (Pamer, 2014). Gut microbiota have been indicated to communicate with the central nervous system and has influence on brain function and behaviour (Cryan \& Dinan, 2012).

Similarly, within honey bees, there is evidence to suggest that gastrointestinal bacteria play a key role in combating disease (Wu, et al., 2013). Like other species, the honey bee microbiome is made up of a mix of beneficial, commensal, and parasitic bacteria (Engel, et al., 2016). In honey bees, evidence has been found that certain species of Firmicutes bacteria can inhibit the growth of two principal pathogens, 
Paenibacillus larvae and Melissococcus plutonius, responsible for American and European Foulbrood disease, respectively (Forsgren, et al., 2010; Vasquez, et al., 2012). In bumble bees, variation in gut community has been shown to either hinder or encourage the proliferation of the parasite Crithidia bombi (Koch, et al., 2011; Carvieau, et al., 2014). Some symbiotic species of bacteria have been shown to have a range of effects when hosted by different insect species across various orders. Of these, Wolbachia is the most prolific (Warren, et al., 2008; LePage \& Borderstein, 2013).

Bacterial strains in the genus Wolbachia are Gram-negative cytoplasmically and maternally inherited within the Rickettsiaceae family that are present in the reproductive tissues of a plethora of invertebrates (Warren, 2008). These infections confer a variety of effects on their hosts, ranging from reproductive manipulation that benefits the transmission of the bacteria, to obligate mutualisms in nematodes, as well as facultative mutualisms in a variety of taxa. These facultative effects have various non-pathogenic effects, including increased virus resistance (Hoffmann, et al. 2011; Walker, et al. 2011). It is currently thought that Wolbachia is the most widely abundant intercellular bacterial species in insects (LePage \& Borderstein, 2013). Present in all major insect orders, as well as arachnids and isopods, Wolbachia is being hailed as one of the biggest bacteria 'pandemics' in the history of life from a biodiversity perspective (LePage \& Borderstein, 2013).

Wolbachia has attracted considerable attention for its ability to manipulate its hosts. Application potential of the conferred bacteria-host phenotypes effects are extensive. These applications range from increasing Wolbachia abundance in populations of mosquitoes to limit reproduction and lower population numbers through induction of cytoplasmic incompatibility (Walker, et al, 2011, Hoffman, et al., 2011), to transinfecting species of arthropods with strains of Wolbachia to prevent the vectoring of viruses (Dutra, et al., 2016; Aliota, et al. 2016), to the curing of Wolbachia where it is obligate to nematodes in order to reduce the cases of filariasis (Iturbe-Ormaetxe, et al., 2011; Tamarozzi, et al., 2014). Previously, these applications have only been used in order to mediate human diseases. However, there is scope for these Wolbachia-induced phenotypes to be applied to zoonotic diseases, particularly in threatened invertebrates, and perhaps honey bees (Apis mellifera). Wolbachia has been reported in very low densities in a common honey bee suspecies (A. m. carnica) (Pattabhiramaiah, et al., 2011). However, most authors consider it uncommon or a seasonal infection in these honey bees (Evison, et al., 2011; Yanez, et al., 2016).

Numerous studies have reported that Wolbachia infection confers anti-pathogenic effect in its hosts. Pathogens include several RNA viruses, Plasmodium species, fungi, and bacteria. Resistance is determined by an interaction between Wolbachia strain and host taxa (Zug \& Hammerstein, 2016). Drosophila melanogaster wild-type flies infected with a strain of Wolbachia (wMel, and its variants $w \mathrm{MelCS}$ and $w$ MelPop) survive significantly longer when infected with RNA viruses, than do those without Wolbachia 
(Hedges, et al. 2008). Moreover, wMel-infected Aedes aegypti mosquitoes cannot carry viral dengue fever (Walker, et al., 2009, 2011). This has led to a population replacement strategy by the Eliminate Dengue Project (EDP) in Australia, South East Asia, and South America, with promising results. This success has encouraged the use of similar techniques to reduce the levels of malaria in a range of third world countries. The main carriers of Plasmodium malaria (Anopheline mosquitoes) do not naturally possess Wolbachia infection and are of particular interest. Anopheline mosquitoes transinfected with Wolbachia had few defects and caused refractoriness to Plasmodium infection (Bian, et al., 2013). Strains of Wolbachia naturally present in tsetse flies, the sole vectors of African trypanosomes, have the potential for the eradication of sleeping sickness and nagana (a livestock disease) (Doudoumis, et al., 2012). Additionally, and of considerable recent interest, is the use of Wolbachia to reduce the spread of Zika virus (ZIKV). Zika is an arbovirus (spread by arthropods) that is responsible for an outbreak of febrile diseases in the Americas, and is vectored by A. aegypti mosquitoes. Wolbachia-infected A. aegypti are highly resistant to two currently circulating ZIKV strains (Dutra, et al., 2016; Aliota, et al. 2016). Wolbachia-harbouring individuals displayed lower viral prevalence and abundance, decreased disseminated infection, and, critically, did not carry ZIKV particles in the saliva, suggesting transmission had been blocked.

Computer modelling predicts that host protection will evolve in vertically transmitted parasites when they compete with horizontally transmitted pathogens in the same host (Zug \& Hammerstein, 2012). As such, Wolbachia can maintain its position in the host population (Hedges, et al., 2008). Wolbachia possess a number of genetic abnormalities that are different from the rest of the Rickettsailles and these have been accredited to its success as an intracellular invader. Similar to the rest of the Ricketsailes, Wolbachia have small genomes (1.1 - 1.7 million base pairs) and are in accordance with the reductive trend following adaption to the host cell (Langridge, et al., 2015). However, Wolbachia genomes contain a high number of mobile and repetitive elements, with the latter comprising approximately $15 \%$ of the $w$ Mel strain genome. These repeats undergo fast rates of recombination, allowing for quick adaptation into host cells. Most repeats transcribe Ankyrin domain proteins (ANK). These mediate the attachment of integral membrane proteins to the spectrin-actine based membrane cytoskeleton and are common in eukaryotes but unusual in bacteria. These repeats might mediate host-pathogen interactions (Wu, et al., 2004). Generally, the presence of repeats and mobile elements, is incongruent with the partitioning into parasitic or mutualistic strains among the Rickettsiales. Interestingly, Wolbachia strains that facilitate obligate nematodes symbiosis often have fewer repetitive elements and do not lack phage sequences (Fenn \& Blaxter, 2006). Ankyrin domain proteins and prophage genes might be associated with Wolbachia-host cell interactions (Sinkins, et al., 2005). Direct effects of ANK and prophage genes within the bacteria phenotype remain unclear. However, their expression profiles appear to be associated with reproductive phenotypes (Walker, et al., 2007). 
The mechanisms underlying the antiviral effects of Wolbachia are poorly understood. Antiviral effects are more common than antibacterial activity, suggesting their underlying mechanisms are independent as they do not occur together (Wong, et al., 2011; Rottschaefer \& Lazzaro, 2012). To date, reported antiviral effects are currently known to be limited to RNA viruses. Wolbachia density is correlated with strength of these antiviral properties (Graham, et al., 2012). Two mechanistic explanations exist. Firstly, viral interference might result from the success of Wolbachia in competition for host resources (Osborne, et al., 2009, 2012; Frentiu, et al., 2010; Wong, et al., 2011; Lu, et al., 2012). Alternatively, several studies have suggested that Wolbachia might upregulate host immune response, particularly genes involved in the Toll and Immune Deficiency (IMD) pathway (Kambris, et al., 2009, 2010; Bian, et al., 2010; Pan, et al., 2012). While not essential for Wolbachia-mediated antiviral protection, the RNAi pathway plays a small part in blocking RNA viruses replication (Hedges, et al., 2012; Terradas, et al., 2017). However, while a mechanistic explanation of Wolbachia's antiviral effects is lacking, successful host manipulations highlight its use (Hughes \& Rasgon, 2014).

Strains vary markedly in their conferred antiviral effects within a single host species. For example, in Drosophila simulans, several strains of Wolbachia confer strong antiviral properties (wMel, $w \mathrm{Ri}$ and $w \mathrm{Au}$ ) while other common variants ( $w \mathrm{Ha}$ and $w \mathrm{No}$ ) produce no such effects (Osborne, et al., 2009). Malekilling native Wolbachia strains do not protect D. bifasciata flies from Drosophila C Virus or Flock House Virus (Longdon, et al., 2012) and several native African armyworm strains (wExe1, wExe2, and wExe3) significantly increase double stranded DNA baculovirus-induced mortality (Graham, et al., 2012). Similar strains also have different effects in different hosts. Recent studies have shown that $w$ MelPop (a varient of the $w \mathrm{Mel}$ strain) protects A. aegypti mosquitoes from bacteria, RNA viruses, malaria parasites, and parasitic filarial nematodes (Kambris, et al., 2009; Moreira, et al., 2009). However, the $w$ Mel strain in $D$. melanogaster and D. simulans confers protection from some RNA viruses but not bacterial pathogens, cellular parasites, or filarial nematodes (Teixerira, et al, 2008; Wong, et al., 2011; Martinez, et al., 2012; Rottschaefer \& Lazzaro, 2012). Therefore, strain selection in transinfection experiments is critical to mediating diseases in the insects.

\section{Wolbachia as a honey bee symbiont}

It may be possible to manipulate increased viral resistance, potentially to key viruses like DWV, in honey bees through the manipulation of Wolbachia. The effects of reported natural Wolbachia infection in Apis mellifera carnica (the Carniolan honey bee, the most common managed subspecies; hence referred to as Apis mellifera) has not been examined and therefore the Wolbachia-host phenotypic is unknown. The investigation into the phenotype caused by Wolbachia infection in honey bees is reliant on artificial 
infection of Wolbachia into A. mellifera. Samples of honey bees previously found positive for natural Wolbachia have since been destroyed and so cannot be further investigated (Pattabirhimaiah, pers. comm., 2017). No additional Wolbachia-positive bees have been found or are available. Intra-order transinfection between dipterans is common (Hughes, et al., 2014) but successful inter-order transinfection is less so, with few successful inter-order transinfections detailed to date (van Meer \& Stouthamer, 1999; Zhong \& Li, 2014; Kageyama, et al, 2017). To the best of my knowledge, transinfection into honey bees has never been attempted. However, natural infection of Wolbachia in the honey bee subspecies Cape bee (Apis mellifera capensis) and the Africanized bee (A. m. scutellata), and evidence of natural low density Wolbachia infection in A. mellifera, would suggest that artificial infection is plausible. Therefore, the novel approach used in dipteran hosts may be conferred to hymenopterans, using an appropriate strain of Wolbachia compatible with the honey bee immune system. Previous successful insertions of foreign strains of Wolbachia in arthropods with facultative results, including increased viral resistance (e.g., Walker, et al., 2011; Bain, et al, 2013; Dutra, et al., 2016), make Wolbachia a strong candidate against Deformed wing virus and other honey bee RNA viruses. Established transinfection methodologies make this concept potentially viable.

\section{THESIS STRUCTURE}

My goal in this study was to attempt a transinfection of Wolbachia into Western honey bees. This investigation was conducted to determine the phenotypic effect of Wolbachia in Western honey bees, by attempting novel transinfection of Wolbachia bacteria into honey bees with the ultimate goal of increasing resistance against pathogenic RNA viruses. Existing strategies to increase honey bee resistance to these pathogens and Varroa are limited to breeding programmes that select for beneficial behaviours such as heightened hygiene and the development of pesticides in order to reduce the impact of disease vectors. To the best of my knowledge, the infection of a bacteria found in the honey bee host, that is not hosted in the gut, has not before been considered as a strategy to confer resistance. This is, therefore, the first study to emply a number of previously successful transinfection methodologies used for dipteran studies in hymenopterans, as well innovative new protocols for Wolbachia infection utilizing honey bee insemination.

In Chapter 2, investigated the natural Wolbachia infection that was reported in honey bees by Pattabhiramaiah, et al. (2011), its relatedness to other Wolbachia supergroups and potential as an artificial infection strain source. I screened a number of hymenopteran species for Wolbachia and discovered Wolbachia infection in the European tube wasp Ancistrocerus gazelle where it has never been found before. I then attempted to infect honey bees with a stable infection of Wolbachia strain wMel in order to investigate the host-phenotype interaction induced. I trialed a variety of transinfection techniques on honey bees at 
varying life stages (eggs, larvae, pupae and adults), including sound microinjection protocols and I developed a novel methodology utilizing artificial insemination in queens. I then investigated the possible cause of failed transinfection attempts. I looked at the expression of a range of immune response peptides over time, post-microinjection of live and dead Wolbachia, to determine the degree of immune response in honey bees to foreign bacteria.

In Chapter 3, I discuss my findings, their implications and future recommendations in this field. Appendix 1 provides thorough information regarding honey bee larval rearing protocol.

Appendices 2 and 3 provide supplementary information on this study, including GenBank accession numbers and primer sequences used.

\section{Research aims}

Specifically, this thesis aims to:

1. Determine the strain of Wolbachia found in the reported natural infection of Apis mellifera as found by Pattabhiramaiah, et al. (2011) in context to a robust Wolbachia supergroup phylogeny.

2. Attempt to instigate a Wolbachia infection in A. mellifera through existing microinjection protocols that have been used in previously successful transinfection experiments in dipterans.

3. Produce a novel methodology of Wolbachia infection through artificial insemination in $A$. mellifera.

4. Characterise the immune upregulation of antimicrobial peptides expressed in A. mellifera when challenged with Wolbachia bacteria. 


\section{CHAPTER 2}

\section{Wolbachia transinfection viability in pre-pupated Apis mellifera}

\section{INTRODUCTION}

Bacterial strains in the genus Wolbachia are gram-negative cytoplasmically and maternally inherited Rickettsaiae, which are present in the reproductive tissues of a plethora of invertebrates (Warren, 2008). Meta-analyses suggest that between $40 \%$ and $60 \%$ of all terrestrial arthropods are infected, making Wolbachia the mostly widely distributed endosymbiotic panzootic from a biodiversity perspective (Zug \& Hammerstein, 2012; Frost, 2014; Wienert et al., 2015). Host specificity and phenotype changes between lineages of Wolbachia, which are classified into 16 supergroups named $A-F$ and $H-Q$ in order of their descriptions (Glowska, et al., 2015; Gerth, et al., 2016). These infections can confer a variety of effects on their hosts ranging from reproductive manipulations, obligate mutualism in nematodes, as well as facultative mutualisms in a variety of taxa with various non-pathogenic effects, including increased viral resistance and increased fecundity (Teixeira, et al., 2008; Warren, et al, 2008; Fast, et al., 2011; Walker, et al. 2011; Hoffmann, et al. 2011).

In Drosophila spp. flies, natural Wolbachia infection increases fecundity fourfold in D. mauritania compared to uninfected individuals (Fast, et al., 2011), and infection in D. melanogaster increases resistance to Drosophila C Virus and other RNA viruses (Hedges, et al, 2008). The artificial infection of Wolbachia native to D. melanogaster (w Mel strain) into Aedes sp. mosquito hosts has been successful, causing infected individuals to express cytoplasmic incompatibility as well as refractoriness to viral dengue fever infection (Walker, et al., 2011; Bian, et al., 2016). This phenotype combination has been the basis of the Eliminate Dengue Project which has now had successful controlled release of infected mosquitos in ten countries across the globe. This success has led to similar projects aimed at reducing the transmission of other insect-borne diseases, including Zika virus (ZIKV; (Dutra, et al., 2016; Aliota, et al. 2016), Plasmodium malaria (Bian, et al., 2013), and sleeping sickness spread by tsetse flies (Doudoumis, et al., 2012, 2013).

Manipulating antiviral effects of Wolbachia may also be applied in zoonotic fields. Instead of removing the vector's ability to carry viruses, where the emphasis is on ceasing the spread of infection, it 
can be used to stop the carrying of viruses by the target directly, as has been witnessed in Drosophila spp. (Teixeira, et al., 2008; Hedges, et al., 2004) and Aedes mosquitoes (Dutra, et al., 2016). Therefore, if transinfection into other Dipteran species has resulted in successful viral resistance, transinfection of Wolbachia into other species is plausible. One potential employment is in Western honey bees (Apis mellifera) to increase viral resistance against debilitating RNA viruses that have been suspected to be the main cause of worldwide honey bee decline over the last 50 years (De Miranda \& Genersch, 2010; Schroeder \& Martin, 2012).

Honey bees are considered the world's most economically important pollinator, with 104 leading global food crop commodities dependent on them (Le Conte \& Navajas, 2008; vanEnglesdorp \& Meixner, 2010). Now considered by some to be the "most important productive livestock" (Stoic, et al., 2016), the honey bee is the primary choice of agricultural pollinator worldwide (Klein, et al., 2007). Long term population decline throughout Europe and the United Sates has highlighted the importance of these insects, where bees are absent the yield of a number of fruits, vegetables, seeds, and nuts falls by up to 96\% (Potts, et al., 2010). The decline in honey bees has been blamed on a number of pathogens, namely the network between the ectoparasite Varroa destructor and RNA viruses Deformed wing virus (DWV) and Kashmir bee virus (KBV) (Cornman, et al, 2012; Schroeder \& Martin, 2012). Current strategies to reduce this pathogenic mutualism has been limited to the breeding of beneficial grooming behaviours such as varroa sensitive hygiene (Danka, et al., 2011) and miticide development (Mattos, et al., 2017; Rinkevich, et al., 2017). Therefore, the transinfection of bacteria with the intention of directly reducing viral loads is a novel approach for honey bee health management.

A natural infection of Wolbachia in Apis mellifera was reportedly found in low density by Pattabhiramaiah et al. (2011a), who amplified segments of the Wolbachia ribosomal 16S gene in both workers and queens of a common strain of commercial bees (A. m. carnica) from hives in Bremen and Ploen, Germany. Honey bee subspecies, the Cape bee, A. m. capensis and the Africanized bee, A.m. scutellata, both native to South Africa, are also naturally infected with Wolbachia (Hoy, et al., 2003; Jeyaprakash, et al., 2003). The phenotypic effects and results of the Wolbachia infections in any of these species have never been examined. Unfortunately, further samples of the Wolbachia-infected Carniolan honey bees are no longer available (pers. comm, Pattabhiramaiah, 2017 ) and so cannot be further analyzed. With the majority of honey bees testing negative for Wolbachia (Cox-Foster, et al., 2007; Martinson, et al.,

\footnotetext{
${ }^{1}$ Email correspondence with Mahesh Pattabhiramaiah and Dorothea Brueckner of the Honeybee Research Unit from the University of Bremen, Germany concluded that there are "no samples left from bees infected with Wolbachia in the laboratory". Therefore, no further research can be conducted on samples showing natural infection.
} 
2007; Yanez, et al., 2017), highlighting the rarity of infection, assessments of Wolbachia-host phenotype will be limited to the ability to create a stable artificial infection within Apis mellifera.

A variety of approaches for bacterial transinfection exist, with varying levels of success dependent on the host species and age (reviewed by Hughes \& Rasgon, 2014). The most common methodology is microinjection of Wolbachia cells into the host with the aim of proliferation into the germ line. The offspring of the $\mathrm{F}_{0}$ are then tested for Wolbachia presence to determine infection of the ovaries and the capacity for maternal transmission. Microinjection can be operated on both embryos and older life stages including larvae, pupae and adults (Grenier et al., 1998; Kubota, et al., 2005; Kageyama, et al., 2008). Generally, embryonic microinjection of very young eggs has the highest rate of infection success due to the increased rate of bacterial cells reaching the germline and developing ovaries. However, eggs have a higher mortality rate than their more developed counterparts, creating a tradeoff between recipient survival and transinfection success (Hughes \& Rasgon, 2014). Wolbachia injected intrathoracically in dipteran larvae and pupae has been shown to be somewhat successful, taking advantage of Wolbachia's tendency to migrate to the germline (Frost, et al., 2014). In adult Drosophila melanogaster, injected Wolbachia are seen to localize within the stem cell niche within the germline (Frydman, et al., 2006). Wolbachia can often be successfully extracted from host egg cytoplasm and injected into recipient embryos or adults with successful infection, though in many cases Wolbachia must be reared in a cell culture of the recipient to reduce immune response against injected material (Walker, et al, 2009, 2011). Additional to microinjection, co-rearing of host and recipient has also shown to have limited success (Huigens, et al., 2004), and oral infection is inappropriate due to Wolbachia's intracellular lifestyle (Rasgon, et al., 2006).

This study examines the viability of artificial Wolbachia infection through existing transinfection protocols. I first phylogenetically examine natural infecting strain of Wolbachia found in A. mellifera (Pattabhiramaiah et al., 2011a, b) against a robust Wolbachia phylogeny to determine the relationship between this and other Wolbachia strains. I screen a number of hymenopterans that are not known to naturally host Wolbachia and discover it in the European tube wasp, Ancistrocerus gazella where it has not previously been reported. Microinjection protocols are then trialed extensively in varying life stages of honey bees. I conceptualize and attempt a novel methodology utilizing artificial insemination as means by which to transinfect intracellular bacteria, which has never been attempted. I then infect honey bees with Deformed wing virus in order to determine if Wolbachia infection has an effect on survival in individuals honey bees. Lastly, I assess the expression of a number of antimicrobial peptides in first instar honey bee larvae following Wolbachia microinjection to determine the immune response of larvae exposed to Wolbachia. 


\section{METHODS AND MATERIALS}

\section{Phylogenic investigation}

To determine the feasibility of artificial Wolbachia transinfection in Apis mellifera, the previously described naturally infecting Wolbachia strain found in A. mellifera (Pattabhiramaiah et al., 2011a) was examined against a robust phylogeny of Wolbachia strains from all described supergroups and classification of hostphenotype relationships was reviewed.

A robust phylogeny of existing Wolbachia was created using five genes, ribsomal $16 \mathrm{~S}$, citrate synthase ( $g l t A)$, a heat shock protein ( $g r o E L)$, an essential cell division protein ( $f t s Z$ ) and a common surface protein (wsp) from the Wolbachia infection naturally found in the named host. Representatives from each of 16 of the 17 Wolbachia supergroups described so far were used to accurately evaluate Wolbachia-host phenotype and place the infection previously reported within bees (Pattabhiramaiah, et al., 2011a). Host taxa from supergroup $G$ were excluded due to inadequate Multilocus Sequence Typing (MLST) evidence, as suggested by Baldo \& Werren (2007). Fifty-seven independent host taxa were used, plus the Pattabhiramaiah, et al. (2011a) sequence, totaling 59 hosts. NCBI accession numbers for sequences of all five genes from all host taxa are provided in Appendix 2. Two species from the Ehrlichia genera were used as outgroups (Glowska, et al. 2015). All Wolbachia sequences were aligned in MEGA 7.0 (Kumar, et al., 2015) per gene and aligned with Clustal $W$. The ends of sequences were manually trimmed. Total lengths of alignments were $639 \mathrm{bp}$ for $g l t A, 876 \mathrm{bp}$ for groEL, 735bp for ftsZ, 592bp for $16 \mathrm{~S}, 452 \mathrm{bp}$ for wsp, and $3,297 \mathrm{bp}$ for a concatenated alignment that included taxa for which at least two of four gene sequences were available, with the exception of the Apis species, for which only one gene had been sequenced. All five sequences were run through Baysian Inference using the BEAST package (Drummond, et al., 2012) as a combined analysis. The genes' substitution models were independent as per diagnosis from jModelTest (Darriba, et al., 2012), with 16S, ftsZ and wsp using the Tamura-Nei 93 model (TN93; Tamura \& Nei, 1993) with gamma distribution at four levels, and $g r o E l$ and $g l t A$ best suited to the HKY85 model (Hasegawa, et al., 1985) with gamma distribution at four levels. Strains were treated as species and a Yule Process tree prior was applied with a strict clock model (Almerão, et al., 2012). The concatenated tree was developed by linking individual gene trees in BEAUTi and were then processed through BEAST for Bayesian Inference using Markov chain Monte Carlo (MCMC) with 10,000,000 steps and 10\% burn-in. This analysis was conducted three times to ensure consistency. The resulting tree was run through Tracer and then annotated in TreeAnnotator (Rambaut \& Drummond, 2010a, b) and finally visualized using FigTree (Rambaut, 2009). Available literature was reviewed to determine established phenotypic effects of Wolbachia on host taxa. This information was then used to inform phenotypic trends within supergroups. 
In order to find a reliable source of Wolbachia, the Victoria University of Wellington wildtype Drosophila melanogaster fly colony was screened using standard PCR in order to determine Wolbachia presence. Whole genomic DNA was extracted from flies by grinding 10 flies per sample using pestles with $5 \% \beta$-mercaptoethanol, with chloroform and isopropanol purification. Concentrations of DNA were quantified with a NanoDrop spectrophotometer (Thermo Fisher Scientific, Inc., Waltham, USA). To detect Wolbachia, the wsp gene was amplified using primers wsp $81 \mathrm{~F}$ and wsp691R (further information on primers used in this study can be found in Appendix 2). Polymerase Chain Reaction (PCR) was performed

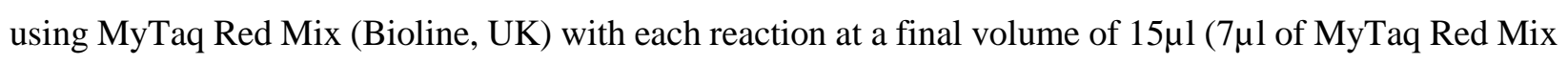
buffer, $1 \mu \mathrm{l}$ each of forward and reverse primers and $1 \mu \mathrm{l}$ of DNA sample and $\mathrm{ddH}_{2} \mathrm{O}$ to the final volume). The thermal cycling conditions were an initial denaturation at $95^{\circ} \mathrm{C}$ for 1 minute; and 30 cycles of denaturation at $95^{\circ} \mathrm{C}$ for 15 seconds, annealing at $50^{\circ} \mathrm{C}$ and extension at $72^{\circ} \mathrm{C}$ for 10 seconds; with a final extension step at $72^{\circ} \mathrm{C}$ for 5 minutes and held at $4^{\circ} \mathrm{C}$. Amplification was visualized in a $1.5 \%$ agarose gel stained with SyberSafe DNA Gel Stain (Thermo Fisher, USA). Drosophila melanogaster and Ancistrocerus gazella (see below) were used as independent positive controls and no template controls were used as negative controls. Positive sequences were sequenced by Massey Genome Service (Massey University, Palmerston North, NZ) and screened against similar sequences on the National Centre for Biotechnology's (NCBI) Basic Local Alignment Search Tool (BLAST).

In order to determine the Wolbachia strain present in Drosophila melanogaster in the Victoria University colonies, a Maximum Likelihood tree was produced with a number of international Wolbachia strains, including $w \mathrm{Mel}$ to determine their relationship. Wolbachia surface protein (wsp) sequences were collected from Genbank, analysed in MEGA 7.0 (Kumar, et al., 2015) and aligned using ClustalW and manually trimmed. ML heuristic searches were conducted through the NNI (Nearest Neighbour Interchange) method under the TN93 model with gamma distribution at four levels.

Whilst screening D. melanogaster for Wolbachia, a number of hymenopterans were screened for Wolbachia. The Asian paper wasp (Polistes chinensis), the common wasp (Vespula vulgaris), the German wasp (V. germanica), the Western yellowjacket (V.pensylvanica), the European tube wasp (Ancistrocerus gazella), the invasive Argentine ant (Linepithema humile) and the New Zealand native ant (Monomorium antarcticum), as well as the honey bee mite, Varroa destructor were screened. In order to determine the native supergroup of Ancistrocerus gazella, Maximum Likelihood tree was produced with a number of international Wolbachia strains, including $w \mathrm{Mel}$ to determine their relationship. Wolbachia chaperonin gene GroEL gene sequences from a variety of supergroups were collected from Genbank and aligned in MEGA 7.0 (Kumar, et al., 2015) aligned using ClustalW and manually trimmed. ML heuristic searches 
were conducted through the NNI method under the TN93 model with gamma distribution at four levels. Accession numbers can be found in Table 1 .

\section{Wolbachia isolation}

Wolbachia was isolated from wildtype Drosophila melanogaster, which is naturally infected with the $w$ Mel strain, from colonies at Victoria University of Wellington. Flies were grown and maintained at $25^{\circ} \mathrm{C}$, with $60 \%$ relative humidity on standard apple juice/yeast/oatmeal medium. A standard 12 hour light:dark cycle was implemented (Ashburner, 1989). Flies were induced to lay by provision of yeast paste 12 hours prior to laying. Isolation methodologies from several Drosophila body components were examined in order to find the highest concentration of Wolbachia: whole female flies, dissected fly ovaries, pools of whole dechorionated eggs (50 eggs per pool), and cytoplasm extracted from eggs less than 60 minutes postovideposition.

Drosophila melanogaster eggs were collected within one hour of oviposition. Eggs that were to serve as Wolbachia donors were washed in $70 \%$ ethanol for 2 minutes and rinsed twice in double distilled water $\left(\mathrm{ddH}_{2} \mathrm{O}\right)$. Eggs were dechorionized in $50 \%$ standard commercial bleach for 2 minutes followed by two sets of 2 minute $\mathrm{ddH}_{2} \mathrm{O}$ rinses. Eggs were maneuvered with a sterile size 0 paint brush and lined up on a glass slide with strips of double sided tape to prevent movement during cytoplasm extraction. Cytoplasm was extracted using a glass capillary needle. Needles had approximately $10 \mu \mathrm{m}$ tips and were individually pulled using a laboratory duel-stage micropipette puller (Tritech Research Ltd., Los Angeles, USA). Cytoplasm was vacuumed from the dechorionated eggs using a digital microinjector and a direct drive mechanical micromanipulator (both Tritech Research Ltd., Los Angeles, USA). The extract from 100 eggs worth of cytoplasm was placed into a sterile $0.6 \mathrm{ml}$ microcentrifuge tube and kept on ice. This cytoplasm was then purified from an adapted protocol from Xi and Dobson (2005) and Rasgon et al. (2006). Cytoplasm and developmental cells were pelleted by centrifugation at $300 \mathrm{x} g$ for 5 minutes to remove large debris. The supernatant was transferred into a new centrifuge tube and spun at $12,000 \mathrm{x} \mathrm{g}$ for 10 minutes to pellet Wolbachia cells. The pellet was resuspended in phosphate-buffered saline (PBS) buffer and kept on ice prior to use. Five microliters were aliquoted for cell viability staining using 50nM SYTO11 dye (ThermoFisher Ltd., Waltham, USA) to determine Wolbachia presence and $0.4 \%$ Trypan Blue to assess the percentage of non-viable cells.

To determine Wolbachia presence, pooled egg cytoplasm DNA was extracted using DNA Miniprep Kit (Zymo Research, USA) following manufacturer instructions. DNA was quantified using a NanoDrop spectrophotometer (Thermo Fisher Scientific, Inc., Waltham, USA). The Wolbachia surface protein (wsp) 
gene was amplified using primers $w s p 81 \mathrm{~F}$ and $w s p 691 \mathrm{R}$. PCR was conducted using protocols mentioned previously using $w s p$ primers.

Samples with positive wsp bands (including positive controls to exclude sequencing error) had their PCR products purified using $1 \mu 1$ of ExoSAP-IT cleanup reagent (Thermo Fisher, USA) and following manufacturer's instructions, were incubated at $36^{\circ} \mathrm{C}$ for 15 minutes, then at $80^{\circ} \mathrm{C}$ for 15 minutes. Cleaned products sequenced with the forward wsp $81 \mathrm{~F}$ primer. Sequencing was completed by Massey Genome Service (Massey University, Palmerston North, NZ). Sequences were searched in the NCBI BLAST nucleotide database to determine identity. Those that matched at least $98 \%$ with a known Wolbachia wsp sequence were deemed to be positive for Wolbachia infection.

\section{Microinjection assays}

\section{Egg microinjections}

Honey bee (Apis mellifera carnica) eggs were collected from on-site beehives at Victoria University of Wellington, New Zealand. To collect eggs of a known age, queen bees were placed inside a queen cage (part of the Ezi-Queen queen rearing system, Auckland, New Zealand). Prior to queen containment, the cage was placed into the hive for one hour in place of a brood frame to allow the workers to acclimatize and clean out any existing honey or previously unsuccessful eggs. Queens were removed after three hours of containment. On a few occasions, when the queen was not able to be located, a fresh frame of pulled wax was placed in the brood box in place of a brood comb and left for three hours before removal. Laid eggs were transported in a warm $\left(\sim 28^{\circ} \mathrm{C}\right)$ box kept humid with a damp sponge. The viability of eggs is highly sensitive to disturbance, with movement of eggs from comb to plate having a significant effect on hatch rate (Collins, 2002). Therefore, eggs were kept in the EziQueen frame or within a section of cut comb to reduce direct contact during injection and laboratory handling. All eggs were injected immediately after removal before cell differentiation which occurs between 4-6 hours post oviposition.

Eggs were microinjected with one unit of resuspended Wolbachia (1psi for 0.1 second, Tritech Digital Microinjector) administered by a micromanipulated glass capillary needle. It is difficult to determine the exact quantity of each injection, but they were optimized to "inflate" the egg without overpressurizing it as explained by Xi and Dobson (2005). Optimal needle tip width was determined by trial and error. It was determined that a $10 \mu \mathrm{m}$ tip was the smallest tip that would both minimize trauma in the egg but prevent clogging (in any tip smaller than $10 \mu \mathrm{m}$ clogging of the needle occurred frequently). Injections were made into the posterior end of the egg, as illustrated in Figure 1. Eggs were then kept in comb/frame in standard larval rearing conditions, at $35.4^{\circ} \mathrm{C}$ with $80-90 \%$ relative humidity until hatching. 
See Appendix section 1A Bee Larval Rearing Protocol for more detail. Approximately one quarter of the number of eggs that were injected with Wolbachia were injected with phosphate-buffered saline (PBS) as controls per trial.

A random sample of 20 intact microinjected eggs per treatment were taken per trial to be assessed for Wolbachia presence.

\section{Larvae and pupae microinjections}

Previous microinjection of Wolbachia into the larval stages of insects and isopods has proven successful, particularly in $\mathrm{F}_{0}$ and has been shown to be an effective method to study Wolbachia somatic colonization (Grenier, et al., 1998; Kageyama, et al. 2008). I similarly attempted to infect honey bee larvae with Wolbachia via microinjection. Apis mellifera larvae were collected from brood combs by cutting sections of comb with a sharp knife. Larvae were aged by eye as per Human et al. (2014) and all instars (larval phases) were included in subsequent injections. Larvae were kept in comb to reduce contact prior to injection to reduce contact-induced mortality. Injections were conducted through the same methodology as with eggs but were targeted at the $5^{\text {th }}$ and $6^{\text {th }}$ abdominal segment of larvae where the germcell is located (Dearden, 2006).

White-eyed pupae were carefully removed from capped comb using blunt ended forceps (to reduce the likelihood of mechanical damage) and laid dorsal-side down onto a $72 \mathrm{~mm}$ petri dish lined with a Kimwipe ${ }^{\circledR}$. Pupae were covered and immobilized by placing them in $-20^{\circ} \mathrm{C}$ for 60 seconds. Pupae were injected between the $3-4^{\text {th }}$ abdominal segment, which is a common feeding place for $V$. destructor (Kanbar \& Engels, 2003). Approximately one third of the quantity of larvae and pupae that were injected with Wolbachia were injected with phosphate-buffered saline (PBS) as controls. Replicates varied dependent on the number of individuals of the required life stage found in the comb in any given trial.

Both larvae and pupae were kept in standard rearing conditions $\left(34.5( \pm 1)^{\circ} \mathrm{C}\right.$ with $80-90 \%$ relative humidity) on comb for 12 hours. After 12 hours all dead larvae were removed to eliminate individuals killed from injection-related damage. Individuals still alive after 12 hours were transferred from comb to $72 \mathrm{~mm}$ petri dishes and fed ad-libtum standard larvae diet (53\% royal jelly, 3\% glucose, 3\% fructose, 1\% yeast extract; see Appendix 1). Larvae and pupae were checked for mortality at 12, 24, 48 and 56 hours postmicroinjection. Larvae and pupae were euthanized 72 hours post-injection and kept at $-80^{\circ} \mathrm{C}$ prior to DNA extraction and analysis.

Survival analyses for eggs, larvae and pupae were conducted on R (R Development Core Team, 2008) using the "survival" (Therneau, 2015), "survminer" (Kassambara \& Kosinski, 2016) "simPH" 
(Gandrud, 2017) packages. Data was partitioned by treatment, a variable with two factors, Wolbachia injections and control injections (PBS injections). Within treatment groups, individuals were classed into life stages at four levels: egg, young larvae (between instars 1-3), older larvae (between instars 3-6), and pupae. Analyses were conducted within and between groups. Between groups, Chi-squared tests was conducted to compare survival curves associated with each treatment, and confirmed with Wald and Log Rank tests, both with a single degree of freedom. Within treatment groups, to determine the impact of life stage on survival rate, Log-likelihood ratio models were expressed with an exponential distribution, to produce Chi-square ratios and pairwise comparisons made between life stages. Confidence intervals were constructed using a robust nonparametric method by Brookmeyer \& Crowley (1982).

A1
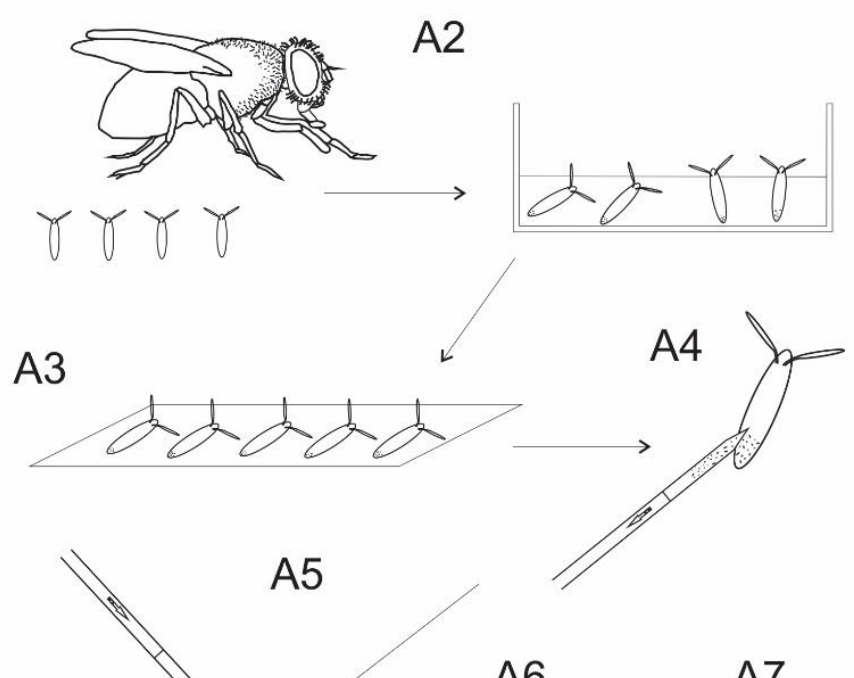

A5

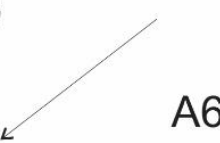

A6

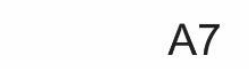

A7

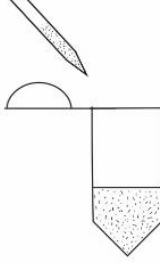

\llcorner
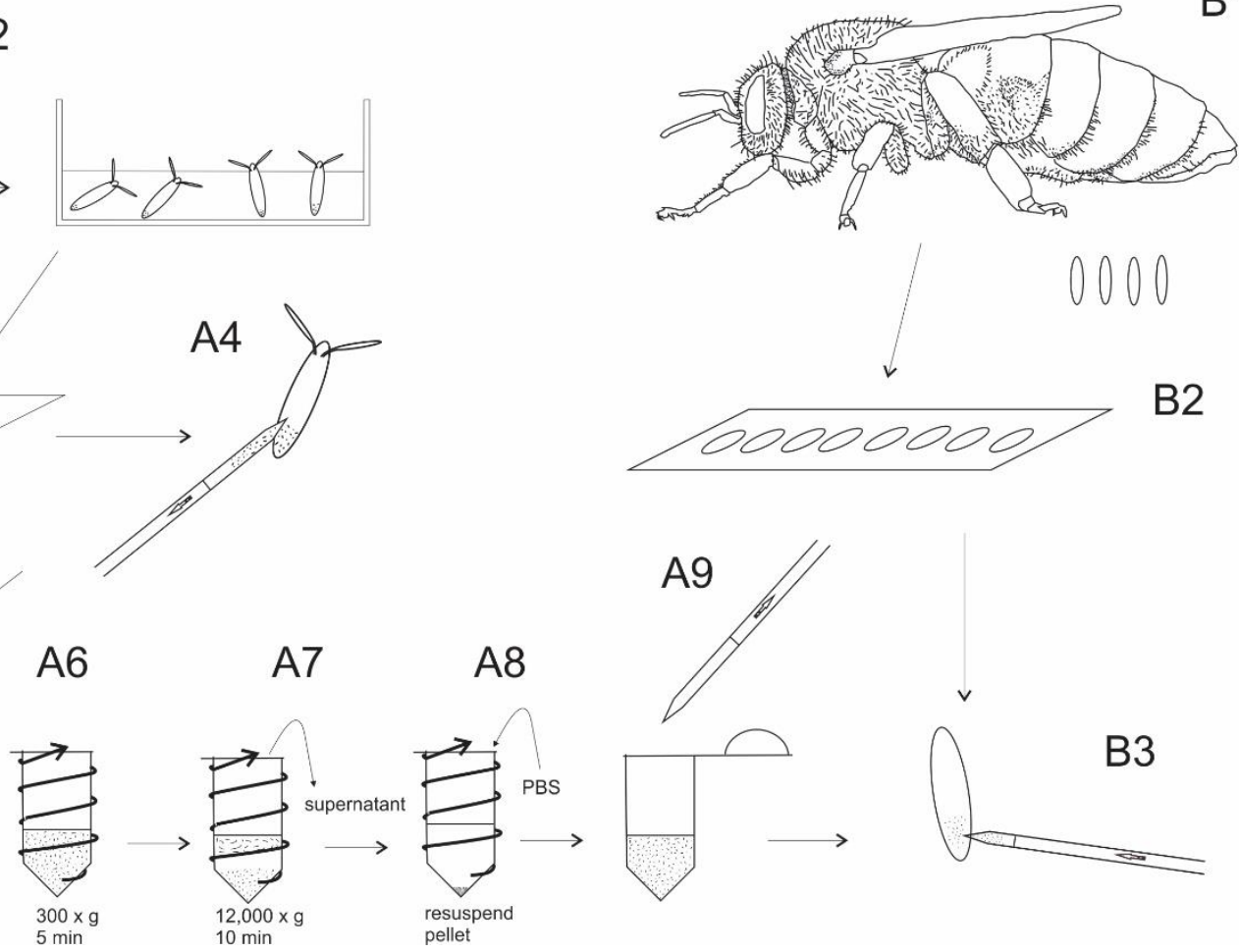

Figure 1 Overview of the microinjection process modified from Xi \& Dobson (2005) and Rasgon, et al. (2006). A1, Wolbachiainfected Drosophila melanogaster and her eggs; A2, D. melanogaster eggs being dechorionated in 1:1 diluted bleach solution for two minutes followed by two water rinses (not shown); A3, dechorionated eggs laid out on a glass slide; A4; Wolbachia-positive cytoplasm vacuumed from eggs via $10 \mu \mathrm{m}$ needle; A5; cytoplasm ejected into eppendorf tube for short term storage and kept on ice. A6, centrifugation of cytoplasm at $300 \mathrm{x}$ g for 5 minutes to separate large debris. A7, Supernant is removed and then spun for 10 minutes at 12,000 x g to pellet Wolbachia. A8, Pellet resuspended with phosphate-buffered saline (PBS). A9, isolated suspended Wolbachia vacuumed into needle. B1; Apis mellifera queen and her eggs; B2, eggs laid out on slide (eggs were kept in the comb to reduce egg disturbance); B3, Apis mellifera eggs injected in the posterior end with resuspended Wolbachia. Source: author's own. 


\section{Artificial insemination assay}

Transinfected Wolbachia requires access to the ovaries of the recipient to integrate into the ovarian tissue and allow maternal transmission (Werren et al., 2008; Hughes, et al., 2014). An alternative to thoracic or embryonic injections is to infect the $F_{0}$ 's ovaries directly so that eggs produced in the $F_{1}$ are infected without the need for further intervention (Hughes \& Rasgon, 2014). In honey bees, artificial insemination is common industry practice to breed queens (and therefore colonies) with desirable traits and for genetic studies (Hunt, et al., 1998; Cobey, 2007). Here, I attempted a Wolbachia transinfection simultaneously with an artificial insemination event. Utilizing such methods have never before been attempted in Wolbachia transinfection studies, nor has the purposeful bacterial infection in bees through artificial insemination.

Honey bee virgin queens were artificially inseminated with Wolbachia using a modified artificial insemination protocol used in the New Zealand commercial apiculture industry (BettaBees New Zealand, Ltd.), following protocols similar to Cobey et al (2013). Five-day old virgin queens were supplied by Beaut Bees Ltd. (Auckland, NZ). Virgin queens were couriered as per standard industry practice in plastic vented containers with up to seven nurse bees and supplied with industry-grade "queen candy" (50\% icing sugar, $50 \%$ honey) as a food supplement. Queens were placed into dequeened hives 48 hours prior to insemination to allow the hive workers to be exposed to queen pheromones and prevent negative or defensive interaction post-insemination. Twenty-four hours prior to inseminations, queens were removed from their hives and anesthetized for 5 minutes under $\mathrm{CO}_{2}$, transferred into queen cell cages with a queen excluder opening to allow workers to access her and then placed back into their respective hives.

Semen was collected from approximately 150 drones to the total of $50 \mu 1$. Semen was diluted and activated with $10 \%$ industry-standard insemination buffer $(0.11 \% \mathrm{NaCl}, 0.06 \%$ tris, $1 \%$ glucose, $10 \%$ lysine, $10 \%$ argenine, $90 \%$ distilled autoclaved water with the antibiotic component left out). Wolbachia was isolated from approximately 300 Drosophila melanogaster eggs as previously described. Wolbachia cells were kept in cell-free Schneider's Drosophila media supplemented with $10 \%$ heat-inactivated fetal bovine serum as described by Ragson et al. (2006) and Gamston \& Ragson (2007), and kept at $4{ }^{\circ} \mathrm{C}$ prior to insemination. In a sub-sample, bacteria viability was checked using an $10 \mu \mathrm{L}$ aliquot of isolated cells stained with SYTO11 to visualize Wolbachia and 0.4\% Trypan blue dye to determine the quantity of unviable bacterial cells. Viable and dead cells were counted under 510nm fluorescent microscopy.

During insemination, queens were briefly anesthetized with $\mathrm{CO}_{2}$ for approximately 15 seconds until major movements ceased before being placed into a plastic queen holder, orientated so the end of her abdomen was sticking out of the hold, and her head was facing downward into a low flow of $\mathrm{CO}_{2}$. A small pair of specially designed pressure-controlled forceps were used to hold and gently pull the queen's stinger outwards and a special hook on the ventral side used to open the queen's oviduct passage (Fig. 6B). Ten 
microlitres of semen-buffer mix containing Wolbachia was injected using a glass capillary needle after Wolbachia was identified post-staining. The queens were then returned to their respective hives in the same queen cell container with queen candy to eat through to encourage acclimatization post insemination.

Hives were kept under strict containment. As the potential effects of Wolbachia have not been evaluated in A. mellifera, interaction between infected queens and naive bees was strictly controlled and we were careful to not release any transinfected bees into the environment. Therefore all hives were kept indoors with no access to the outdoors. Sample size in this experiment was consequently limited by quarantine requirements and minimization of interactions between bees belonging to different queens. A single control queen was inseminated with semen containing no additional Wolbachia. Only one control queen was used due to restricted availability of queens within the same cohort by the supplier, and budget and quarantine constraints. Ovaries from one additional queen were taken 24 hours after insemination to screen for ovarian infection as we were confident of no pre-existing Wolbachia infection.

Hives were kept indoors and isolated from one another (for quarantine purposes) for the next five weeks. Queens were sampled 2 weeks and 5 weeks post-inseminations when a brood frame was removed and replaced with a fresh frame with additional pollen supplements. Worker bees were collected from frames within the hive. Samples were immediately frozen at $-80^{\circ} \mathrm{C}$ to test for Wolbachia as described above.

\section{Deformed Wing Virus infection and survival assay}

In the event of Wolbachia infection in the progeny of inseminated queens, it was important to utilize these individuals to determine the phenotypic influence of Wolbachia. To do evaluate Wolbachia's influence on RNA viruses in A. mellifera, individual adult bees that were suspected to be infected with Wolbachia were infected with Deformed wing virus (DWV).

Deformed wing virus was extracted from a pool of red-eyed A. mellifera pupae (approximately 1920 days post egg oviposition) from Varroa destructor mite-infested hives and homogenized in potassium phosphate buffer (PPS; pH8) with 10\% diethyl ether and chloroform purification before pelleting remaining cell debris for 2 minutes at $13,000 \mathrm{x}$. The homogenate was passed through a $0.22 \mu \mathrm{m}$ bacteria filter and then serially diluted (Remnant, pers. comm. 2018). Extracted DWV was kept at $-20^{\circ} \mathrm{C}$ prior to injection. It was likely that this extract contained other viral particles other than DWV. Deformed wing virus viral RNA was extracted with the Quick gDNA Miniprep Kit (Zymo Research, USA) following manufacturer instructions. RNA was reverse transcribed into cDNA using Superscript III Reverse Transcriptase (Thermofisher, USA) using specific oligonucleotide primers and dNTPs, following manufacturer's instructions. Deformed wing virus presence was diagnosed through standard PCR using standard Platinum Taq (Thermofisher, USA). Each $15 \mu \mathrm{L}$ reaction was made up of $2.5 \mu \mathrm{L}$ of $10 \mathrm{X}$ buffer, $0.75 \mu \mathrm{L} 50 \mathrm{mM} \mathrm{MgCl}_{2}$, 
$0.5 \mu \mathrm{L} 10 \mathrm{mM}$ dNTPs, $0.5 \mu \mathrm{L}$ of each forward and reverse primer, approximately 100ng of template, 0.1 Platinum taq, and $\mathrm{ddH}_{2} \mathrm{O}$ to $15 \mu \mathrm{L}$. A standard thermocycling protocol was followed, comprised of: initial denaturation at $94^{\circ} \mathrm{C}$ for 2 minutes, 30 cycles of $94^{\circ} \mathrm{C}$ for 30 seconds, $55^{\circ}$ for 30 seconds and $72^{\circ} \mathrm{C}$ for 1 minute, followed by a final elongation step of $72^{\circ} \mathrm{C}$ for 5 minutes and held at $4{ }^{\circ} \mathrm{C}$. Products were visual on a $1.5 \%$ agarose gel and stained with SYBR Safe DNA stain (Invitrogen, USA).

Prior to microinjection, adult worker bees were anesthetized, immobilized in groups of ten, by cooling them at $-20^{\circ} \mathrm{C}$ for two minutes (Human, et al., 2013). Anesthetized bees were then injected with DWV through a glass capillary needle with a $10 \mu \mathrm{m}$ tip. Each bee received approximately the same volume of extract to ensure consistency, with settings of 1 psi pressure for 0.1 seconds on a digital microinjector (MINJ-D; Tritech Research, Ltd.). This manipulation was done manually, with DWV suspensions injected ventrally through the intersegmental membrane between the $3^{\text {rd }}$ and $4^{\text {th }}$ abdominal segment (the typical feeding place of $V$. destructor (Kanbar \& Engels, 2003)). Control pupae were injected with the same quantity of DWV-free potassium phosphate buffer.

Bees were kept in standardized incubation conditions at $34.5^{\circ} \mathrm{C}$ and $80 \% \mathrm{RH}$ in vented containers and fed with 50\% sucrose solution. Bees were kept with bees from the same hive to prevent mixing progeny from inseminated queens and control queens. Survival was monitored evert 6 hours up to 64 hours post-injection. Once dead, bees were frozen at $-80^{\circ} \mathrm{C}$, and bees that survived up to 64 hours were euthanized and also kept at $-80^{\circ} \mathrm{C}$.

\section{PCR Screening for infection}

Wolbachia infection in larvae injected with isolated Wolbachia was diagnosed 72 hours post-injection. DNA and RNA were extracted from pools of three larvae in the same instar by homogenizing samples using pellet pestles (Sigma-Alrdrich, USA) in GENEzol reagent (Geneaid, Taiwan) with 5\% $\beta$-mercaptoethanol, with chloroform and isopropanol purification (Gruber, et al., 2017). For adult bees, pools of three bees were homogenized by bead-beating (BeadBeater 16, Biposec products, USA). Due to limited tissue in injected eggs, egg DNA was extracted using DNA Miniprep Kit (Zymo Research, USA), following manufacturer instructions, instead of the GENEzol protocol. Concentrations of DNA were quantified with a NanoDrop spectrophotometer (Thermo Fisher Scientific, Inc., Waltham, USA).

To detect Wolbachia, the wsp gene was amplified using primers wsp $81 \mathrm{~F}$ and wsp691R. PCR was performed using MyTaq Red Mix (Bioline, London, UK) with each reaction at a final volume of $15 \mu 1(7 \mu l$ of MyTaq Red Mix buffer, $1 \mu 1$ each of forward and reverse primers and $1 \mu 1$ of DNA sample and ddH $_{2} \mathrm{O}$ to the final volume). The thermal cycling conditions were an initial denaturation at $95^{\circ} \mathrm{C}$ for 1 minute; and 30 
cycles of denaturation at $95^{\circ} \mathrm{C}$ for 15 seconds, annealing at $50^{\circ} \mathrm{C}$ and extension at $72^{\circ} \mathrm{C}$ for 10 seconds; with a final extension step at $72^{\circ} \mathrm{C}$ for 5 minutes and held at $4^{\circ} \mathrm{C}$. Amplification was visualized in a $1.5 \%$ agarose gel stained with SyberSafe DNA Gel Stain (Thermo Fisher, USA). Drosophila melanogaster and Ancistrocerus gazella were used as independent positive controls and no template controls were used as negative controls.

\section{Immune response}

In order to determine the honey bee immune response to Wolbachia microinjection, the expression of a number of downstream antimicrobial peptides (AMP) were assessed in first instar larvae. First instar larvae were microinjected instead of eggs in this experiment in order to accurately determine mortality in injected individuals and eliminate cases of inhibited or downregulated peptide expression confounded by death. In eggs, mortality is unable to be determined apart from observed lack of development. It is difficult to determine egg development without the use of a microscope, whereas in larvae, development can be monitored by eye.

The antimicrobial peptides, abaecin, apidaecin, defensin and hymenoptaecin were chosen for their previously determined affinity to gram-negative bacteria (Table 2; Evans, 2004; Evans, et al., 2006). The housekeeping gene Proteasome 54kD subunit (Pros54) was used for reference (Cameron, et al., 2013) and Wolbachia titre was determined by the wMel primer (Chrostek, et al., 2013). Information on all primers can be found in Appendix 3. Wolbachia is a Gram-negative bacterium and in order to rule out potential upregulation of other non-specific bacteria, abaecin, an AMP that targets Gram-positive bacteria, was included in these experiments.

First instar honey bee larvae were randomly assigned one of three treatments: Wolbachia microinjection, heat-treated Wolbachia microinjection (where isolated Wolbachia was incubated at $95^{\circ} \mathrm{C}$ for 10 minutes (Rasgon, et al., 2006), or no microinjection (control). Larvae were microinjected with one unit of either resuspended Wolbachia or heat-treated Wolbachia (1psi for 0.1 second, Tritech Digital Microinjector) administered by a micromanipulated glass capillary needle as described above. It was determined that a $10 \mu \mathrm{m}$ tip was the smallest tip that would minimize trauma in the egg but prevent clogging (in any tip smaller than $10 \mu \mathrm{m}$ clogging of the needle occurred frequently). Individuals were then kept in standard conditions for either $0,12,24,36$, or 48 hours and then frozen at $-80^{\circ} \mathrm{C}$ for genetic analysis.

DNA and RNA were extracted from pools of three larvae by homogenizing samples using pellet pestles (Sigma-Alrdrich, USA) in GENEzol reagent (Geneaid, Taiwan) with 5\% $\beta$-mercaptoethanol, and chloroform and isopropanol purification (Gruber, et al., 2017). DNA was removed using the PerfeCta DNase I (Quanta Bio Inc.) following manufacture's instruction. cDNA was prepared by reverse 
transcription of $8 \mu \mathrm{L}$ RNA (approximately 80ng) with random hexamers and oligo(dT) primers using qScript XLT cDNA SuperMix (Quanta Bio Inc.) and incubated for 5minutes at $25^{\circ} \mathrm{C}, 60$ minutes at $42^{\circ} \mathrm{C}$ and 5 minutes at $85^{\circ} \mathrm{C}$. The resulting cDNA was diluted 1:10 with nuclease-free water.

Drosophila melanogaster egg DNA used for confirmation of Wolbachia presence was extracted using DNA Miniprep Kit (Zymo Research, USA), following manufacturer instructions. Concentrations of DNA were quantified with a NanoDrop spectrophotometer (Thermo Fisher Scientific, Inc., Waltham, USA).

\section{Gene expression analyses}

Quantitative real-time PCR (qPCR) was performed to detect expression of the four nominated antimicrobial peptides, a reference gene, and Wolbachia with specific oligio(dT) primers run in duplicate using a magnetic induction cycler (Mic qPCR Cycler, Bio Molecular Systems). Reaction mixes of $20 \mu \mathrm{L}$ contained $10 \mu \mathrm{L}$ PerfeCta SYBR Green Fastmix, $2 \mu \mathrm{L}$ cDNA template, and $2 \mu \mathrm{L}$ of each forward and reverse primer at $10 \mathrm{nM}$. Thermal protocol followed that of Evans et al. (2006) consisting of 5 minutes at $95^{\circ} \mathrm{C}$, then 40 cycles of a four step protocol of $94^{\circ} \mathrm{C}$ for 20 seconds, $60^{\circ} \mathrm{C}$ for 30 seconds, $72^{\circ} \mathrm{C}$ for 1 minute, and $78^{\circ} \mathrm{C}$ for 20 seconds. Amplification was followed by a melt-curve dissociation program to confirm expected product size. Results were screened for appropriate dissociation values to check for and eliminate primer-dimer artifacts.

Antimicrobial peptide and Wolbachia primer expression were standardized against the reference gene Proteasome 54kD subunit (Pros54; Cameron, et al., 2013) to find $\Delta \mathrm{Ct}$ scores for each gene. Microinjection treatments (Wolbachia or heat-treated Wolbachia) were then standardized against control treatment values for each gene using the $\Delta \Delta \mathrm{Ct}$ method to determine the expression fold change $\left(2^{\wedge}-\Delta \Delta \mathrm{Ct}\right)$ (Schmittgen and Livak, 2008). Differences in expression between genes were tested using two-way ANOVAs, with gene and treatment as factors using R (R Core Development Team, 2013). 
Table 1 Information about the honey bee antimicrobial peptides examined in this study: abaecin, apidaecin, hymenoptaecin, and defensin.

\begin{tabular}{|c|c|c|c|}
\hline Peptide & Target & Characteristics & Reference \\
\hline Abaecin & Gram-positive bacteria & $\begin{array}{l}\text { Proline-rich. } \\
\text { Composed of } 34 \text { amino acids. } \\
\text { Abaecin-like peptides also } \\
\text { found in bumble bee } \\
\text { hemolymph. }\end{array}$ & $\begin{array}{l}\text { Xu, et al., } 2009 \\
\text { Hara \& Yamakawa, } 1995 \\
\text { Evans, } 2004\end{array}$ \\
\hline Apidaecin & $\begin{array}{l}\text { Gram-negative bacteria but } \\
\text { can affect gram-positive at } \\
\text { high enough concentrations. } \\
\text { Permeate bacterial membrane } \\
\text { without lytic effect. } \\
\text { Inhibit bacterial DnaK heat } \\
\text { shock proteins and chaperonin } \\
\text { GroEL-GroES complex. }\end{array}$ & $\begin{array}{l}\text { Proline-rich } \\
\text { Composed of } 18 \text { amino acids. } \\
\text { Four natural forms, but only } \\
\text { apidaecins 1a, } 1 \mathrm{~b} \text { and } 2 \\
\text { detected in bees in vivo. }\end{array}$ & $\begin{array}{l}\text { Casteels, et al., } 1989 \\
\text { Casteels, et al., } 1993 \\
\text { Casteels-Josson, et al., } 1993 \\
\text { Casteels \& Tempst, } 1994 \\
\text { Li, et al., } 2006\end{array}$ \\
\hline Hymenoptaecin & $\begin{array}{l}\text { Gram-positive and gram- } \\
\text { negative bacteria. } \\
\text { Accesses bacterial periplasmic } \\
\text { space by creating small lesions } \\
\text { in the outer membrane. }\end{array}$ & $\begin{array}{l}\text { Glycin-rich. } \\
\text { Linear, composed of } 93 \text { amino } \\
\text { acids. } \\
\text { Single form found in } A \text {. } \\
\text { mellifera, while } 13 \text { forms } \\
\text { found in A. cerana. } \\
\text { Low basal levels in honey bee } \\
\text { brood than in adult workers. }\end{array}$ & $\begin{array}{l}\text { Casteel } \text { et al., } 1993 \\
\text { Chan, } \text { et al., } 2006 \\
\text { Xu, et al., } 2009\end{array}$ \\
\hline Defensin & $\begin{array}{l}\text { Gram-positive and some gram- } \\
\text { negative bacteria, fungi, } \\
\text { protozoa and some viruses. }\end{array}$ & $\begin{array}{l}\text { Cysteine-rich. } \\
\text { Two natural forms found in } \\
\text { honey bees, defensin-1 and } \\
\text { defensin- } 2 \text {. } \\
\text { Key antimicrobial component } \\
\text { of honey. }\end{array}$ & $\begin{array}{l}\text { Casteels-Josson } \text { et al., } 1994 \\
\text { Mandrioli, et al., } 2003 \\
\text { Bulet \& Stocklin, } 2005 \\
\text { Evans } \text { et al., 2006 } \\
\text { Kwakman } \text { et al., 2011, } 2012 \\
\text { Reviewed in Ilyasov et al, } \\
2012\end{array}$ \\
\hline
\end{tabular}

\section{RESULTS}

\section{Phylogeny}

The Bayesian Inference (BI) Wolbachia phylogeny produced was unique in that it is the first tree (to date) to include representatives of all 16 known supergroups ( $A-F, H-Q$; Figure 2$)$ and include information on phenotypic traits. Topology was congruent with existing phylogenies that have looked at individual or few supergroups, including that produced by Glowska, et al. (2015), Gerth, et al. (2014) and Casiraghi, et al. (2005). The tree had good support. Basal support was high, with posterior probabilities of 0.7-1. Support for the placement of the supergroups in general was well supported, however positions between taxa within these groups were less resolved. Multiple BI runs resulted in identical trees, and similar posterior probabilities, implying convergence among runs. Effective sample sizes (ESS) ranged from 2232 to 2420 between tree runs (an estimate of how many truly independent samples as a parameter of the output of Markov chain Monte Carlo runs, which determines the accuracy of topology placements (Drummond, et al., 2006; Lenfear, et al., 2016)). 
Tree topology distinguishes supergroups in agreement with other studies (Glowska, et al., 2015). Supergroups $A$ and $B$ include Wolbachia strains from arthropods only (Werren, et al., 1995), while supergroup $C$ and $D$ are restricted to obligate filarial nematodes (Taylor, et al. 2013). Supergroup $E$ is made up of Collemobolla Mesaphoriura italica and Folsomia candida (Timmermans, et al., 2004), and supergroup $F$ is individual in that it contains both arthropod and nematode hosts (Ros et al, 2009). Supergroup $H$ contains only isopterans in the Zootermopsis genus (Wang, et al., 2014), while supergroup I infect siphonapteran fleas (Gorham, et al., 2003), Supergroup $J$ holds only the animal parasitic nematode Dipetalonema gracile (Ros, et al., 2009); while $K$ infects spider mites (e.g. Bryobia spp.), and $L$ holds the plant-boring Radopholus similis (Spirurda) (Ros, et al., 2009). Supergroups $M$ and $N$ contain hemipteran aphids (Augustinos et al., 2011), while $O$ contains the lepidopteran pest Bemisia tabaci; and groups $P$ and $Q$ contain quill mites and pseudoscorpians (Glowska, et al., 2015). Wolbachia that was previously reported to be found in found in A. mellifera (Pattabhiramaiah, et al., 2011a) was found clustered closely to Drosophila melanogaster's native $w \mathrm{Mel}$ strain.

Phenotypic review found that the effects of Wolbachia on different taxa could be split into four categories: reproductive manipulation, obligate mutualism, facultative mutualism, and undetermined effects. This information is summarized in Table 2 below. Of all Wolbachia taxa, $34.5 \%$ caused some sort of reproductive manipulation, $29 \%$ possessed obligate mutualisms with their hosts, $10.3 \%$ shared facultative mutualisms to some extent, and $27.5 \%$ had undetermined effects. These effects are only the known and empirically tested traits that populate the literature. It is highly likely that these strains have additional undetermined effects beyond what has been tested. Some strains had multiple effects, such as the wCon strain occurring in Tribolium confusum which can be beneficial despite incurring weak cytoplasmic incompatibility in its hosts. The natural Wolbachia infection present in all filarial nematodes in groups $C, D$ and $F$ are known as obligate mutualists; many arthropod hosts in supergroups $B$ and $F$ were victims of reproductive manipulation, with the majority thought to express cytoplasmic incompatibility. Outside of supergroup A, facultative mutualism was found only in plant parasites, aphids Brevicoryne brassicae and Aphis fabae, and the burrowing nematode Radopholus similis (Augustinos, et al, 2011). Phenotypic effects in supergroup $A$ are varied, with a number possessing facultative effects as well as inducing cytoplasmic incompatibility.

The Maximum Likelihood phylogeny of several common Wolbachia strains was produced (Fig. 3A). Wolbachia sourced from the Victoria University colonies was placed neatly in the $w$ Mel group, showing strong similarities with $w$ Mel from around the world and backed up with very strong bootstrap support (>0.8). 


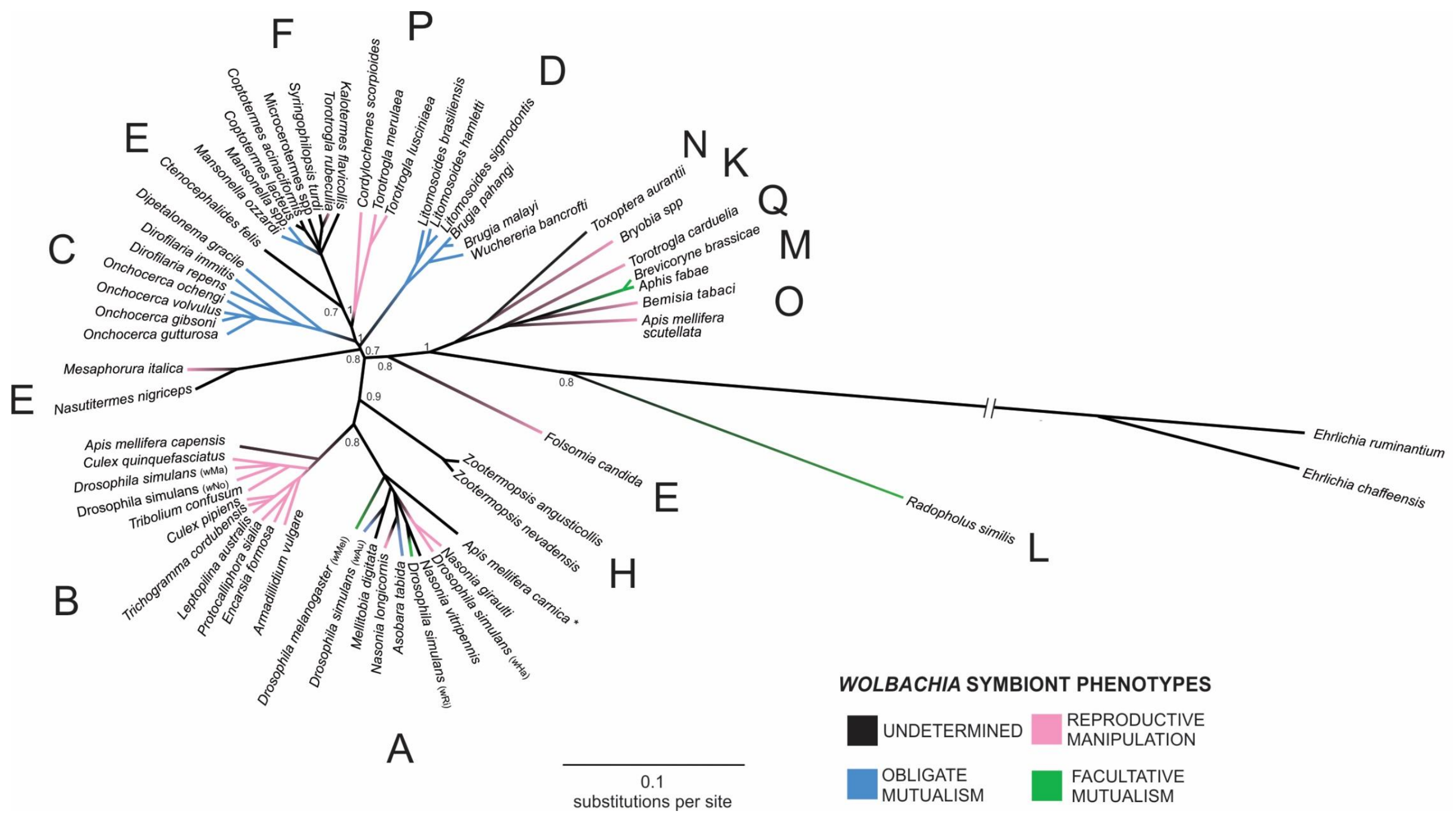

Figure 2 Concatenated Bayesian phylogenic tree of Wolbachia infections of 57 host taxa and outgroup (Ehrlichia spp. - a related group of bacteria in

Rikettsiales). Sequence concatenated from rRNA $16 \mathrm{~S}$ gene, gltA, groEL and ftsZ gene sequences (2,845bp). Topology labels represent Wolbachia host taxa from which Wolbachia was identified and posterior probabilities are labeled on nodes. Colouration key represents phenotypic effects of Wolbachia on presented host taxa (refer to Table 2), showing facultative mutualism (green), obligate mutualism (blue), reproductive manipulation (pink) and undetermined effects

(black).Supergroup clades are shown by capital letters outside the corresponding supergroup. Suspected Apis mellifera Wolbachia sequence (Pattabhiramaiah, et al.,2011) is indicated by * and is placed within the A supergroup. For accession numbers please refer to Appendix 2 . 
Of the screened hymenopterans, Wolbachia was not present in any of the wasp species. Wolbachia has been found in low abundance in Vespula germanica and V. vulgaris previously (Evison, et al., 2012). Wolbachia was also not found in Monomorium antarcticum or Linepthema humile, congruent with other studies (Reuter, et al., 2004). A Wolbachia infection was discovered in Ancistrocerus gazella from which it has not been found before. The produced phylogeny places the solitary parasitoid within the $A$ supergroup (Figure 3B) along with Asobara fabidae. Bootstrap support was highly supportive and produced topology was congruent with similar phylogenies (eg Glowska, et al.,

2015; Ma, et al., 2017)

\section{Wolbachia isolation}

Wolbachia was successfully extracted from Drosophila melanogaster in a number of forms. Wolbachia presence was visualized under fluorescent microscopy (Fig 4 a) of whole flies, egg cytoplasm, dechorionated eggs, and fly ovaries. All contained and showed positive for Wolbachia (Fig 4C). Egg cytoplasm was chosen as the candidate for host Wolbachia cells as cytoplasm was extracted at age prior to cell division and specialization, thus reducing the likelihood of excess host cells being included in subsequent microinjections.
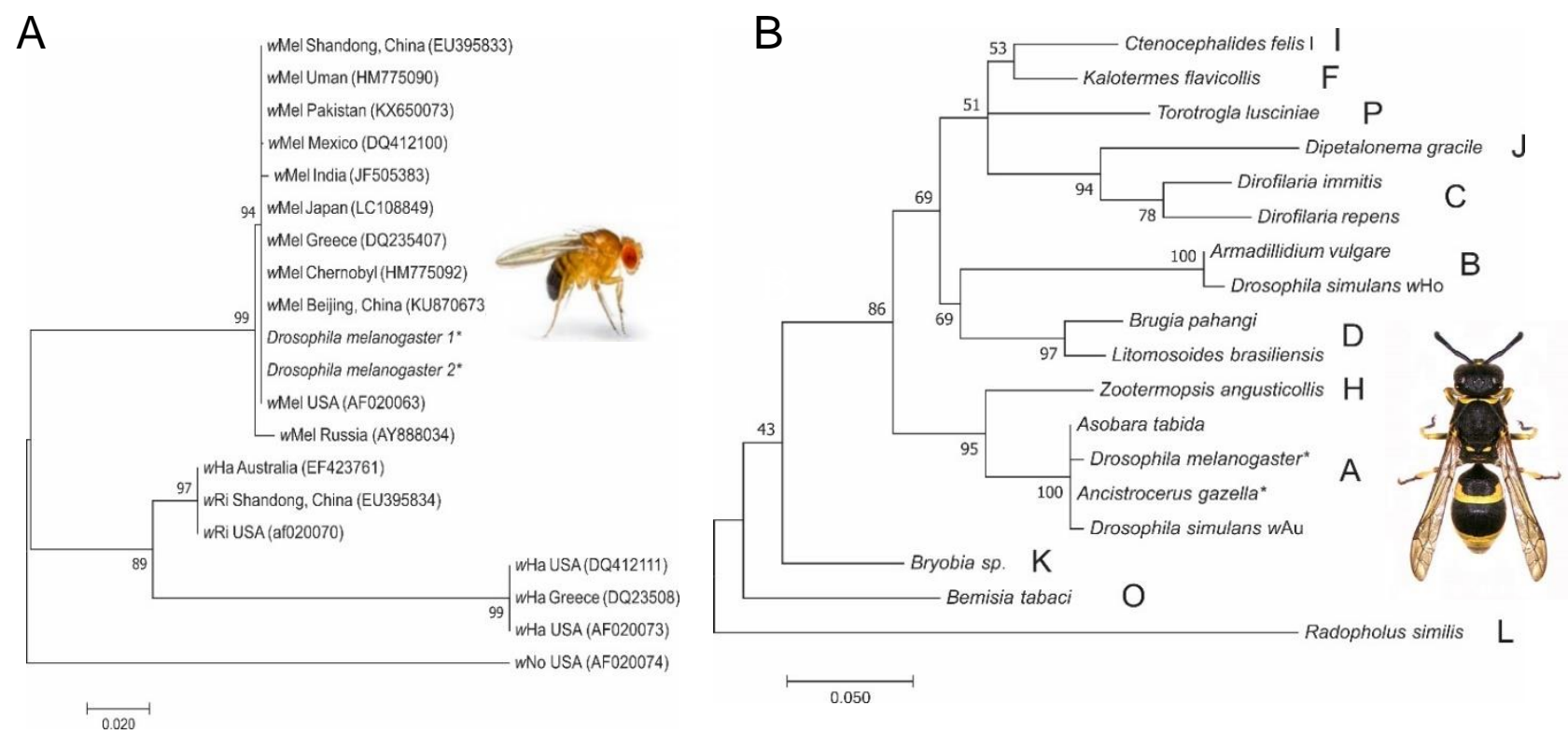

Figure 3 A) Maximum likelihood phylogeny of Wolbachia pipientis strains of the Wolbachia surface protein (wsp) found in Drosophila melanogaster in the Victoria University Drosophila colony against international D melanogaster strains. Sequence accession numbers are in brackets. Numbers on nodes show bootstrap support. * indicates sequences from this study. Scale bar represents nucleotide seInsert: Drosophila melanogaster, https://kxci.org/podcast/drosophila-melanogaster/

B) Maximum likelihood phylogeny of Ancistrocerus gazella placement within the Wolbachia supergroup syndrome. Accession numbers as per Table 1 . Numbers on nodes show bootstrap support. * indicates sequences from this study. D. melanogaster sequence identical to Drosophila melanogaster $1 *$ in A. Insert: Ancistrocerus gazelle, Landcare Research, New Zealand 
Table 2 Taxa information for the phylogeny presented in Figure 2. Information includes the Wolbachia host species, the strain of naturally infecting Wolbachia if known, Wolbachia strain's respective supergroup for that taxa, Wolbachia-host phenotype and sources for phenotypic information. CI, cytoplasmic incompatibility; PI, parthenogenesis induction; undetermined. Ordered by Supergroup. Dotted lines separate Supergroups.

\begin{tabular}{|c|c|c|c|c|c|}
\hline $\begin{array}{l}\text { Wolbachia host } \\
\text { species }\end{array}$ & Order & $\begin{array}{l}\text { Wolbachia } \\
\text { strain }\end{array}$ & Supergroup & $\begin{array}{l}\text { Wolbachia } \\
\text { phenotype }\end{array}$ & Phenotype references \\
\hline Apis mellifera & Hymenoptera & - & A & Undetermined & Pattabhiramaiah, et al. 2011 \\
\hline Asobara tabida & Hymenoptera & wAtab1 & A & Obligate mutualist & Dedeine, et al., 2005 \\
\hline $\begin{array}{l}\text { Drosophila } \\
\text { melanogaster }\end{array}$ & Diptera & $w M e l$ & A & $\begin{array}{l}\text { Facultative } \\
\text { mutualism; CI }\end{array}$ & Werren, et al 2008; Fry, et al. 2004 \\
\hline $\begin{array}{l}\text { Drosophila } \\
\text { simulans }\end{array}$ & Diptera & $w A u$ & A & $\begin{array}{l}\text { Facultative } \\
\text { mutualism; CI }\end{array}$ & Sutton, et al., 2014 \\
\hline $\begin{array}{l}\text { Drosophila } \\
\text { simulans }\end{array}$ & Diptera & wHa & A & $\mathrm{CI}$ & Zabalou, et al. 2008 \\
\hline $\begin{array}{l}\text { Drosophila } \\
\text { simulans }\end{array}$ & Diptera & $w R i$ & A & $\begin{array}{l}\text { Facultative } \\
\text { mutualism }\end{array}$ & Hoffmann, et al., 2015 \\
\hline $\begin{array}{l}\text { Encarsia } \\
\text { formosa }\end{array}$ & Hymenoptera & wEfo & A & PI & Stouthamer, et al. 2002 \\
\hline $\begin{array}{l}\text { Mellitobia } \\
\text { digitata }\end{array}$ & Hymenoptera & $w D i g$ & A & Undetermined & - \\
\hline Nasonia giraulti & Hymenoptera & wNigPa & A & $\mathrm{CI}$ & Bordenstein, et al., 2000 \\
\hline $\begin{array}{l}\text { Nasonia } \\
\text { vitripennis }\end{array}$ & Hymenoptera & wNvit & A & $\mathrm{CI}$ & Bordenstein, et al., 2000 \\
\hline $\begin{array}{l}\text { Tribolium } \\
\text { confusum }\end{array}$ & Coleoptera & $w$ Con & A & Facultative; CI & Wade et al., 1995 \\
\hline $\begin{array}{l}\text { Apis mellifera } \\
\text { capensis }\end{array}$ & Hymenoptera & wCap-B1 & B & Undetermined & - \\
\hline $\begin{array}{l}\text { Apis mellifera } \\
\text { scutellata }\end{array}$ & Hymenoptera & wCap-B2 & B & Undetermined & - \\
\hline $\begin{array}{l}\text { Armadillidium } \\
\text { vulgare }\end{array}$ & Isopod & wVulC & $\mathrm{B}$ & Feminization & Valette et al, 2013 \\
\hline Culex pipiens & Diptera & wPip & $\mathrm{B}$ & $\mathrm{CI}$ & Rasgon \& Scott, 2003 \\
\hline $\begin{array}{l}\text { Culex } \\
\text { quinquefasciatus }\end{array}$ & Diptera & wPip & B & $\mathrm{CI}$ & de Almedia, et al., 2011 \\
\hline $\begin{array}{l}\text { Drosophila } \\
\text { simulans }\end{array}$ & Diptera & $w N o$ & $\mathrm{~B}$ & $\mathrm{CI}$ & Zabalou, et al. 2008 \\
\hline $\begin{array}{l}\text { Leptopilina } \\
\text { australis }\end{array}$ & Hymenoptera & $w A u s$ & $\mathrm{~B}$ & PI & Cook \& Butcher, 1999 \\
\hline $\begin{array}{l}\text { Nasonia } \\
\text { longicornis }\end{array}$ & Hymenoptera & wNLonCA1 & $\mathrm{B}$ & $\mathrm{CI}$ & Bordenstein, et al., 2000 \\
\hline $\begin{array}{l}\text { Protocalliphora } \\
\text { sialia }\end{array}$ & Hymenoptera & wProtSi & $\mathrm{B}$ & - & $\begin{array}{l}\text { Baudry, et al., 2003; Whitworth, et } \\
\text { al., } 2007\end{array}$ \\
\hline $\begin{array}{l}\text { Trichogramma } \\
\text { cordubensis }\end{array}$ & Hymenoptera & $w T c o$ & $\mathrm{~B}$ & PI & $\begin{array}{l}\text { Pintureau, et al., 2002; Grenier, et al., } \\
2002\end{array}$ \\
\hline $\begin{array}{l}\text { Dirofilaria } \\
\text { immitis }\end{array}$ & Spirurida & $w D i$ & $\mathrm{C}$ & Obligate mutualist & Bandi, et al., 1999 \\
\hline $\begin{array}{l}\text { Dirofilaria } \\
\text { repens }\end{array}$ & Spirurida & & $\mathrm{C}$ & Obligate mutualist & Taylor, et al., 2000 \\
\hline $\begin{array}{l}\text { Onchocerca } \\
\text { gibsoni }\end{array}$ & Spirurida & $w O g$ & $\mathrm{C}$ & Obligate mutualist & Tamarozzi, et al., 2011 \\
\hline
\end{tabular}




\begin{tabular}{|c|c|c|c|c|c|}
\hline $\begin{array}{l}\text { Onchocerca } \\
\text { gutturosa }\end{array}$ & Spirurida & - & $\mathrm{C}$ & Obligate mutualist & Tamarozzi, et al., 2011 \\
\hline $\begin{array}{l}\text { Onchocerca } \\
\text { ochengi }\end{array}$ & Spirurida & $w O o$ & $\mathrm{C}$ & Obligate mutualist & Tamarozzi, et al., 2011 \\
\hline $\begin{array}{l}\text { Onchocerca } \\
\text { volvulus }\end{array}$ & Spirurida & - & $\mathrm{C}$ & Obligate mutualist & Hise \& Gillette-Ferguson, 2004 \\
\hline Brugia malayi & Spirurida & - & $\mathrm{D}$ & Obligate mutualist & Foster, et al., 2005 \\
\hline Brugia pahangi & Spirurida & - & $\mathrm{D}$ & Obligate mutualist & Andrews, et al., 2012 \\
\hline $\begin{array}{l}\text { Litomosoides } \\
\text { brasiliensis }\end{array}$ & Spirurida & - & $\mathrm{D}$ & Obligate mutualist & Chagas-Moutinho, et al., 2015 \\
\hline $\begin{array}{l}\text { Litomosoides } \\
\text { hamletti }\end{array}$ & Spirurida & - & $\mathrm{D}$ & Obligate mutualist & Hoerauf, et al., 2000 \\
\hline $\begin{array}{l}\text { Litomosoides } \\
\text { sigmodontis }\end{array}$ & Spirurida & - & $\mathrm{D}$ & Obligate mutualist & Hoerauf, et al., 2000 \\
\hline $\begin{array}{l}\text { Wuchereria } \\
\text { bancrofti }\end{array}$ & Spirurida & $w W b$ & $\mathrm{D}$ & Obligate mutualist & Gayen, et al. 2010 \\
\hline $\begin{array}{l}\text { Folsomia } \\
\text { candida }\end{array}$ & Collembola & - & $\mathrm{E}$ & PI & Pike \& Kingcomb, 2009 \\
\hline $\begin{array}{l}\text { Coptotermes } \\
\text { acinaciformis }\end{array}$ & Dictyoptera & - & $\mathrm{F}$ & Undetermined & Salunke et al. 2010 \\
\hline $\begin{array}{l}\text { Coptotermes } \\
\text { lacteus }\end{array}$ & Dictyoptera & - & $\mathrm{F}$ & Undetermined & - \\
\hline $\begin{array}{l}\text { Kalotermes } \\
\text { flavicollis }\end{array}$ & Dictyoptera & - & $\mathrm{F}$ & Undetermined & Panaram \& Marshall, 2006 \\
\hline $\begin{array}{l}\text { Mansonella } \\
\text { ozzardi }\end{array}$ & Spirurida & - & $\mathrm{F}$ & Obligate mutualist & Kairser, et al., 2008 \\
\hline Mansonella sp. & Spirurida & - & $\mathrm{F}$ & Obligate mutualist & Kairser, et al., 2008 \\
\hline $\begin{array}{l}\text { Microcerotermes } \\
\text { sp }\end{array}$ & Dictyoptera & - & $\mathrm{F}$ & Undetermined & - \\
\hline $\begin{array}{l}\text { Syringophilopsis } \\
\text { turdi }\end{array}$ & Parasitiformes & - & $\mathrm{F}$ & Undetermined & Wang, et al., 2011 \\
\hline $\begin{array}{l}\text { Mesaphorura } \\
\text { italica }\end{array}$ & Isoptera & $w$ Ita & $\mathrm{H}$ & PI & Czarnetzki \& Tebbe, 2003 \\
\hline $\begin{array}{l}\text { Nasutitermes } \\
\text { nigriceps }\end{array}$ & Isoptera & - & $\mathrm{H}$ & Undetermined & Salunke et al., 2010 \\
\hline $\begin{array}{l}\text { Zootermopsis } \\
\text { angusticollis }\end{array}$ & Isoptera & - & $\mathrm{H}$ & Undetermined & Salunke et al., 2010 \\
\hline $\begin{array}{l}\text { Zootermopsis } \\
\text { nevadensis }\end{array}$ & Isoptera & - & $\mathrm{H}$ & Undetermined & Salunke et al., 2010 \\
\hline $\begin{array}{l}\text { Ctenocephalides } \\
\text { felis }\end{array}$ & Siphonaptera & - & I & Unknown & Rolain, et al., 2003 \\
\hline $\begin{array}{l}\text { Dipetalonema } \\
\text { gracile }\end{array}$ & Spirurida & - & $\mathrm{J}$ & Obligate mutualist & Ferri et al., 2011 \\
\hline Bryobia sp. & Spider mite & - & $\mathrm{K}$ & Feminization & Ros, et al., 2012 \\
\hline $\begin{array}{l}\text { Radopholus } \\
\text { similis }\end{array}$ & Spirurida & - & $\mathrm{L}$ & Facultative & Haegeman, et al, 2009 \\
\hline Aphis fabae & Hemiptera & - & M & Faculative mutualism & Augustinos, et al., 2011 \\
\hline $\begin{array}{l}\text { Brevicoryne } \\
\text { brassicae }\end{array}$ & Hemiptera & $w B r a K M M 1$ & M & Undetermined & - \\
\hline $\begin{array}{l}\text { Toxoptera } \\
\text { aurantii }\end{array}$ & Hemiptera & $w A u G L M$ & $\mathrm{~N}$ & Undetermined & - \\
\hline Bemisia tabaci & Lepidoptera & $w T a b$ & $\mathrm{O}$ & CI & $\begin{array}{l}\text { Nirgianaki et al, 2003; Ahmed, et al., } \\
2010\end{array}$ \\
\hline $\begin{array}{l}\text { Cordylochernes } \\
\text { scorpioides }\end{array}$ & Pseudoscorpian & $w \operatorname{Csc} 2$ & $\mathrm{O}$ & Male killing & Koop, et al., 2009 \\
\hline
\end{tabular}




\begin{tabular}{|c|c|c|c|c|c|}
\hline $\begin{array}{l}\text { Torotrogla } \\
\text { lusciniaea }\end{array}$ & Parasitiformes & EG074 & $\mathrm{P}$ & $\mathrm{CI} / \mathrm{PI}$ & Glowska, et al., 2015 \\
\hline $\begin{array}{l}\text { Torotrogla } \\
\text { merulaea }\end{array}$ & Parasitiformes & EG035 & $P$ & $\mathrm{CI} / \mathrm{PI}$ & Glowska, et al., 2015 \\
\hline $\begin{array}{l}\text { Torotrogla } \\
\text { rubeculia }\end{array}$ & Parasitiformes & EG169 & $P$ & $\mathrm{CI} / \mathrm{PI}$ & Glowska, et al., 2015 \\
\hline $\begin{array}{l}\text { Torotrogla } \\
\text { carduelia }\end{array}$ & Parasitiformes & EG121 & Q & $\mathrm{CI} / \mathrm{PI}$ & Glowska, et al., 2015 \\
\hline \multicolumn{6}{|l|}{ Outgroup } \\
\hline $\begin{array}{l}\text { Ehrlichia } \\
\text { chaffeensis }\end{array}$ & Rickettsiales & & & & Glowska, et al., 2015 \\
\hline $\begin{array}{l}\text { Ehrlichia } \\
\text { ruminantium }\end{array}$ & Rickettsiales & & & & Glowska, et al., 2015 \\
\hline
\end{tabular}



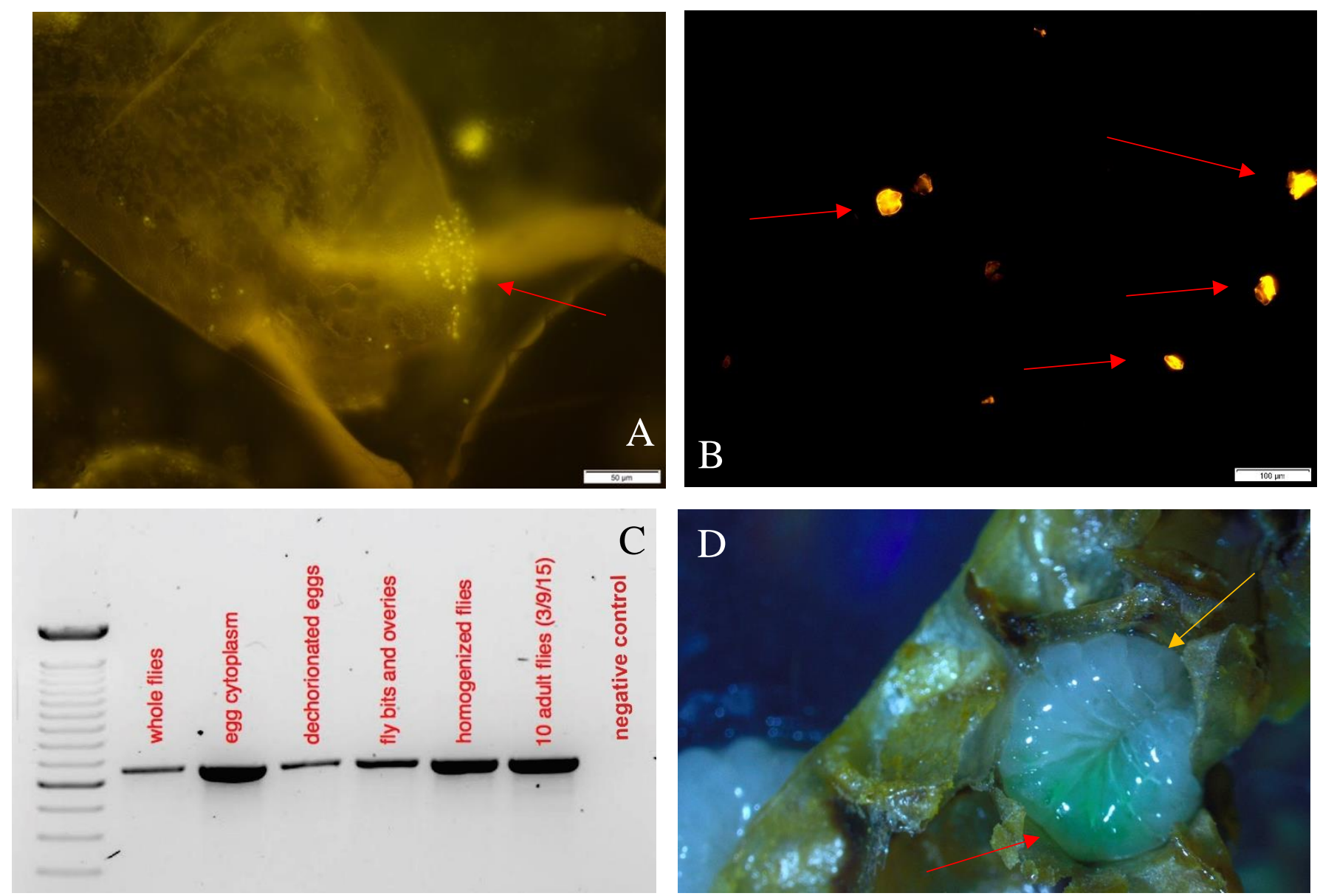

Figure 4 A) Wolbachia in the ventral-anterior of a 10 minute-old Drosophila melanogaster egg stained with SYTO11 dye. B) Wolbachia present in honey bee drone semen mixed before insemination stained with SYTO11 dye. Wolbachia presence was confirmed with PCR amplification and subsequent sequences. C) Visualized PCR products of Wolbachia surface protein (wsp) on a 1.5\% agarose gel, sourced from Victoria University's Drosophila melanogaster colonies of varying body parts and eggs. D) Fifth instar A. mellifera larvae injected with Phosphate-buffered saline (PBS) and inert green dye to show injection location between the 5-6 body segment (red arrow). Yellow arrow indicates larvae head for reference. Larvae were kept in honey bee comb to reduce mortality. Source: Jess Russell

\section{Microinjection assays}

In total, 1207 individuals were injected with either Wolbachia or control phosphate-buffered saline (PBS) containing no Wolbachia. These individuals were comprised of 882 eggs, 89 young larvae (between instars 1-3), 96 older larvae (between instars 4-6), and 40 pupae. Of these, no eggs injected with Wolbachia hatched after 72 hours post-injection, however, $22 \%$ of the embryos in the control treatment of injection with PBS injected hatched successfully.

Larvae and pupae that died 12 hours post-injection were considered to have died of mechanical injury from injection. Seventy-two hours after being injected only $6.4 \%$ of Wolbachia-injected individuals were alive ( $n=953)$, compared to $20 \%$ of control-injected individuals $(n=200)$ (Figure 5B). Survival 
probability was significantly lower in individuals injected with Wolbachia than those control injected $\left(\chi^{2}=\right.$ 47.5, 1df, $p<0.001)$. There were significant differences in the survival of eggs $(t=12.5, p<0.001)$ and older larvae $(t=10.6, p<0.001)$ between treatments (Fig. 5A). Complete mortality of eggs in Wolbachia injected individuals may be responsible for the clear differentiation in survival between treatment groups (Fig 5B).

Larval life stage had significant influence on survival probability irrespective of whether individuals were injected with Wolbachia or control PBS (Wolbachia: $\chi^{2}=464.65, p<0.001$; Control: $\chi^{2}=$ $729.72, p<0.001$ ). Life stages each had different survival probability from one another (overall, Likelihood ratio test $=55.4, p<0.0001)$ but with varying degrees of statistical significance when paired against one another (Table 2). Earlier life stages - eggs in particular - had very low survival followed by a general increase in survivorship with age. Of all microinjected individuals screened for Wolbachia 72 hours postinjection via PCR amplification, none produced positive bands.

High mortality in eggs was expected. However, in order to determine whether Wolbachia infection was possible in eggs, only a few eggs needed to survive. However, the complete mortality of all eggs injected with Wolbachia, but not those injected with PBS, implies an effect of Wolbachia that may explain the mortality.

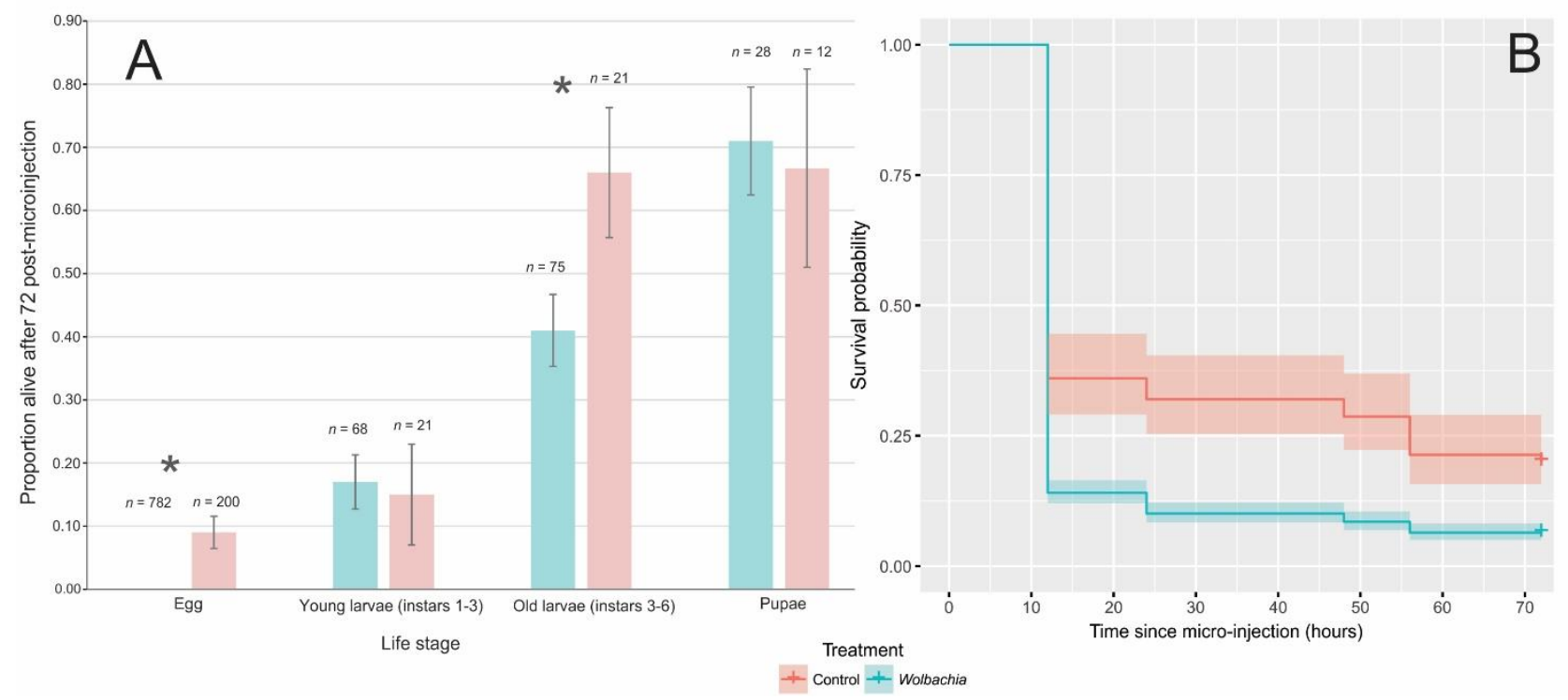

Figure 5 A) Proportion of Apis mellifera individuals of varying life stages (egg, young larvae, older larvae, and pupae) alive after 72 hours post micro-injection with either Wolbachia or control phosphate-buffered saline (PBS) $( \pm$ SE). Statistically significant differences between groups indicated by *. B) Kaplein-Meyer survival graph of cumulative survival of all life stages (eggs, young larvae, older larvae, and pupae) post microinjection with Wolbachia or PBS controls. Shading around the lines indicate $95 \%$ confidence intervals. 


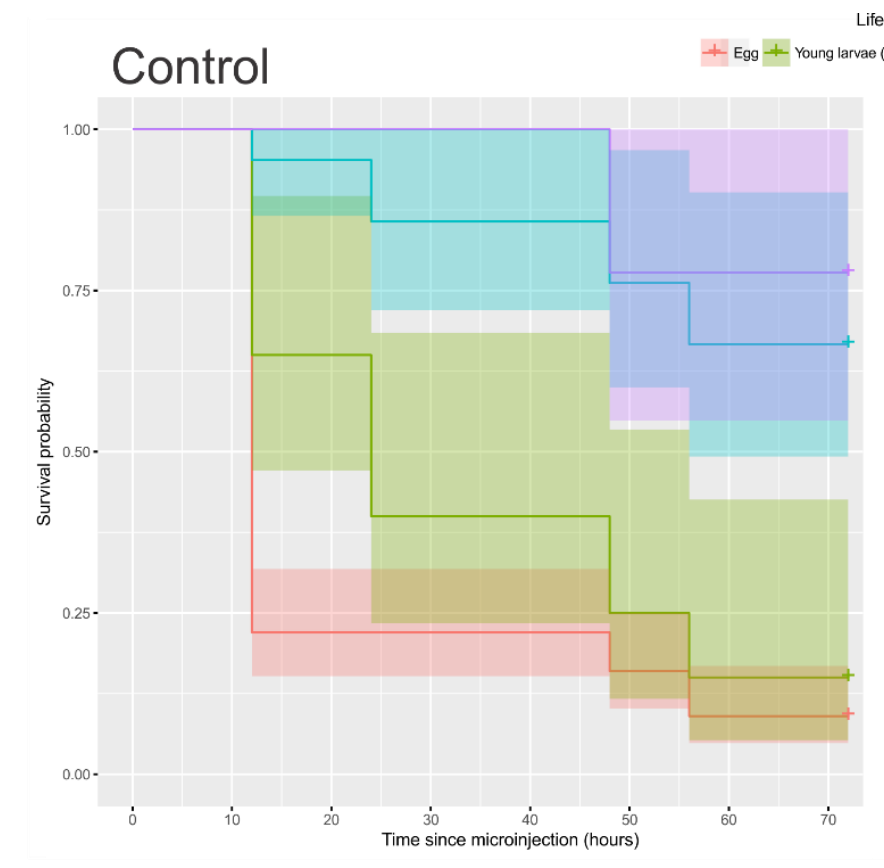

$(1-3)+$ Older Larvae $(3-6)+$ Pupae

Wolbachia

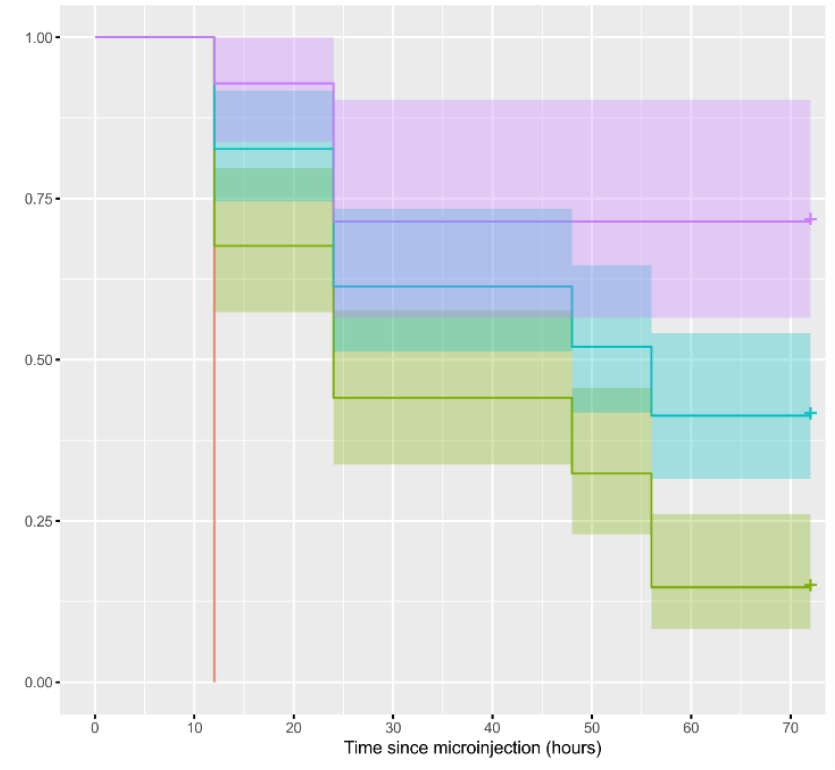

Figure 6 Kaplain Meyer survival curves of pre-pupated Apis mellifera microinjected with either Wolbachia or phosphate-buffered saline (control). Colours represent life stage: Red: egg; green: young larvae (instars 1-3); blue: old larvae (instars 3-6); purple: white-eyed pupae. Shading around lines represent $95 \%$ confidence intervals.

Table 2 Pairwise comparisons between survival curves of pre-pupated Apis mellifera microinjected with either Wolbachia or phosphate-buffered saline (control). Each value is comparing the survival curve between life stage as per Figure 6. Analysis by Long-rank tests with p-value adjustment using the Benjamini and Hochberg method (1995) to account for false errors in multiple testing. All comparisons were significant at the 5\% significance level in the Wolbachia treatment. In the control treatment, all comparisons were significant also, apart from the difference between young larvae and egg survival, and between pupae and older larvae survival.

Wolbachia-injected

\begin{tabular}{lllll}
\hline & Egg & Larvae (1-3) & Larvae (3-6) & Pupae \\
\hline Egg & - & - & - & - \\
Larvae (1-3) & $<0.0001$ & - & - & - \\
Larvae (3-6) & $<0.0001$ & 0.0007 & - & - \\
Pupae & $<0.0001$ & $<0.0001$ & 0.0132 & - \\
\hline
\end{tabular}

\section{Control}

\begin{tabular}{lllll}
\hline & Egg & Larvae (1-3) & Larvae (3-6) & Pupae \\
\hline Egg & - & - & - & - \\
Larvae (1-3) & 0.2041 & - & - & - \\
Larvae (3-6) & $<0.0001$ & 0.0004 & - & - \\
Pupae & $<0.0001$ & 0.0002 & 0.5174 & -
\end{tabular}




\section{Artificial insemination}

The semen that was inoculated with Wolbachia used for insemination was deemed positive for Wolbachia through visual analysis under $510 \mathrm{~nm}$ fluorescent microscopy (Fig 3B) and less than $10 \%$ of bacterial cells were unviable when stained under $10 \%$ trypan blue. The definitive presence of Wolbachia in the semencytoplasm mix was also assessed using PCR amplification of the wsp gene, which also proved positive (Fig $8 \mathrm{~A})$.Of the 5 inseminated queens, three were successfully fertilized, queens laying viable fertilized eggs after two weeks. Eggs and larvae of fertilized queens that were tested for Wolbachia through PCR screening were not positive after two weeks. After five weeks, eggs and larvae showed a faint band when PCR products were visualized (Fig 7). These bands were approximately one third of the length of the expected $w s p$ products and were sent for sequencing. The sequences were non-conclusive for $w s p$ with unspecific peaks, and when searched in the BLAST database showed no resemblance to any other nucleotide sequence in the GenBank database. It was concluded that these samples did not contain Wolbachia and that partial bands present were due to non-specific binding.

To determine Wolbachia ovarian infection post insemination, ovaries of inseminated queens were dissected and screened for Wolbachia. Ovaries 24 hours-post infection showed a positive band for wsp, evidence that Wolbachia reached the ovaries within 24 hours. However, ovaries of laying queens taken 6 weeks-post insemination produced no bands in the same PCR reaction. Figure 8 summarizes all microinjection and artificial insemination results.

\section{Well \#}

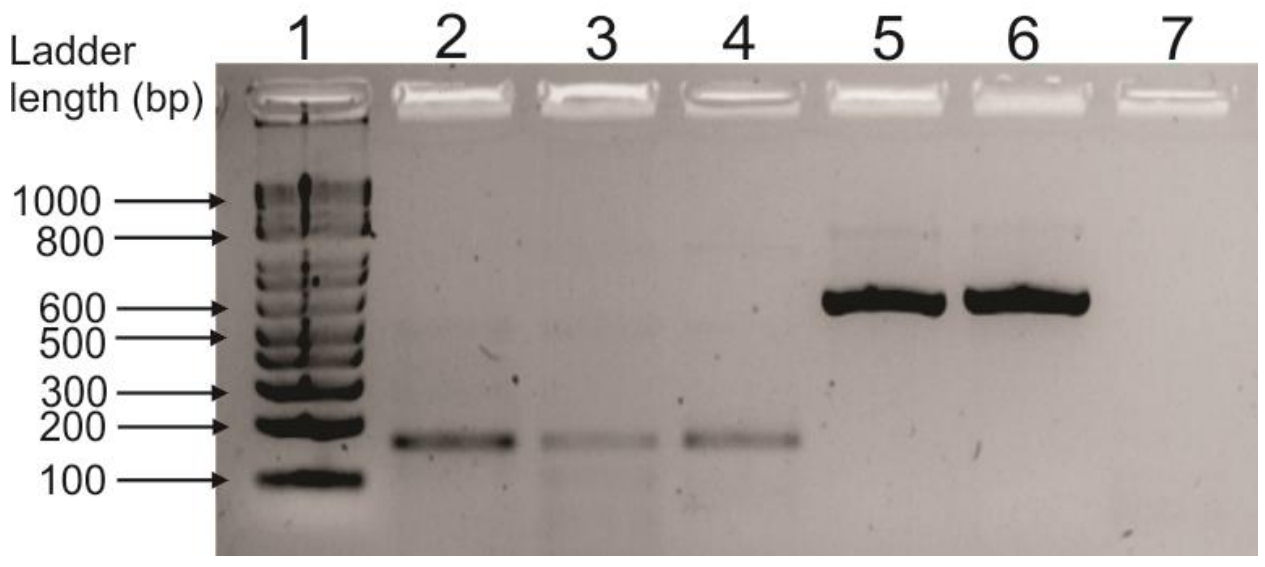

Figure 7 Visualised PCR products of $w s p$ gene on $1.5 \%$ agarose gel. Lanes: L, Hyperladder 1kb; 1, fertilized queen \#1 pooled larvae sample five weeks-post insemination; 2 , fertilized queen \#2 pooled larvae sample five weeks-post insemination; 3 , fertilized queen \#3 pooled larvae sample five weeks-post insemination; 4, positive control (D. melanogaster); 5 , positive control ( $A$. gazella); 6, negative control (inseminated queen \#4 no Wolbachia); 7, no DNA template control. 


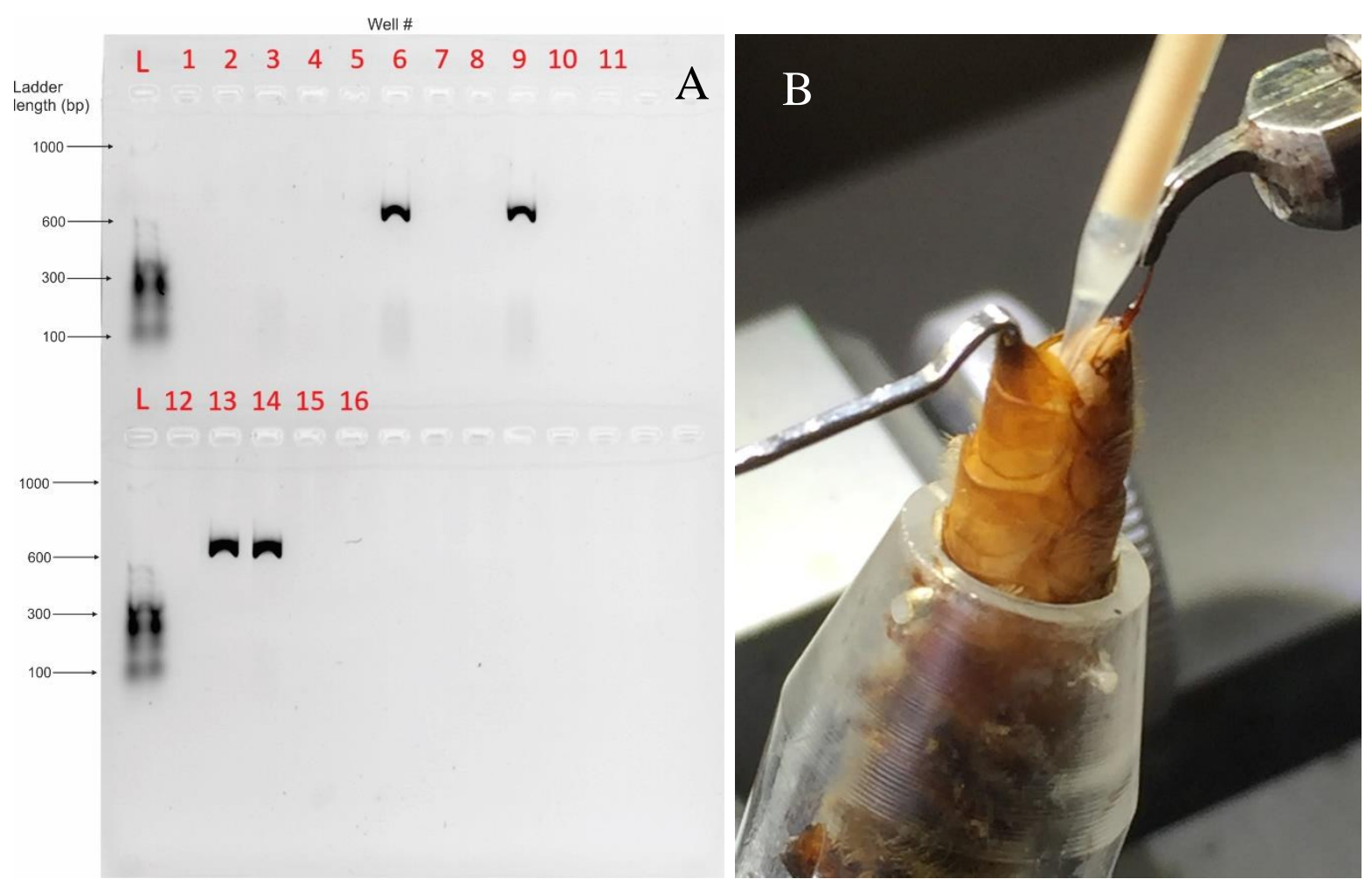

Figure 8 A) Summary of all visualised PCR products of wsp gene (to show presence of Wolbachia) on 1.5\% agarose gel. All life stages belong to Apis mellifera unless otherwise mentioned and all were PCR screened 72 hours-post treatment unless otherwise stated.

L: Hyperladder $100 \mathrm{~kb}$, top half is very faint. Lane 1: Control adult A. mellifera (no treatment); 2: A. melifera eggs injected with Wolbachia,; 3: Larvae injected with Wolbachia; 4: Pupae injected with Wolbachia; 5: Adults injected with Wolbachia; 6: A. mellifera drone semen mixed with isolated Wolbachia; 7: Control drone semen with no added Wolbachia; 8: Control queen ovaries (no artificial insemination); 9: Artificially inseminated ovaries with semen containing Wolbachia, 24 hours post insemination event; 10: Artificially inseminated ovaries with semen containing Wolbachia, 6 weeks post insemination event; 11: Fertilized AI queen eggs; 12: Fertilized AI queen larvae; 13: Isolated Wolbachia used for injections and inseminations sourced from Drosophila melanogaster; 14: Positive control (Drosophila melanogaster); 15: AI queen stomatic cells; 16: NTC

B) A. mellifera queen being artificially inseminated with $15 \mu \mathrm{L}$ of drone semen mixed with live Wolbachia using a glass capillary needle as per industry practice.

\section{Deformed wing virus infection and assay}

As the insemination event was limited to a single round of artificial inseminations, it was important to conduct any subsequent assays on the inseminated queen's eggs and larvae even if Wolbachia hadn't been yet diagnosed. In order to utilize progeny from artificially inseminated queens that were potentially infected with Wolbachia, this assay was conducted prior to sequencing confirmation of Wolbachia infection. During the time of sequencing of the PCR band of larvae from queens inseminated with Wolbachia, 269 adult 
progeny of inseminated queens were injected with DWV. Deformed wing was found present in bees from both Wolbachia inseminated queens and control bees based on PCR diagnosis.

After 64 hours, only four individuals remained alive between both treatments. There was a very high level of mortality between 0 and 12 hours-post-injection, which levelled off after 12 hours (Fig. 9). Treatment (DWV or control) had no significant influence on mortality (Long rank $=0.6325, p=0.4586$ ). However, as the survival of bees without any kind of injection was not measured, it is not possible to conclude that mechanical injury alone explains the mortality rate.

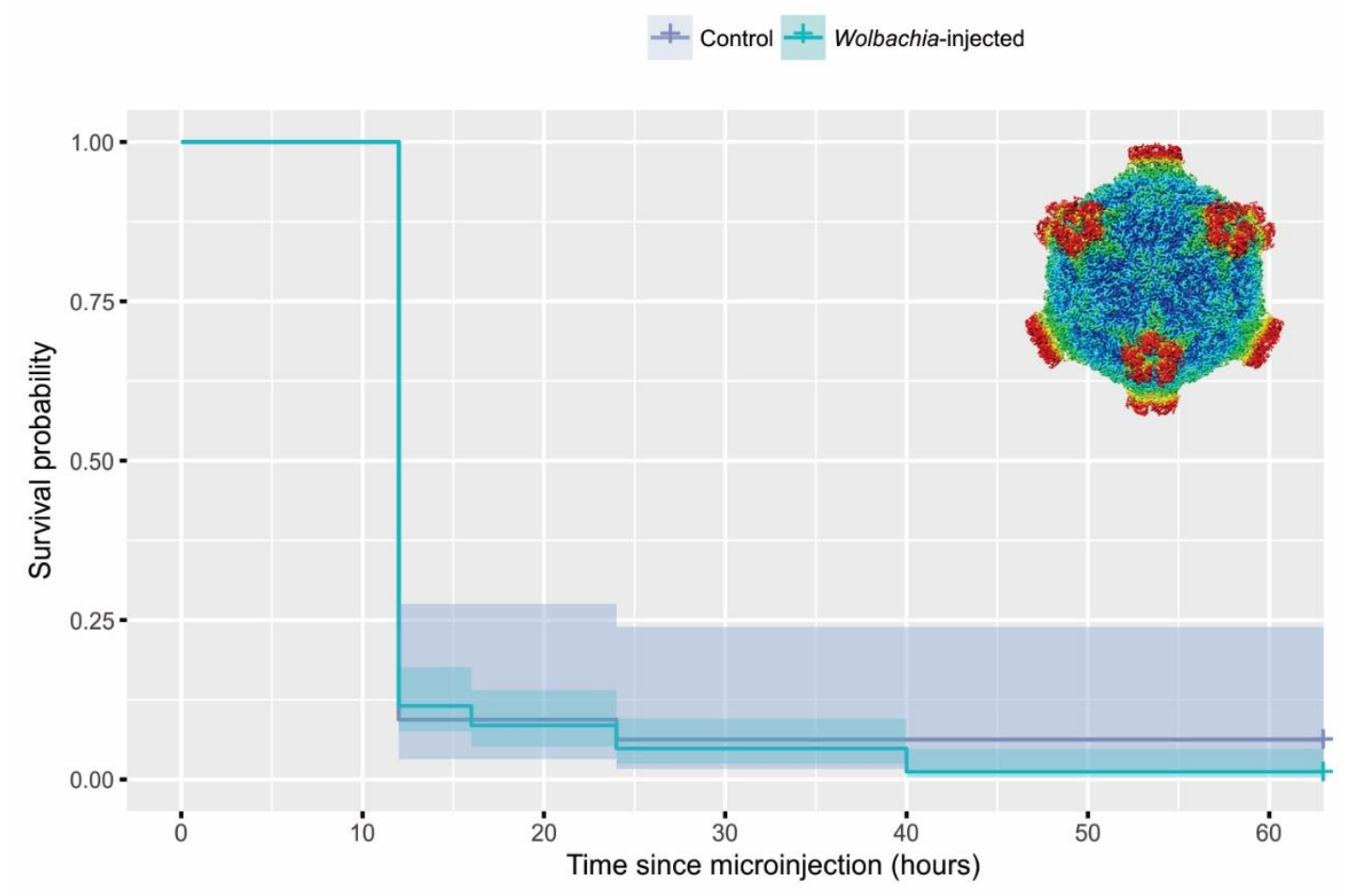

Figure 9 Kaplain-meyer survival graph of honey bees injected with DWV suspected to be infected with Wolbachia after F0 artificial insemination. Individuals were monitored every six hours up to 64 hours post-injection. Shadows indicate $95 \%$ confidence intervals. Insert is a visual representation of the molecular surface of a Deformed wing virus particle under cryo-electron microscopy by Skubnik et al. (2017).

\section{Antimicrobial peptide expression}

Of the four antimicrobial peptides examined, only apidaecin was significantly upregulated post-Wolbachia microinjection compared to control treatments $(F=6.425, p=0.0129$; Figure 10). No AMP was upregulated in response to being injected with heat-treated Wolbachia. In individuals injected with Wolbachia, Wolbachia expression is high immediately after injection but decreases with increasing acceleration over 
the course of 48 hours. Apidaecin was significantly upregulated 8-fold in comparison to control individuals who were not injected $(F=2.271, p=0.0439)$. By 24 hours this expression increased to a maximum mean relative expression of 12 times that of control individuals. Between 24 and 48 hours, Wolbachia and apidaecin both fall to near control expression levels. In this time frame there was an increase in hymenoptaecin from 0.28 to 3.13 times that of control treatments.

In the heat-treated treatments, Wolbachia expression was nearing identical to control treatments. Its presence was still recorded, however the $2^{\wedge}(\Delta \Delta \mathrm{Ct})$ method does not allow 0 expression as $2^{\wedge}(0)=1$, meaning that an expression of Wolbachia in control or heat-treated treatments does not equate to experimental contamination. Small expressional increases in abaecin and hymenoptaecin were recorded in heat-treated treatments but never surpassing twice that of the control treatment.

The correlation of highly upregulated apidaecin and falling Wolbachia suggests immune response in A. mellifera larvae in response to experimental infection. The slow rise in apidaecin between 0 and 24 hours correlates with the steepest fall in Wolbachia expression. Wolbachia expression reaches negligible levels by 48 hours post-injection and apidaecin follows this trend. Error bars may be explained by variation in the quantities of Wolbachia during microinjection and variation between individual bees immune response.
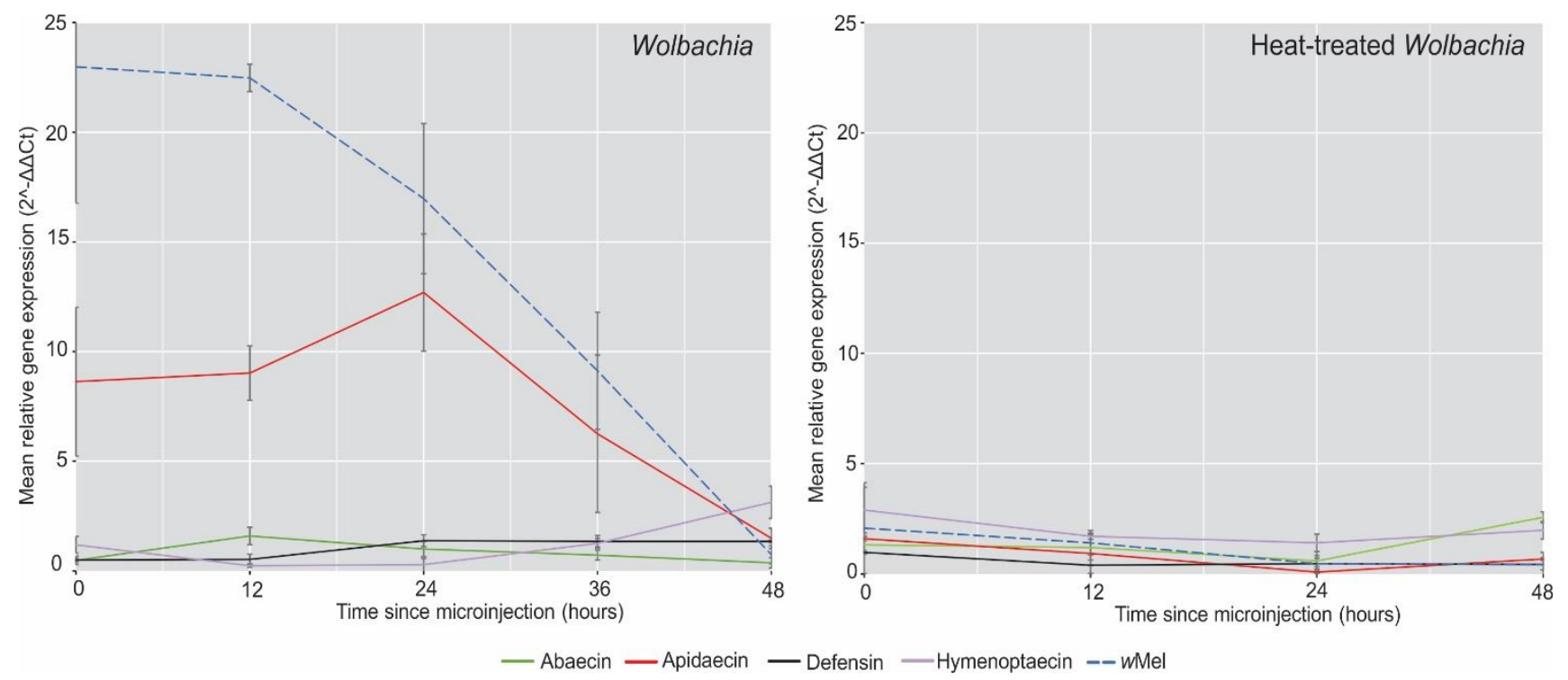

Figure 10 Mean relative antimicrobial expression in first instar Apis mellifera larvae following microinjection with Wolbachia or Wolbachia heat-treated for 30 minutes at $85^{\circ} \mathrm{C}$ over 48 hours. Treatment expression of antimicrobial peptide genes (abaecin, apidaecin, defensin, and hymenoptaecin) and Wolbachia $(w \mathrm{Mel})$ is recorded as $2^{\wedge}(\Delta \Delta \mathrm{Ct})$, with treatment expression standardized against housekeeping gene prost 54 and standardized against control treatment (no microinjection). Error bars are \pm 1 SE. 


\section{DISCUSSION}

\section{Microinjection}

Transinfection of Wolbachia into Apis mellifera did not prove successful via microinjection techniques that have been successfully used in Drosophila species (Xi et al., 2005; Walker, et al., 2009). Younger honey bee life stages were of higher risk of mortality, with zero eggs microinjected with Wolbachia hatching, only $22 \%$ of control embryos hatching and a lower proportion of young larvae suviving than older larvae in both treatments. Handling of young lifestages, particularly eggs, is precarious and high mortality in pre-pupated Apis mellifera has been noted in other studies (DuPraw, 1961; Collins, 2002, 2004). Based on previous studies, it appears that honey bee eggs have lower hatch rates than seen in other model insects, including Drosophila, which is reported to have a minimum hatch rate around 85\% (Prout \& Clark, 2000; Rashed, et al., 2008) Aedes mosquitoes of $87.5 \%$ (Edgerly, et al., 1993; McMeniman, et al., 2009), and the flour beetle Tribolium castaneum at approximately $80 \%$ in favourable conditions (Howe, 1957). Honey bees however, particularly carniolan bees (A. m. carnica, the species used in this study) hatch almost half as consistently, with a minimum hatching rate as low as $60 \%$, dependant on queen characteristics, and further reduced by any change in ambient humidity (Collins, 2004; Al-Ghamdi, et al., 2014). Moreover, Collins (2002) found that any movement of honey bee eggs from the comb to plate has significant effect on hatch rate. Further manipulation, including lifting of the egg, further reduced the hatch rate by almost $50 \%$. Older eggs appear to tolerate more handling than younger eggs. Previous successful honey bee microinjection experiments have found considerably lowered hatch rates in injected bees compared to those found in control treatments (Milne, et al., 1988). Eggs 24 hours old or younger have been considered too readily damaged to collect them from the comb safely to use for further experiments (Collins \& Mazur, 2006).

The significant difference in hatch rate between Wolbachia-injected and control eggs, or more, the lack of any Wolbachia-injected eggs hatching at all, suggests that there is something the Wolbachia isolate that prevents hatching. The isolation protocol used in this study was somewhat rudimentary, and it is possible that left over constituent from D. melanogaster egg cytoplasm may have had a cytotoxic effect in A. mellifera eggs. However, this protocol has been successfully used to infect Wolbachia-cured Drosophila and mosquito cell lines (Xi \& Dobson, 2005; Rasgon et al., 2011). It is also possible that the Wolbachia itself is causing the increase in immune response.

The signficant differences between life stages over all microinjection experiments indicates that resilience is strongly correlated with age, as is to be expected with the growth of individuals and the development of the immune system and defensive pathways (Evans, et al., 2006). However, the tradeoff between successful infection and survival exists (Hughes \& Rasgon, 2014) and needs to be addressed when 
considering future Wolbachia infection avenues utlizing microinjection. Compounding effects influencing egg hatch rate (including intrinsically low hatch rates) including: ambient stress, changes in temperature and humidity during injection, and mechanical trauma increase of egg turgidity and increase the likelihood of cytoplasm spill, all create harsh conditions for the embryo to overcome in its development. Therefore, additional effort needs to be placed on older life stages where mortality is reduced. Alternatively, isolating the bacteria through a more specific protocol and suspending in a differently media may be beneficial.

A potential limitiation in this study was the abiguity of liquid injected into the recipient individual. The Tritech digital microinjector (Tritech, USA) was always set on the minimum settings (1psi for 0.1 seconds) but the quantity of liquid expelled from the needle changed visibly between individuals and when expelled onto an empty slide. Therefore, it is difficult to say that the differing quantities of isolate injected did not have an influence onsurvival, particularly between Wolbachia and control treatments in eggs. It was clear however, that older individuals responded better to larger quantities, likely due to it being a lesser percentage of overall body volume. Previous successful honey bee microinjection experiments use very fine needles $(\sim 5 \mu \mathrm{m})$ but utilize either innate oils (Milne, et al., 1988) or very small particles, such as interference RNAs (RNAi) (Dearden, et al., 2009) and so did not experience clogging of the needle point. However, in this study, due to clogging difficulties, perhaps to large quantities of suspended bacteria, a minimum needle point width of $10 \mu \mathrm{m}$ was required, potentially leading to further trauma of the eggs and young larvae.

\section{Wolbachia strain}

Phylogenetic analysis showed that the strain reported by Pattabhiramaiah (2011) was very closely related to the $w \mathrm{Mel}$ strain native to some Drosophila melanogasteri populations. It was found that the $D$. melanogaster colony at Victoria University of Wellington was naturally infected with $w$ Mel. It is possible that the $w \mathrm{Mel}$ strain, while naturally infecting D. melanogaster, is not compatibile as an artificial infectant in A. mellifera. Alternative strains from closely related A. m. capensis or A. m. scutellata (wCap-B1 and $w$ Cap-B2) may be more appropriate. However, importation of South African bees into New Zealand is unlawful, posing considerable biosecurity risk (Biosecurtiy Act (2015)) and is therefore not a logistical possibility here. This may be a promising avenue for research in other countries, however.

It has been shown that closely related Wolbachia strains can infect evolutionarily distant host species, while the same host species can carry diverse Wolbachia strains (Werren, et al., 1995, 2008). This investigation found a clear example of this, seen in the strains originating from closely-related honey bee subspecies A. m. capensis and A. m. scutellata (wCap-B1 and $w$ Cap-B2) that were placed into distant 
supergroups $B$ and $O$ respectively within our phylogenetic analysis. The $w$ Cap-B2 formed a monophyly with Lepidopteran Bremisia tabaci with a divergence less than $2.5 \%$ over all genes, distant from $w$ Cap-B1.

The phylogenetic analysis in this study (Fig. 2) highlights that naturally occurring strains from closely related hosts do not have predictable phenotypic interaction with their given hosts and that it cannot be assumed that closely related strains will behave in the same way. The lack of congruence between strain relatedness makes the choice of candidate strain for transinfection less simple than picking the strain from a species closely related to the recipient host. In this case, while it may be beneficial to examine strains found naturally in Hymenoptera, there is no way to predict their effects. The $w \mathrm{Mel}$ strain native to $D$. melanogaster has been well-studied (e.g. Harcombe \& Hoffman, 2004; Thomas, et al., 2011; Walker, et al., 2011; Ross, et al., 2017) and while it provides pathogen blocking and increased lifespan in some hosts, its cytoplasmic incompatibility-inducing properties need to be taken into consideration when using Wolbachia as a means of conservation (Blagrove, et al., 2012). Therefore, careful quarantine protocols should be followed in all future studies due to the variety of unknown (and potentially unpredictable effects) of Wolbachia.

That being said, there is evidence of successful transinfection between orders of insects in a number of successful inter-order transinfections, which generally experiment with cytoplasmic-incompatibility inducing strains. These include transinfection from Muscidifurax uniraptor (Hymenoptera: Pteromalidae) to Drosophila simulans (Meer \& Stouthamer, 1999), transinfection of a known CI strain from the parasitic wasp Scleroderma guani $(w \mathrm{SguBJ})$ to the whitefly Bemisia tabaci (Zhong \& Li, 2014); and from lepidopteran butterfly (Eurema mandarina) to the hymenopteran saw fly (Athalia rosae) (Kageyama, et al., 2017). All of these studies and the majority of successful transinfection studies have utlized host or recipient cell lines inoculated with Wolbachia in order to improve infection rates. In this study, I was not able to explore the avenue of Apis mellifera cell lines due to logistical, permitting, and funding issues. In future, however, this approach may be required in order to have successful transinfection as well as examine in-vitro effects of Wolbachia in honey bee cells.

\section{Artificial insemination}

This study is the first to attempt the novel approach of artificial insemination as a transinfection methodolgy using semen containing Wolbachia. The methodology was unsuccessful in this instance, but remains a unique avenue. Reasons for failure may include insufficient Wolbachia concentration in semen solution, or misrepresentative sampling of Wolbachia in viability testing resulting in unexpected quantities of dead bacteria. Queen ovaries were positive for Wolbachia 24 hours post-insemination, implying that the bacteria 
was effective in reaching the ovaries, and the migration implies that it was viable. However, it is possible that the queen immune system may have played a role in it not being present 6-weeks post-insemination.

As Wolbachia's effect on A. mellifera is unknown, queens inseminated with Wolbachia were kept under strict containment protocols, inside an enclosed bee room with no outdoor access as was required to reduce biosecurity risk. High densities of bees belonging to different hives in close proximity over a six week duration may have caused increased stress for both queens, workers and drones. Increased stress has been shown to increase the likelihood of bacterial infections in insects (Boucias \& Pendland, 2012) by altering the internal mirohabitat or resulting in nutrient deficiency and thereby reducing immunocompetancy. However intra-ceullar infections rely on the survival of their hosts and therefore this stress may have been detrimental to invasion. The positive PCR presence of Wolbachia in inseminated queens 24 hour post-insemination highlights that insemination is an efficient pathway by which to place Wolbachia in the oviaries.

\section{Deformed wing virus assay}

Due to the injected inseminated progeny not being infected with Wolbachia, the Deformed wing virus assay was not informative. However, the development of methodologies for this assay will be beneficial for future experiments. As Deformed wing virus is made up of multiple closely-related viral variants (de Miranda \& Genersch, 2012) with several master variants (DWV-A and DWV-B), it will be important to select an appropriate strain for further infection studies. It has been found that both DWV-A and DWV-B have been detected in honey bees in the absence of Varroa (Yue \& Genersch, 2005; Zioni, et al., 2011; Martin, et al., 2012). However, DWV-A is the only strain that has been detected in honey bee colonies which, in the presence of Varroa mites, leads to colony death (Di Prisco, et al., 2011; Martin, et al., 2012; Mordecai, et al., 2015). There have been no reported instances of DWV-B being directly linked to colony death.

\section{Immune response}

The signficant upregulation of apideaecin in first instar larvae microinjected with Wolbachia, but not in those injected with heat-treated Wolbachia, suggests live Wolbachia elicits an immune response in immature honey bee larvae. High initial Wolbachia expression was expected due to prior microinjection. Early initial apidaecin expression in this assay is supported by Casteels et al. (1993), who found that apidaecin expression can be detected early post infection in honey bees inoculated with $E$. coli with highest levels being reached approximately 12 hours post-incoculation and remaining up-regulated and steady for the next 24 hours. In the assay presented here, the highest apidaecin levels were reached at 24 hours post injection but had an initial, potentially latent, expression at 0 hours relative to control treatments. This initial expression of apidaecin is consistent in all trials, and may be explained by stress caused during the lifting 
process from the comb to microscope plate and exacerbated by a drop in ambient temperature, from $34.5^{\circ} \mathrm{C}$ in the hive down to room temperature (approximately $22^{\circ} \mathrm{C}$ ) during the microinjection phase, which is close to the optimum temperature for proline-rich peptide activity (Zufelato, et al., 2004; Danihlik, et al., 2015).

The absence of upregulated abaecin expression confirms that other inherited Gram-positive bacteria, that were not controlled for, such as Spiroplasma, were not responsible for the increase of apidaecin which is reported to effect Gram-positive bacteria at high concentrations (Cisak, et al., 2015; Danihlik, et al., 2015). As causal effect has not been determined, however, it cannot be confirmed that other gram-negative bacteria besides Wolbachia are not influencing expression.

By 48 hours post-injection, Wolbachia expression was comparable to that of control treatments. In microinjection trials, eggs and larvae were euthenized and diagnosed for Wolbachia infection via PCR 72 hours post-microinjection. If trends found in this assay are consistent, they would explain why larvae in the microinjection trials appeared negative via PCR for Wolbachia presence despite direct microinjection of the bacteria. Additionally, false negative reactions with insect material have been documented (Jayaprakash \& Hoy, 2000). Beckmann and Fallon (2012) discovered, after inconsistencies between Wolbachia infection in adult Culex pipiens mosquitoes observed through microscopy and subsequent PCR results, that DNA templates prepared from whole insect bodies contains an inhibitor of the PCR reaction. Decapitation of the mosquitoes prior to DNA extraction restored reliability of PCR reactions. Due to the early developmental stages of the honey bee larvae microinjected, decapitation was not considered in DNA extraction protocols. Therefore, there is evidence to suggest that Wolbachia may have been present in microinjected individuals despite seemingly negative PCR results. Additionally, this would explain why the ovaries from the queen euthenized 24 hours post-artificial insemination reported positive for $w \mathrm{Mel}$ via PCR. Moreover, this increased immune response may provide explanation for why no honey bee eggs injected with Wolbachia hatched but those injected with only PBS did.

Apidaecin, a proline-rich family of peptides, are found in a number of social hymenoptera, including bumblebees (Bombus terrestris), Vespula wasps (V. germanica, V. vulgaris), and the bald-faced hornet (Dolichovespula maculata). Positively charged apidaecins are attracted to the highly negatively charged outer membrane found on Gram-negative bacteria. Unlike conventional antibacterial peptides, apidaecins are not amiphipathic, allowing them to enter into the periplasmic space of their target without forming pores (Casteels, et al., 1994). This enables them to directly target the heat shock protein DnaK and the bacterial chaperonin GroEL, inhibiting their ATPase activity and preventing protein folding, leading to bacterial death. Apidaecin's antibacterial activity is suspected to be influenced by the metabolic activity of target bacteria, exemplified with this activity being reduced 10-fold when bacteria is depleted in PBS for 
20 hours prior to apidaecin exposure. Therefore, this heightened expression may confirm that Wolbachia cells microinjected were metabolically active.

Few investigations into Wolbachia's effect on the immune expression of antimicrobial markers have been conducted, but the results of these studies have been shown to vary dependent on Wolbachia strain and host. In dipterans (Drosophila simulans and Aedes albopictus there was no evidence induced or suppressed peptide expression (Bourtzis et al., 2000). However, this study examined the influence of Wolbachia on infected and cured populations of species naturally infected by Wolbachia. Therefore, this lack of immune response is not surprising as the presence of Wolbachia as a secondary symbiont in these species is long withstanding (Poinsot \& Merçot, 1997; Dobson, et al., 2002). Conversely, the virulent $w$ Melpop strain, which has pathogenic effects in Drosophila simulans has been shown to upregulate the expression of the AMPs Cecropin C and lysozyme (McGraw \& O'Neill, 2004). This result is thought to be due to the strain's uncontrolled replication lysing host cells, signalling receptors and initiating host immune response (McGraw \& O’Neill, 2004; Siozios, et al., 2008). A recent study by Pan, et al. (2018) found that when Aedes egypti are artificially infected with $w \mathrm{AlbB}$, it boosts basal immune response and upregulates the IMD and Toll pathways, and induces peptidoglycan recognition proteins expression. When these pathways are silenced there is significant reduction in $w \mathrm{AlbB}$ titre. Therefore, the upregulation of immune response in A. mellifera is not unexpected and does not rule out potential successful Wolbachia infection in the future. 


\section{CHAPTER 3}

\section{Conclusions and future recommendations}

\section{CONCLUSIONS}

This thesis investigated the feasibility of transinfecting a strain of the endosymbiont Wolbachia, sourced from Drosophilia melanogaster, into the Western honey bee Apis mellifera. I conducted a thorough investigation on the phylogeny and relationships between all described Wolbachia supergroups in order to determine an appropriate Wolbachia strain for transinfection based from a previously described natural infection in A. mellifera. This phylogeny encompassed 59 representatives from all Wolbachia supergroups and Wolbachia-host phenotypes were reviewed and correlated with each supergroup. It was found that the natural infection found in honey bees by Pattabhiramaiah et al. (2011) was phylogenetically clustered with the Drosophila melanogaster native strain $w \mathrm{Mel}$. Additionally, Wolbachia from supergroup $A$ was discovered in Ancistrocerus gazella, the European tube wasp, where it has never been found before. Using Wolbachia isolated from D. melanogaster, I attempted the first ever transinfection in A. mellifera using established transinfection protocols. I extensively trialed existing microinjection protocols in over 1200 individual bees over various life stages, ranging from freshly laid eggs to red-eyed pupae. I developed and attempted a novel methodology of Wolbachia transinfection through the artificial insemination of queen bees with Wolbachia-inoculated drone semen. When these transinfection attempts proved unsuccessful, I investigated the expression of several antimicrobial peptides in response to Wolbachia microinjection and determined a significant upregulation of the peptide apidaecin in response to the presence of this foreign endosymbiont.

\section{FUTURE RECOMMENDATIONS}

Transinfection of Wolbachia has proven successful via microinjection in a number of dipteran species, including in the Drisiophilidae, Tephritidae and Culicidae families (reviewed by Hughes \& Rasgon, 2014). Included in these microinjection experiments are those into arboviral reservoir Aedes egypti by Walker et al. (2011) to reduce its ability to vector viral dengue fever (DENV). This successful project highlighted Wolbachia's ability to manipulate the ability of its host's immune system to prevent the vectoring of a number of different human mosquito-vectored viruses. This movement has since progressed from solely DENV treatment, to a broad spectrum attempt to reduce the spread of other mosquito-vector diseases, 
including Zika virus, Chikungunya (CHIKV), West Nile and bacterial malaria (Hughes, et al., 2011; Hussain, et al., 2012; Aliota et al., 2016; Dutra, et al., 2016). On the other hand, Wolbachia's negative effects on its hosts have also encouraged research utilizing Wolbachia as a natural form of biocontrol in pest species such as crop pests (Zabalou, et al., 2004, reviewed in Bourtzis, 2008; Blackwood, et al., 2018). With up to $65 \%$ of arthropods estimated to be infected with Wolbachia (Zug \& Hammerstein, 2012; LePage $\&$ Bordenstein, 2013), the literature is flooded with publications on the diagnosis of new species infected with the endosymbiont (Krstić, et al., 2018). Wolbachia has sparked new curiosity regarding the interaction of endosymbionts with their hosts and the immune response (or lack thereof) in response to reproductive manipulations (Siozios, et al., 2008; Herbert \& McGraw, 2018). In fact, Wolbachia has become a research hotspot, with over 3500 peer reviewed publications on the topic being produced since 2000 (Web of Science database, 2018). Despite this research boom, there is no evidence that Wolbachia transinfection has been reported in insects where it does not naturally occur in order to support their conservation.

\section{Cell culturing of Wolbachia}

The transinfection of Wolbachia into the honey bee is a novel concept. However, while current transinfection strategies work effectively between diptertan families, it is possible that they require tweaking to enable successful infection in Apis mellifera. This thesis utilized cytoplasm transfer from eggs of the natural host Drosophila melanogaster to A. mellifera recipient. While this methodology has proven successful previously, particularly in earlier studies (Boyle, et al., 1993; Poinsot \& Mercot, 2001; McGraw, et al., 2001; Xi \& Dobson, 2005), more modern studies, including almost all successful inter-order transinfections, passage Wolbachia in cell culture prior to microinjection (Dobson, et al., 2002; Walker, et al., 2011; Zhong \& Li, 2014; Kageyama, et al., 2017). The shell-vial technique has proven very successful in infecting existing cell lines with Wolbachia (Dobson, et al., 2002). Understandably, the recipient appears more likely to accept a microinjection of self-cells than of non-self (Royet, 2004). The significant relative upregulation of apidaecin found in this study to the presence of Wolbachia, but not to dead, heat-treated Wolbachia, highlights that live foreign bacteria elicits an immune response in first instar larvae. The immature honey bee immune system is substantial (Evans, 2006; Gätschenberger, et al., 2013) and it has been shown that insect eggs contain immune elicitors. The tobacco hornworm (Maduca sexta), for instance, shows upregulation of the embryonic immune system when eggs are challenged (Adbel-latief \& Hiker, 2008) and it has been proven that honey bee eggs inherit vitellogenin, a protein yolk precursor and pathogen recognition receptor (Zhang, et al., 2011; Salmela, et al., 2015). Therefore, it is possible that, when injected into honey bee eggs, Wolbachia elicits an immune response in the eggs, similar to that in larvae, that eventually results in the mortality of the bacteria, egg, or both. 
It appears that Wolbachia retained in cell lines evolves substantially during passaging (McMeniman, et al., 2008; Woolfit, et al., 2013). When a strain of Wolbachia native to D. melanogaster was passaged in an Aedes albopictus cell line for $\sim 300$ serial passages and then reintroduced to the original host, it showed significant loss of infectivity, grew to reduced densities and had limited phenotypic influences compared to the unpassaged strain. (McMeniman, et al., 2008). Further research on genomic evolution of these passaged strains found rapid bursts of genomic changes during cell line passaging, but these alterations do not occur if transinfected prior to culturing (Woolfit, et al., 2013). It appears that very small changes in the genome between strains has significant differences in phenotypic outcome. For instance, genomic differences between variants of the pathogenic $w$ MelPop and the closely related nonpathogenic $w$ MelCS are minor. No SNPs, indels, transposable or mobile elements have been identified between strains, only very minor substitution changes (Woolfit, et al., 2013). Therefore, the adaptation of Wolbachia to the host cell system is important to both the acceptance of the bacteria by the host but also to the evolution of the symbiont. However, the feat of culturing Wolbachia in host cell lines for the purpose of adaption is very time intensive. To develop Wolbachia into a biocontrol agent (Walker, et al., 2011), the wMel derivative wMelPop was cultured in A. egypti culture for 3.5 years to allow adaptation to the mosquito intracellular environment to produce $w$ MelPop-CLA (Woolfit, et al., 2013). Therefore, cell line development to this degree would not have been plausible in the time frame of this thesis. However, it is highly recommended to inoculate Apis mellifera cells with Wolbachia prior to microinjection in further research efforts to reduce immune response and lower the chance of rejection of Wolbachia in the recipient.

\section{Apis mellifera life stage}

Wolbachia's ability to migrate from somatic tissues to the ovaries and germ line is well established (Grenier, et al., 1998; Kang, et al., 2003; Frydman, et al., 2006). To do this, the bacteria must cross a number of tissues, a process that takes up to 15 days in mosquitoes (Frydman, et al., 2006). The total larval stage for the honey bee, from ovideposition to pupation, takes 21 days (Rembold, et al., 1980; Winston, 1991) and they are very sensitive during this time. Collins (2002) found that any handling of eggs reduced their hatch rate by up to $50 \%$. Deviations in relative humidity can cause the shriveling of eggs and significant reduction in the hatching of healthy larvae, with a drop from $90 \%$ to $80 \% \mathrm{RH}$, lowering healthy larvae production by $30 \%$. In-situ, larval rearing conditions are complex. Worker bee larvae is regulated at significantly higher temperatures than that of drone brood irrespective of location of the brood frame within the hive (Levin \& Collison, 1989). Worker eggs and young larvae are kept at higher relative humidity than that of older worker larvae pupae (Li, et al., 2016), with both kept at a higher precision than immature drones, varying, on average, less than $1.5^{\circ} \mathrm{C}$. However, pupae are much more loosely regulated within the hive, and are able to 
withstand greater fluctuations in both temperature and humidity without significant influence on survival (Li, et al., 2016). The honey bee germline is developed by 48 hours post oviposition (Dearden, 2006) and so direct microinjection is required prior to this time, when the egg is at its most sensitive (Collins, 2004). Therefore, microinjection either needs to occur before 48 hours of age, or at a life-stage where the individual will cope with the Wolbachia's 15-day migration. Given the tradeoff between survival and infection, combined with results found in this study, it would be advisable to shift experimental efforts towards older life stages where survival is higher.

\section{Artificial insemination as a novel transinfection route}

The insemination of the $\mathrm{F}_{0}$ as a means of Wolbachia transinfection has never before been attempted. This methodology could cut experimental time substantially if successful, as a single queen with Wolbachiainfected ovaries could produce up to 2000 eggs per day (Winston, 1987), with a single queen typically living 2-3 years. Positive infection of Wolbachia in queen ovaries 24 hours post-artificial inseminations found in this study, suggest that transport of Wolbachia artificially through the sperm duct is a viable and novel approach to transport Wolabchia to the ovaries. The disappearance of Wolbachia in sampling after this time frame is suggestive of an immune response, backed up by the upregulation of apidaecin found in larvae. Insects have been shown to have trans-generational immune priming and cumulative evidence shows that maternal exposure to dead or alive bacterial cells leads to increased immunocompetence in offspring (Moret, 2006; Roth, et al., 2009; Hernandez-Martinez, et al., 2010; Moreau, et al., 2012). Hence, immune upregulation in queens bees to Wolbachia (leading to the potential rejection of Wolbachia) may influence her offspring to resist bacterial infection also. Therefore, bees from multiple hives acting as potential Wolbachia recipients will need to be independent from previously Wolbachia-inseminated queens in future attempts of this methodology.

\section{Honey bee immune response to Wolbachia}

The immune response in insects to Wolbachia is varied and complex. In hosts where Wolbachia is naturally occurrent, such as Drosophila sp., it has been shown that several genes related with both humeral and cellular host immune response are upregulated in the presence of $w \mathrm{Mel}$, including for two AMPs (Zheng, et al., 2011). Additionally, when in Drosophila S2 culture, Wolbachia upregulates several genes involved in the Imd, Toll and JNK (Lemaitre \& Hoffman, 2007), including the NF- $\kappa B$ transcription factors Relish, Dorsal and dJun (Bohmann, et al., 1994; Hetru \& Hoffman, 2009). However, an Anopheles gambiae culture 
infected with $w \mathrm{Ri}$ and $w \mathrm{AlbB}$ showed downregulation of over $75 \%$ of the immune-related genes involved in pathogen recognition that encode for effector molecules including those associated with the production of AMPs (Hughes, et al., 2011). Meanwhile, the infection of $w$ Str in the small brown planthopper (Laodelphax striatellus) did not influence the expression of any immune genes whatsoever (Nakamura, et al., 2011). Kremer, et al., (2012) showed that in the parasitoid wasp Asobara tabida, the regulation of immune genes by native Wolbachia strains were tissue and sex-specific. In male wasps harbouring Wolbachia, numerous upstream genes associated with immune Imd, Toll, JNK and RNAi pathways were significantly upregulated while downstream genes coding for AMPs were downregulated. Immune genes were transcribed at a lower rate in the ovaries of female wasps. Therefore, it is important to further investigate the immune response of honey bees to Wolbachia at a finer scale. It is likely that if one AMP is upregulated, then Wolbachia may be influencing transcription elsewhere. It is recommended to assess this immune response in honey bees at varying life stages, including in queens, to determine Wolbachia's influence.

It may also be beneficial to attempt to quell the honey bee immune system temporarily to increase the likelihood of Wolbachia infection. Modern methodologies such as RNA interference using double stranded RNAs (dsRNAs) have had success in the control of a number of pest insects (Baum, et al., 2007; Tomoyasu, et al., 2008). This process utilizes the enzymes which cleave long artificially supplied dsRNA of a target gene, into short interfering RNA (siRNAs) fragments which bind to the naturally occurring version of the sequence, hindering its translation (Huvenne \& Smagghe, 2010). Utilizing this system, it may be possible to inhibit the transcription factors such as Relish that regulate the expression of target AMPs (Schluns \& Crozier, 2007), lower immune response and thus increase the likelihood of Wolbachia infection.

\section{Wolbachia strain in honey bees}

Wolbachia's effects on its hosts are impossible to predict and therefore the selection of a "suitable" strain is difficult. A lack of suitable outgroup has prevented a satisfactory resolution of its phylogeny (Lo, et al., 2007), and evidence of horizontal transmission within arthropods, as well as between nematodes and arthropods, further confuses its origins and the evolution of phenotypic-effects (Bandi, et al., 1998; Glowska, et al., 2015). The lack of congruency between hosts and symbiont phylogenies (O'Niell, et al., 1992; Stouthamer, et al., 1999), together with closely related Wolbachia present in taxonomically distant hosts as seen in Supergroup F (Baldo, et al., 2006b; Raychoudhury, et al., 2009), and disparate Wolbachia strains in the same host all imply that lateral transmission is frequent and ongoing in Wolbachia (Vavre, et al., 1999; Duron \& Hurst., 2013). However, based on current phylogenies, strains of Wolbachia that have 
been shown to have facultative effects on arthropod hosts are limited to Supergroup $A$, with outliers in plant parasites where Wolbachia may supplement diet (Antonis, et al., 2012). Therefore, examining lab-rearable hymenopterans with natural Wolbachia infection in Supergroup A, such as Nasonia vitripennis may be advantageous. There is no guarantee that effects found in one host will be transferable to another (Warren, et al., 2008). Given that the large majority of Wolbachia's described effects on insects involve reproductive manipulations, strict quarantine protocols should be undertaken.

\section{Future work}

Considering the large quantity of Wolbachia-centred research that continues to be published annually, it is surprising that there is no evidence of Wolbachia transinfection in honey bees, especially given their consistent media attention and the known consequences of global honey bee colony loss. In fact, it seems unlikely that studies similar to the one presented in this thesis have not been conducted previously. The current paradigm within the industry to not publish negative results (Matosin, et al., 2014) makes it difficult to know if similar trials have been conducted with results consistent (or perhaps contrasting) with what is presented in this thesis. Given that science is, by nature, a collaborative discipline, it seems a great waste if multiple parties are following the same routes of investigation and end up with similar negative results that go unpublished when said research could be otherwise informative.

There is nothing to imply that transinfection of Wolbachia into the Western honey bee is not possible. Given the global importance of honey bees to the world's food security, the influence of RNA viruses on their health and past success of Wolbachia as an artificial symbiont, future transinfection attempts in honey bees would not go wasted. 


\section{REFERENCES}

Abdel-Latief, M., \& Hilker, M. (2008). Innate immunity: eggs of Manduca sexta are able to respond to parasitism by Trichogramma evanescens. Insect Biochemistry and Molecular Biology, 38(2), 136145 .

Ahmed, M. Z., Ren, S.-x., Xue, X., Li, X.-X., Jin, G.-h., \& Qiu, B.-L. (2010). Prevalence of endosymbionts in Bemisia tabaci populations and their in vivo sensitivity to antibiotics. Current Microbiology, 61(4), 322-328.

Aizen, M. A., \& Harder, L. D. (2009). The global stock of domesticated honey bees is growing slower than agricultural demand for pollination. Current Biology, 19(11), 915-918.

Al-Ghamdi, A. A., Abou-Shaara, H. F., \& Mohamed, A. A. (2014). Hatching rates and some characteristics of Yemeni and Carniolan honey bee eggs. Journal of Entomology and Zoology Studies, 2(1), 6-10.

Aliota, M. T., Peinado, S. A., Velez, I. D., \& Osorio, J. E. (2016). The wMel strain of Wolbachia reduces transmission of Zika virus by Aedes aegypti. Scientific Reports, 6, srp28792.

Almerão, M. P., Fagundes, N. J. R., Araújo, P. B. d., Verne, S., Grandjean, F., Bouchon, D., \& Araújo, A. M. (2012). First record of Wolbachia in South American terrestrial isopods: prevalence and diversity in two species of Balloniscus (Crustacea, Oniscidea). Genetics and Molecular Biology, 35(4), 980-989.

Andrews, E. S., Crain, P. R., Fu, Y., Howe, D. K., \& Dobson, S. L. (2012). Reactive oxygen species production and Brugia pahangi survivorship in Aedes polynesiensis with artificial Wolbachia infection types. PLoS Pathogens, 8(12), e1003075.

Ashburner, M. (1989). Drosophila. A laboratory handbook: Cold Spring Harbor Laboratory Press.

Augustinos, A. A., Santos-Garcia, D., Dionyssopoulou, E., Moreira, M., Papapanagiotou, A., Scarvelakis, M., . . Borges, P. A. (2011). Detection and characterization of Wolbachia infections in natural populations of aphids: is the hidden diversity fully unraveled? PLoS One, 6(12), e28695.

Baldo, L., \& Werren, J. H. (2007). Revisiting Wolbachia supergroup typing based on WSP: spurious lineages and discordance with MLST. Current Microbiology, 55(1), 81-87.

Bandi, C., Anderson, T. J., Genchi, C., \& Blaxter, M. L. (1998). Phylogeny of Wolbachia in filarial nematodes. Proceedings of the Royal Society of London B: Biological Sciences, 265(1413), 24072413. 
Bandi, C., McCall, J. W., Genchi, C., Corona, S., Venco, L., \& Sacchi, L. (1999). Effects of tetracycline on the filarial worms Brugia pahangi and Dirofilaria immitis and their bacterial endosymbionts Wolbachiafn1. International Journal for Parasitology, 29(2), 357-364.

Baudry, E., Bartos, J., Emerson, K., Whitworth, T., \& Werren, J. (2003). Wolbachia and genetic variability in the birdnest blowfly Protocalliphora sialia. Molecular Ecology, 12(7), 1843-1854.

Baum, J. A., Bogaert, T., Clinton, W., Heck, G. R., Feldmann, P., Ilagan, O., . . Pleau, M. (2007). Control of coleopteran insect pests through RNA interference. Nature Biotechnology, 25(11), 1322.

Beckmann, J., \& Fallon, A. (2014). Decapitation improves detection of Wolbachia pipientis (Rickettsiales: Anaplasmataceae) in Culex pipiens (Diptera: Culicidae) mosquitoes by the polymerase chain reaction. Journal of Medical Entomology, 49(5), 1103-1108.

Benjamini, Y., \& Hochberg, Y. (1995). Controlling the false discovery rate: a practical and powerful approach to multiple testing. Journal of the Royal Statistical Society. Series B (Methodological), 289-300.

Berthoud, H., Imdorf, A., Haueter, M., Radloff, S., \& Neumann, P. (2010). Virus infections and winter losses of honey bee colonies (Apis mellifera). Journal of Apicultural Research, 49(1), 60-65.

Beutler, B. (2004). Inferences, questions and possibilities in Toll-like receptor signalling. Nature, 430(6996), 257.

Beutler, B. (2004). Innate immunity: an overview. Molecular Immunology, 40(12), 845-859.

Bian, G., Joshi, D., Dong, Y., Lu, P., Zhou, G., Pan, X., . . Xi, Z. (2013). Wolbachia invades Anopheles stephensi populations and induces refractoriness to Plasmodium infection. Science, 340(6133), 748-751.

Bian, G., Xu, Y., Lu, P., Xie, Y., \& Xi, Z. (2010). The endosymbiotic bacterium Wolbachia induces resistance to dengue virus in Aedes aegypti. PLoS Pathogens, 6(4), e1000833.

Bian, G., Zhou, G., Lu, P., \& Xi, Z. (2013). Replacing a native Wolbachia with a novel strain results in an increase in endosymbiont load and resistance to dengue virus in a mosquito vector. PLoS Neglected Tropical Diseases, 7(6), e2250.

Bing, X. L., Xia, W. Q., Gui, J. D., Yan, G. H., Wang, X. W., \& Liu, S. S. (2014). Diversity and evolution of the Wolbachia endosymbionts of Bemisia (Hemiptera: Aleyrodidae) whiteflies. Ecology and Evolution, 4(13), 2714-2737.

Blackwood, J. C., Vargas, R., \& Fauvergue, X. (2018). A cascade of destabilizations: combining Wolbachia and Allee effects to eradicate insect pests. Journal of Animal Ecology, 87(1), 59-72. 
Blagrove, M. S., Arias-Goeta, C., Failloux, A.-B., \& Sinkins, S. P. (2012). Wolbachia strain wMel induces cytoplasmic incompatibility and blocks dengue transmission in Aedes albopictus. Proceedings of the National Academy of Sciences, 109(1), 255-260.

Bohmann, D., Ellis, M. C., Staszewski, L. M., \& Mlodzik, M. (1994). Drosophila Jun mediates Rasdependent photoreceptor determination. Cell, 78(6), 973-986.

Boucias, D. G., \& Pendland, J. C. (2012). Principles of Insect Pathology: Springer Science \& Business Media.

Bourtzis, K. (2008). Transgenesis and the management of vector-borne disease. Transgenesis and the Management of Vector-Borne Diseases., 627, 104-113.

Bourtzis, K., Dobson, S. L., Xi, Z., Rasgon, J. L., Calvitti, M., Moreira, L. A., . . Hughes, G. L. (2014). Harnessing mosquito-Wolbachia symbiosis for vector and disease control. Acta tropica, 132, S150-S163.

Bourtzis, K., Pettigrew, M., \& O’Neill, S. (2000). Wolbachia neither induces nor suppresses transcripts encoding antimicrobial peptides. Insect Molecular Biology, 9(6), 635-639.

Bowen-Walker, P. L., \& Gunn, A. (2001). The effect of the ectoparasitic mite, Varroa destructor on adult worker honeybee (Apis mellifera) emergence weights, water, protein, carbohydrate, and lipid levels. Entomologia Experimentalis et Applicata, 101(3), 207-217.

Boyle, L., O'Neill, S. L., Robertson, H. M., \& Karr, T. L. (1993). Interspecific and intraspecific horizontal transfer of Wolbachia in Drosophila. Science, 260(5115), 1796-1799.

Brookmeyer, R., \& Crowley, J. (1982). A confidence interval for the median survival time. Biometrics, 29-41.

Brutscher, L. M., \& Flenniken, M. L. (2015). RNAi and antiviral defense in the honey bee. Journal of Immunology Research, 2015.

Bulet, P., \& Stocklin, R. (2005). Insect antimicrobial peptides: structures, properties and gene regulation. Protein And Peptide Letters, 12(1), 3-11.

Cameron, R. C., Duncan, E. J., \& Dearden, P. K. (2013). Stable reference genes for the measurement of transcript abundance during larval caste development in the honeybee. Apidologie, 44(4), 357366.

Cariveau, D. P., Powell, J. E., Koch, H., Winfree, R., \& Moran, N. A. (2014). Variation in gut microbial communities and its association with pathogen infection in wild bumble bees (Bombus). The ISME Journal, 8(12), 2369.

Casiraghi, M., Bordenstein, S., Baldo, L., Lo, N., Beninati, T., Wernegreen, J., . . Bandi, C. (2005). Phylogeny of Wolbachia pipientis based on gltA, groEL and ftsZ gene sequences: clustering of 
arthropod and nematode symbionts in the F supergroup, and evidence for further diversity in the Wolbachia tree. Microbiology, 151(12), 4015-4022.

Casteels, P., Ampe, C., Jacobs, F., \& Tempst, P. (1993). Functional and chemical characterization of Hymenoptaecin, an antibacterial polypeptide that is infection-inducible in the honeybee (Apis mellifera). Journal of Biological Chemistry, 268(10), 7044-7054.

Casteels, P., Ampe, C., Jacobs, F., Vaeck, M., \& Tempst, P. (1989). Apidaecins: antibacterial peptides from honeybees. The EMBO journal, 8(8), 2387-2391.

Casteels, P., Romagnolo, J., Castle, M., Casteels-Josson, K., Erdjument-Bromage, H., \& Tempst, P. (1994). Biodiversity of apidaecin-type peptide antibiotics. Prospects of manipulating the antibacterial spectrum and combating acquired resistance. Journal of Biological Chemistry, 269(42), 26107-26115.

Casteels-Josson, K., Capaci, T., Casteels, P., \& Tempst, P. (1993). Apidaecin multipeptide precursor structure: a putative mechanism for amplification of the insect antibacterial response. The EMBO Journal, 12(4), 1569-1578.

Chagas-Moutinho, V. A., Silva, R., de Souza, W., \& Motta, M. C. M. (2015). Identification and ultrastructural characterization of the Wolbachia symbiont in Litomosoides chagasfilhoi. Parasites \& Vectors, 8(1), 74.

Chan, Q. W., Melathopoulos, A. P., Pernal, S. F., \& Foster, L. J. (2009). The innate immune and systemic response in honey bees to a bacterial pathogen, Paenibacillus larvae. BMC Genomics, 10(1), 387.

Chrostek, E., Marialva, M. S., Esteves, S. S., Weinert, L. A., Martinez, J., Jiggins, F. M., \& Teixeira, L. (2013). Wolbachia variants induce differential protection to viruses in Drosophila melanogaster: a phenotypic and phylogenomic analysis. PLoS Genetics, 9(12), e1003896.

Cisak, E., Wójcik-Fatla, A., Zając, V., Sawczyn, A., Sroka, J., \& Dutkiewicz, J. (2015). Spiroplasma-an emerging arthropod-borne pathogen? Annals of Agricultural and Environmental Medicine, 22(4), 589-593.

Cobey, S. W. (2007). Comparison studies of instrumentally inseminated and naturally mated honey bee queens and factors affecting their performance. Apidologie, 38(4), 390-410.

Collins, A. M. (2002). Collection of honey bee eggs for cryopreservation. Journal of Apicultural Research, 41(3-4), 89-95.

Collins, A. M. (2004). Variation in time of egg hatch by the honey bee, Apis mellifera (Hymenoptera: Apidae). Annals of the Entomological Society of America, 97(1), 140-146.

Collins, A. M., \& Mazur, P. (2006). Chill sensitivity of honey bee, Apis mellifera, embryos. Cryobiology, $53(1), 22-27$. 
Cook, J. M., \& Butcher, R. D. (1999). The transmission and effects of Wolbachia bacteria in parasitoids. Researches on Population Ecology, 41(1), 15-28.

Cornman, R. S., Tarpy, D. R., Chen, Y., Jeffreys, L., Lopez, D., Pettis, J. S., \& Evans, J. D. (2012). Pathogen webs in collapsing honey bee colonies. PLoS one, 7(8), e43562.

Cox-Foster, D. L., Conlan, S., Holmes, E. C., Palacios, G., Evans, J. D., Moran, N. A., . . Geiser, D. M. (2007). A metagenomic survey of microbes in honey bee colony collapse disorder. Science, $318(5848), 283-287$.

Crailsheim, K., Brodschneider, R., \& Neumann, P. (2009). The COLOSS puzzle: filling in the gaps. Paper presented at the Proceedings of the 4th COLOSS Conference.

Cryan, J. F., \& Dinan, T. G. (2012). Mind-altering microorganisms: the impact of the gut microbiota on brain and behaviour. Nature Reviews Neuroscience, 13(10), 701.

Czarnetzki, A. B., \& Tebbe, C. C. (2004). Detection and phylogenetic analysis of Wolbachia in Collembola. Environmental Microbiology, 6(1), 35-44.

Danihlík, J., Aronstein, K., \& Petřivalský, M. (2015). Antimicrobial peptides: a key component of honey bee innate immunity: Physiology, biochemistry, and chemical ecology. Journal of Apicultural Research, 54(2), 123-136.

Danka, R. G., Harris, J. W., \& Villa, J. D. (2011). Expression of Varroa sensitive hygiene (VSH) in commercial VSH honey bees (Hymenoptera: Apidae). Journal of Economic Entomology, 104(3), 745-749.

US Comtrade Database (2015). International honey exports 2015. Sourced from: https://comtrade.un.org/data/

US Comtrade Database (2016). International honey exports 2016. Sourced from: https://comtrade.un.org/data/

de Almeida, F., Moura, A. S., Cardoso, A. F., Winter, C. E., Bijovsky, A. T., \& Suesdek, L. (2011). Effects of Wolbachia on fitness of Culex quinquefasciatus (Diptera; Culicidae). Infection, Genetics and Evolution, 11(8), 2138-2143.

de Almeida, F., Moura, A. S., Cardoso, A. F., Winter, C. E., Bijovsky, A. T., \& Suesdek, L. (2011). Effects of Wolbachia on fitness of Culex quinquefasciatus (Diptera; Culicidae). Infection, Genetics and Evolution, 11(8), 2138-2143.

de Mattos, I. M., Soares, A. E., \& Tarpy, D. R. (2017). Effects of synthetic acaricides on honey bee grooming behavior against the parasitic Varroa destructor mite. Apidologie, 48(4), 483-494.

Dearden, P. K. (2006). Germ cell development in the Honeybee (Apis mellifera); Vasa and Nanos expression. BMC Developmental Biology, 6(1), 6. 
Dearden, P. K., Duncan, E. J., \& Wilson, M. J. (2009). RNA interference (RNAi) in honeybee (Apis mellifera) embryos. Cold Spring Harbor Protocols, 2009(6), pdb. prot5228.

Decourtye, A., Mader, E., \& Desneux, N. (2010). Landscape enhancement of floral resources for honey bees in agro-ecosystems. Apidologie, 41(3), 264-277.

Dedeine, F., Bouletreau, M., \& Vavre, F. (2005). Wolbachia requirement for oogenesis: occurrence within the genus Asobara (Hymenoptera, Braconidae) and evidence for intraspecific variation in A. tabida. Heredity, 95(5), 394.

Di Prisco, G., Annoscia, D., Margiotta, M., Ferrara, R., Varricchio, P., Zanni, V., . . Pennacchio, F. (2016). A mutualistic symbiosis between a parasitic mite and a pathogenic virus undermines honey bee immunity and health. Proceedings of the National Academy of Sciences, 113(12), 3203-3208.

Dinan, T. G., \& Cryan, J. F. (2012). Regulation of the stress response by the gut microbiota: implications for psychoneuroendocrinology. Psychoneuroendocrinology, 37(9), 1369-1378.

Dobson, S. L., Marsland, E. J., \& Rattanadechakul, W. (2002). Mutualistic Wolbachia infection in Aedes albopictus: accelerating cytoplasmic drive. Genetics, 160(3), 1087-1094.

Doudoumis, V., Alam, U., Aksoy, E., Abd-Alla, A. M., Tsiamis, G., Brelsfoard, C., . . Bourtzis, K. (2013). Tsetse-Wolbachia symbiosis: comes of age and has great potential for pest and disease control. Journal of Invertebrate Pathology, 112, S94-S103.

Doudoumis, V., Tsiamis, G., Wamwiri, F., Brelsfoard, C., Alam, U., Aksoy, E., . . Takac, P. (2012). Detection and characterization of Wolbachia infections in laboratory and natural populations of different species of tsetse flies (genus Glossina). BMC Microbiology, 12(1), S3.

Douglas, A. E. (2011). Lessons from studying insect symbioses. Cell Host \& Microbe, 10(4), 359-367.

Drummond, A. J., Ho, S. Y., Phillips, M. J., \& Rambaut, A. (2006). Relaxed phylogenetics and dating with confidence. PLoS biology, 4(5), e88.

Drummond, A. J., Suchard, M. A., Xie, D., \& Rambaut, A. (2012). Bayesian phylogenetics with BEAUti and the BEAST 1.7. Molecular Biology and Evolution, 29(8), 1969-1973.

DuPraw, E. (1965). The organization of honey bee embryonic cells: I. Microtubules and amoeboid activity. Developmental Biology, 12(1), 53-71.

DuPraw, E. (1967). The honeybee embryo. Methods in Developmental Biology, 183-217.

Duron, O., \& Hurst, G. D. (2013). Arthropods and inherited bacteria: from counting the symbionts to understanding how symbionts count. BMC Biology, 11(1), 45.

Edgerly, J. S., Willey, M. S., \& Livdahl, T. P. (1993). The community ecology of Aedes egg hatching: implications for a mosquito invasion. Ecological Entomology, 18(2), 123-128. 
Ellis, A. M., Myers, S. S., \& Ricketts, T. H. (2015). Do pollinators contribute to nutritional health? PLoS one, 10(1), e114805.

Engel, P., Kwong, W. K., McFrederick, Q., Anderson, K. E., Barribeau, S. M., Chandler, J. A., . . . Doublet, V. (2016). The bee microbiome: impact on bee health and model for evolution and ecology of host-microbe interactions. MBio, 7(2), e02164-02115.

Erler, S., \& Moritz, R. F. (2016). Pharmacophagy and pharmacophory: mechanisms of self-medication and disease prevention in the honeybee colony (Apis mellifera). Apidologie, 47(3), 389-411.

Evans, J., Aronstein, K., Chen, Y. P., Hetru, C., Imler, J. L., Jiang, H., . . Hultmark, D. (2006). Immune pathways and defence mechanisms in honey bees Apis mellifera. Insect Molecular Biology, 15(5), 645-656.

Evans, J. D. (2004). Transcriptional immune responses by honey bee larvae during invasion by the bacterial pathogen, Paenibacillus larvae. Journal of Invertebrate Pathology, 85(2), 105-111.

Evans, J. D., \& Schwarz, R. S. (2011). Bees brought to their knees: microbes affecting honey bee health. Trends in Microbiology, 19(12), 614-620.

Evans, J. D., \& Spivak, M. (2010). Socialized medicine: individual and communal disease barriers in honey bees. Journal of Invertebrate Pathology, 103, S62-S72.

Evison, S. E., Roberts, K. E., Laurenson, L., Pietravalle, S., Hui, J., Biesmeijer, J. C., . . Hughes, W. O. (2012). Pervasiveness of parasites in pollinators. PLoS one, 7(1), e30641.

Ezzati, M., Lopez, A. D., Rodgers, A., \& Murray, C. J. (2004). Comparative quantification of health risks: global and regional burden of disease attributable to selected major risk factors: OMS.

Fast, E. M., Toomey, M. E., Panaram, K., Desjardins, D., Kolaczyk, E. D., \& Frydman, H. M. (2011). Wolbachia enhance Drosophila stem cell proliferation and target the germline stem cell niche. Science, 334(6058), 990-992.

Feldhaar, H., \& Gross, R. (2008). Immune reactions of insects on bacterial pathogens and mutualists. Microbes and Infection, 10(9), 1082-1088.

Feldhaar, H., \& Gross, R. (2009). Insects as hosts for mutualistic bacteria. International Journal of Medical Microbiology, 299(1), 1-8.

Ferri, E., Bain, O., Barbuto, M., Martin, C., Lo, N., Uni, S., . . de Souza Lima, S. (2011). New insights into the evolution of Wolbachia infections in filarial nematodes inferred from a large range of screened species. PLoS one, 6(6), e20843.

Forsgren, E. (2010). European foulbrood in honey bees. Journal of Invertebrate Pathology, 103, S5-S9.

Foster, J., Ganatra, M., Kamal, I., Ware, J., Makarova, K., Ivanova, N., . . Posfai, J. (2005). The Wolbachia genome of Brugia malayi: endosymbiont evolution within a human pathogenic nematode. PLoS biology, 3(4), e121. 
Frentiu, F. D., Robinson, J., Young, P. R., McGraw, E. A., \& O'Neill, S. L. (2010). Wolbachia-mediated resistance to dengue virus infection and death at the cellular level. PLoS one, 5(10), e13398.

Fries, I., Huazhen, W., Wei, S., \& Jin, C. S. (1996). Grooming behavior and damaged mites (Varroa jacobsoni) in Apis cerana cerana and Apis mellifera ligustica. Apidologie, 27(1), 3-11.

Frost, C. L., Pollock, S. W., Smith, J. E., \& Hughes, W. O. (2014). Wolbachia in the flesh: symbiont intensities in germ-line and somatic tissues challenge the conventional view of Wolbachia transmission routes. PLoS one, 9(7), e95122.

Fry, A., Palmer, M., \& Rand, D. (2004). Variable fitness effects of Wolbachia infection in Drosophila melanogaster. Heredity, 93(4), 379.

Frydman, H. M., Li, J. M., Robson, D. N., \& Wieschaus, E. (2006). Somatic stem cell niche tropism in Wolbachia. Nature, 441(7092), 509.

Gallai, N., Salles, J.-M., Settele, J., \& Vaissière, B. E. (2009). Economic valuation of the vulnerability of world agriculture confronted with pollinator decline. Ecological economics, 68(3), 810-821.

Gamston, C., \& Rasgon, J. (2007). Maintaining Wolbachia in cell-free medium. Journal of visualized experiments: JoVE (5).

Gandrud, C., \& Gandrud, M. C. (2017). Package 'simPH'. http://CRAN. R-project. org/package= simph

Gätschenberger, H., Azzami, K., Tautz, J., \& Beier, H. (2013). Antibacterial immune competence of honey bees (Apis mellifera) is adapted to different life stages and environmental risks. PLoS one, $8(6)$, e66415.

Gayen, P., Maitra, S., Datta, S., \& Babu, S. P. S. (2010). Evidence for Wolbachia symbiosis in microfilariae of Wuchereria bancrofti from West Bengal, India. Journal of Biosciences, 35(1), 7377.

Gerth, M. (2016). Classification of Wolbachia (Alphaproteobacteria, Rickettsiales): No evidence for a distinct supergroup in cave spiders. bioRxiv, 046169.

Giuliani, A., Pirri, G., \& Nicoletto, S. (2007). Antimicrobial peptides: an overview of a promising class of therapeutics. Open Life Sciences, 2(1), 1-33.

Glowska, E., Dragun-Damian, A., Dabert, M., \& Gerth, M. (2015). New Wolbachia supergroups detected in quill mites (Acari: Syringophilidae). Infection, Genetics and Evolution, 30, 140-146.

Gorham, C. H., Fang, Q., \& Durden, L. A. (2003). Wolbachia endosymbionts in fleas (Siphonaptera). Journal of Parasitology, 89(2), 283-289.

Graham, R. I., Grzywacz, D., Mushobozi, W. L., \& Wilson, K. (2012). Wolbachia in a major African crop pest increases susceptibility to viral disease rather than protects. Ecology letters, 15(9), 993 1000 . 
Graham, R. I., Grzywacz, D., Mushobozi, W. L., \& Wilson, K. (2012). Wolbachia in a major African crop pest increases susceptibility to viral disease rather than protects. Ecology Letters, 15(9), 9931000 .

Grenier, S., Bernard, P., Heddi, A., Lassabliére, F., Jager, C., Louis, C., \& Khatchadourian, C. (1998). Successful horizontal transfer of Wolbachia symbionts between Trichogramma wasps. Proceedings of the Royal Society of London B: Biological Sciences, 265(1404), 1441-1445.

Grenier, S., Gomes, S. M., Pintureau, B., Lassablière, F., \& Bolland, P. (2002). Use of tetracycline in larval diet to study the effect of Wolbachia on host fecundity and clarify taxonomic status of Trichogramma species in cured bisexual lines. Journal of Invertebrate Pathology, 80(1), 13-21.

Grimble, R. (2001). Nutritional modulation of immune function. Proceedings of the Nutrition Society, 60(3), 389-397.

Gruber, M. A., Cooling, M., Baty, J. W., Buckley, K., Friedlander, A., Quinn, O., Russell, J. F. E. J., Lester, P. J. (2017). Single-stranded RNA viruses infecting the invasive Argentine ant, Linepithema humile. Scientific reports, 7(1), 3304.

Haddad, N., Bataeneh, A., Albaba, I., Obeid, D., \& Abdulrahman, S. (2009). Status of colony losses in the Middle East. Paper presented at the Proceedings of the 41st Apimondia Congress, Mointpellier, France.

Haegeman, A., Vanholme, B., Jacob, J., Vandekerckhove, T. T., Claeys, M., Borgonie, G., \& Gheysen, G. (2009). An endosymbiotic bacterium in a plant-parasitic nematode: member of a new Wolbachia supergroup. International Journal for Parasitology, 39(9), 1045-1054.

Hara, S., \& Yamakawa, M. (1995). A novel antibacterial peptide family isolated from the silkworm, Bombyx mori. Biochemical Journal, 310(Pt 2), 651.

Harcombe, W., \& Hoffmann, A. (2004). Wolbachia effects in Drosophila melanogaster: in search of fitness benefits. Journal of Invertebrate Pathology, 87(1), 45-50.

Hasegawa, M., Kishino, H., \& Yano, T.-a. (1985). Dating of the human-ape splitting by a molecular clock of mitochondrial DNA. Journal of Molecular Evolution, 22(2), 160-174.

Hedges, L. M., Brownlie, J. C., O'neill, S. L., \& Johnson, K. N. (2008). Wolbachia and virus protection in insects. Science, 322(5902), 702-702.

Herbert, R. I., \& McGraw, E. A. (2018). The nature of the immune response in novel Wolbachia-host associations. Symbiosis, 74(3), 225-236.

Hernández-Martínez, P., Naseri, B., Navarro-Cerrillo, G., Escriche, B., Ferré, J., \& Herrero, S. (2010). Increase in midgut microbiota load induces an apparent immune priming and increases tolerance to Bacillus thuringiensis. Environmental Microbiology, 12(10), 2730-2737. 
Hetru, C., \& Hoffmann, J. A. (2009). NF-кB in the immune response of Drosophila. Cold Spring Harbor Perspectives in Biology, 1(6), a000232.

Hise, A., Gillette-Ferguson, I., \& Pearlman, E. (2004). The role of endosymbiotic Wolbachia bacteria in filarial disease. Cellular Microbiology, 6(2), 97-104.

Hoerauf, A., Volkmann, L., Nissen-Paehle, K., Schmetz, C., Autenrieth, I., Büttner, D. W., \& Fleischer, B. (2000). Targeting of Wolbachia endobacteria in Litomosoides sigmodontis: comparison of tetracyclines with chloramphenicol, macrolides and ciprofloxacin. Tropical Medicine \& International Health, 5(4), 275-279.

Hoffmann, A., Montgomery, B., Popovici, J., Iturbe-Ormaetxe, I., Johnson, P., Muzzi, F., . . Dong, Y. (2011). Successful establishment of Wolbachia in Aedes populations to suppress dengue transmission. Nature, 476(7361), 454.

Hoffmann, A. A., Ross, P. A., \& Rašić, G. (2015). Wolbachia strains for disease control: ecological and evolutionary considerations. Evolutionary Applications, 8(8), 751-768.

Hoffmann, J. A. (2003). The immune response of Drosophila. Nature, 426(6962), 33.

Hoffmann, J. A., Reichhart, J.-M., \& Hetru, C. (1996). Innate immunity in higher insects. Current opinion in Immunology, 8(1), 8-13.

Howe, R. (1962). The effects of temperature and humidity on the oviposition rate of Tribolium castaneum (Hbst.)(Coleoptera, Tenebrionidae). Bulletin of Entomological Research, 53(2), 301-310.

Hoy, M. A., Jeyaprakash, A., Alvarez, J. M., \& Allsopp, M. H. (2003). Wolbachia is present in Apis mellifera capensis, A. m. scutellata, and their hybrid in Southern Africa. Apidologie, 34(1), 53-60.

Hughes, G. L., \& Rasgon, J. L. (2014). Transinfection: a method to investigate Wolbachia-host interactions and control arthropod-borne disease. Insect Molecular Biology, 23(2), 141-151.

Hughes, G. L., Ren, X., Ramirez, J. L., Sakamoto, J. M., Bailey, J. A., Jedlicka, A. E., \& Rasgon, J. L. (2011). Wolbachia infections in Anopheles gambiae cells: transcriptomic characterization of a novel host-symbiont interaction. PLoS Pathogens, 7(2), e1001296.

Hughes, G. L., Ren, X., Ramirez, J. L., Sakamoto, J. M., Bailey, J. A., Jedlicka, A. E., \& Rasgon, J. L. (2011). Wolbachia infections in Anopheles gambiae cells: transcriptomic characterization of a novel host-symbiont interaction. PLoS Pathogens, 7(2), e1001296.

Huigens, M., De Almeida, R., Boons, P., Luck, R., \& Stouthamer, R. (2004). Natural interspecific and intraspecific horizontal transfer of parthenogenesis-inducing Wolbachia in Trichogramma wasps. Proceedings of the Royal Society of London B: Biological Sciences, 271(1538), 509-515.

Human, H., Brodschneider, R., Dietemann, V., Dively, G., Ellis, J. D., Forsgren, E., . . Jaffé, R. (2013). Miscellaneous standard methods for Apis mellifera research. Journal of Apicultural Research, $52(4), 1-53$. 
Hung, A. C., Adams, J. R., \& Shimanuki, H. (1995). Bee parasitic mite syndrome.(II). The role of Varroa mite and viruses. American bee journal (USA).

Hung, A. C., Shimanuki, H., \& Knox, D. A. (1996). The role of viruses in bee parasitic mite syndrome. American Bee Journal.

Hunt, G. J., Guzmán-Novoa, E., Fondrk, M. K., \& Page, R. E. (1998). Quantitative trait loci for honey bee stinging behavior and body size. Genetics, 148(3), 1203-1213.

Huvenne, H., \& Smagghe, G. (2010). Mechanisms of dsRNA uptake in insects and potential of RNAi for pest control: a review. Journal of Insect Physiology, 56(3), 227-235.

Ilyasov, R., Gaifullina, L., Saltykova, E., Poskryakov, A., \& Nikolenko, A. (2012). Review of the expression of antimicrobial peptide defensin in honey bees Apis mellifera L. Journal of Apicultural Science, 56(1), 115-124.

Iturbe-Ormaetxe, I., Walker, T., \& LO'Neill, S. (2011). Wolbachia and the biological control of mosquitoborne disease. EMBO reports, 12(6), 508-518.

Jeyaprakash, A., Hoy, M. A., \& Allsopp, M. H. (2003). Bacterial diversity in worker adults of Apis mellifera capensis and Apis mellifera scutellata (Insecta: Hymenoptera) assessed using 16S rRNA sequences. Journal of Invertebrate Pathology, 84(2), 96-103.

Johnson, R. M., Ellis, M. D., Mullin, C. A., \& Frazier, M. (2010). Pesticides and honey bee toxicityUSA. Apidologie, 41(3), 312-331.

Kageyama, D., Narita, S., \& Noda, H. (2008). Transfection of feminizing Wolbachia endosymbionts of the butterfly, Eurema hecabe, into the cell culture and various immature stages of the silkmoth, Bombyx mori. Microbial Ecology, 56(4), 733.

Kageyama, D., Wang, C.-H., \& Hatakeyama, M. (2017). Wolbachia infections of the butterfly Eurema mandarina interfere with embryonic development of the sawfly Athalia rosae. Journal of Invertebrate Pathology, 150, 76-81.

Kaiser, W., Huguet, E., Casas, J., Commin, C., \& Giron, D. (2010). Plant green-island phenotype induced by leaf-miners is mediated by bacterial symbionts. Proceedings of the Royal Society of London B: Biological Sciences, rspb20100214.

Kambris, Z., Blagborough, A. M., Pinto, S. B., Blagrove, M. S., Godfray, H. C. J., Sinden, R. E., \& Sinkins, S. P. (2010). Wolbachia stimulates immune gene expression and inhibits Plasmodium development in Anopheles gambiae. PLoS Pathogens, 6(10), e1001143.

Kambris, Z., Cook, P. E., Phuc, H. K., \& Sinkins, S. P. (2009). Immune activation by life-shortening Wolbachia and reduced filarial competence in mosquitoes. Science, 326(5949), 134-136.

Kanbar, G., \& Engels, W. (2003). Ultrastructure and bacterial infection of wounds in honey bee (Apis mellifera) pupae punctured by Varroa mites. Parasitology Research, 90(5), 349-354. 
Kassambara, A., \& Kosinski, M. (2016). Survminer: drawing survival curves using'ggplot2'. 2016. $R$ package version $0.3,1$.

Kevan, P., \& Phillips, T. (2001). The economic impacts of pollinator declines: an approach to assessing the consequences. Conservation ecology, 5(1).

Kleijn, D., Winfree, R., Bartomeus, I., Carvalheiro, L. G., Henry, M., Isaacs, R., . . Rader, R. (2015). Delivery of crop pollination services is an insufficient argument for wild pollinator conservation. Nature communications, 6, 7414.

Klein, A.-M., Vaissiere, B. E., Cane, J. H., Steffan-Dewenter, I., Cunningham, S. A., Kremen, C., \& Tscharntke, T. (2007). Importance of pollinators in changing landscapes for world crops. Proceedings of the Royal Society of London B: Biological Sciences, 274(1608), 303-313.

Koch, H., \& Schmid-Hempel, P. (2011). Socially transmitted gut microbiota protect bumble bees against an intestinal parasite. Proceedings of the National Academy of Sciences, 108(48), 19288-19292.

Koop, J. L., Zeh, D. W., Bonilla, M. M., \& Zeh, J. A. (2009). Reproductive compensation favours malekilling Wolbachia in a live-bearing host. Proceedings of the Royal Society of London B: Biological Sciences, rspb20091230.

Kragol, G., Lovas, S., Varadi, G., Condie, B. A., Hoffmann, R., \& Otvos, L. (2001). The antibacterial peptide pyrrhocoricin inhibits the ATPase actions of DnaK and prevents chaperone-assisted protein folding. Biochemistry, 40(10), 3016-3026.

Kremer, N., Charif, D., Henri, H., Gavory, F., Wincker, P., Mavingui, P., \& Vavre, F. (2012). Influence of Wolbachia on host gene expression in an obligatory symbiosis. BMC microbiology, 12(1), S7.

Krstić, O., Cvrković, T., Mitrović, M., Radonjić, S., Hrnčić, S., Toševski, I., \& Jović, J. (2018). Wolbachia infection in natural populations of Dictyophara europaea, an alternative vector of grapevine Flavescence dorée phytoplasma: effects and interactions. Annals of Applied Biology, $172(1), 47-64$.

Kubota, M., Morii, T., \& Miura, K. (2005). In vitro cultivation of parthenogenesis-inducing Wolbachia in an Aedes albopictus cell line. Entomologia Experimentalis et Applicata, 117(1), 83-87.

Kumar, S., Stecher, G., \& Tamura, K. (2016). MEGA7: molecular evolutionary genetics analysis version 7.0 for bigger datasets. Molecular Biology and Evolution, 33(7), 1870-1874.

Kwakman, P. H., Te Velde, A. A., De Boer, L., Vandenbroucke-Grauls, C. M., \& Zaat, S. A. (2011). Two major medicinal honeys have different mechanisms of bactericidal activity. PLoS one, 6(3), e17709.

Kwakman, P. H., \& Zaat, S. A. (2012). Antibacterial components of honey. IUBMB life, 64(1), 48-55.

Lanfear, R., Hua, X., \& Warren, D. L. (2016). Estimating the effective sample size of tree topologies from Bayesian phylogenetic analyses. Genome Biology and Evolution, 8(8), 2319-2332. 
Langridge, G. C., Fookes, M., Connor, T. R., Feltwell, T., Feasey, N., Parsons, B. N., . . Humphrey, T. (2015). Patterns of genome evolution that have accompanied host adaptation in Salmonella. Proceedings of the National Academy of Sciences, 112(3), 863-868.

Laughton, A. M., Boots, M., \& Siva-Jothy, M. T. (2011). The ontogeny of immunity in the honey bee, Apis mellifera L. following an immune challenge. Journal of Insect Physiology, 57(7), 10231032.

Lautenbach, S., Seppelt, R., Liebscher, J., \& Dormann, C. F. (2012). Spatial and temporal trends of global pollination benefit. PLoS one, 7(4), e35954.

Le Conte, Y., \& Navajas, M. (2008). Climate change: impact on honey bee populations and diseases. Revue Scientifique et Technique-Office International des Epizooties, 27(2), 499-510.

Lemaitre, B., \& Hoffmann, J. (2007). The host defense of Drosophila melanogaster. Annual Review of Immunology, 25, 697-743.

LePage, D., \& Bordenstein, S. R. (2013). Wolbachia: can we save lives with a great pandemic? Trends in Parasitology, 29(8), 385-393.

Levin, C. G., \& Collison, C. H. (1990). Broodnest temperature differences and their possible effect on drone brood production and distribution in honeybee colonies. Journal of Apicultural Research, 29(1), 35-44.

Li, Y., Xiang, Q., Zhang, Q., Huang, Y., \& Su, Z. (2012). Overview on the recent study of antimicrobial peptides: Origins, functions, relative mechanisms and application. Peptides, 37(2), 207-215. doi:https://doi.org/10.1016/j.peptides.2012.07.001

Lo, N., Paraskevopoulos, C., Bourtzis, K., O'neill, S., Werren, J., Bordenstein, S., \& Bandi, C. (2007). Taxonomic status of the intracellular bacterium Wolbachia pipientis. International Journal of Systematic and Evolutionary Microbiology, 57(3), 654-657.

Longdon, B., Fabian, D. K., Hurst, G. D., \& Jiggins, F. M. (2012). Male-killing Wolbachia do not protect Drosophila bifasciata against viral infection. BMC Microbiology, 12(1), S8.

Lu, P., Bian, G., Pan, X., \& Xi, Z. (2012). Wolbachia induces density-dependent inhibition to dengue virus in mosquito cells. PLoS Neglected Tropical Diseases, 6(7), e1754.

Mandrioli, M., Bugli, S., Saltini, S., Genedani, S., \& Ottaviani, E. (2003). Molecular characterization of a defensin in the IZD-MB-0503 cell line derived from immunocytes of the insect Mamestra brassicae (Lepidoptera). Biology of the Cell, 95(1), 53-57.

Martin, S. J. (2001). The role of Varroa and viral pathogens in the collapse of honeybee colonies: a modelling approach. Journal of Applied Ecology, 38(5), 1082-1093. 
Martin, S. J., Highfield, A. C., Brettell, L., Villalobos, E. M., Budge, G. E., Powell, M., . . Schroeder, D. C. (2012). Global honey bee viral landscape altered by a parasitic mite. Science, 336(6086), 1304-1306.

Martinez, J., Longdon, B., Bauer, S., Chan, Y.-S., Miller, W. J., Bourtzis, K., . . Jiggins, F. M. (2014). Symbionts commonly provide broad spectrum resistance to viruses in insects: a comparative analysis of Wolbachia strains. PLoS Pathogens, 10(9), e1004369.

Martinson, V. G., Danforth, B. N., Minckley, R. L., Rueppell, O., Tingek, S., \& Moran, N. A. (2011). A simple and distinctive microbiota associated with honey bees and bumble bees. Molecular Ecology, 20(3), 619-628.

Matosin, N., Frank, E., Engel, M., Lum, J. S., \& Newell, K. A. (2014). Negativity towards negative results: a discussion of the disconnect between scientific worth and scientific culture. In: The Company of Biologists Ltd.

McGraw, E. A., \& O’Neill, S. L. (2004). Wolbachia pipientis: intracellular infection and pathogenesis in Drosophila. Current Opinion in Microbiology, 7(1), 67-70.

McMeniman, C. J., Lane, R. V., Cass, B. N., Fong, A. W., Sidhu, M., Wang, Y.-F., \& O'neill, S. L. (2009). Stable introduction of a life-shortening Wolbachia infection into the mosquito Aedes aegypti. Science, 323(5910), 141-144.

Merçot, H., \& Poinsot, D. (2009). Infection by Wolbachia: from passengers to residents. Comptes Rendus Biologies, 332(2-3), 284-297.

Michener, C. D. (2007). The Bees of the World. 2nd. Ed. Johns Hopkins, Baltimore.

Milne Jr, C. P., Phillips, J. P., \& Krell, P. J. (1988). Microinjection of early honeybee embryos. Journal of Apicultural Research, 27(2), 84-89.

Ministry of Primary Industries, N. Z. (2015). 2017 Apiculture Monitoring Programme. Retrieved from

Mordecai, G. J., Brettell, L. E., Martin, S. J., Dixon, D., Jones, I. M., \& Schroeder, D. C. (2015). Superinfection exclusion and the long-term survival of honey bees in Varroa-infested colonies. The ISME Journal, 10(5), 1182.

Moreau, J., Martinaud, G., Troussard, J. P., Zanchi, C., \& Moret, Y. (2012). Trans-generational immune priming is constrained by the maternal immune response in an insect. Oikos, 121(11), 1828-1832.

Moret, Y. (2006). 'Trans-generational immune priming': specific enhancement of the antimicrobial immune response in the mealworm beetle, Tenebrio molitor. Proceedings of the Royal Society of London B: Biological Sciences, 273(1592), 1399-1405.

Nakamura, Y., Gotoh, T., Imanishi, S., Mita, K., Kurtti, T., \& Noda, H. (2011). Differentially expressed genes in silkworm cell cultures in response to infection by Wolbachia and Cardinium endosymbionts. Insect Molecular Biology, 20(3), 279-289. 
Nazzi, F., Brown, S. P., Annoscia, D., Del Piccolo, F., Di Prisco, G., Varricchio, P., . . Pennacchio, F. (2012). Synergistic parasite-pathogen interactions mediated by host immunity can drive the collapse of honeybee colonies. PLoS Pathogens, 8(6), e1002735.

Neff, J. L., \& Simpson, B. B. (1993). Bees, pollination systems and plant diversity. Sourced from http:// http://agris.fao.org/agris-search/search.do?recordID=GB9522809

Neumann, P., \& Carreck, N. L. (2010). Honey bee colony losses. Journal of Apicultural Research, 49(1):1-6.

Nirgianaki, A., Banks, G. K., Frohlich, D. R., Veneti, Z., Braig, H. R., Miller, T. A., . . Bourtzis, K. (2003). Wolbachia infections of the whitefly Bemisia tabaci. Current microbiology, 47(2), 00930101.

Ollerton, J., Winfree, R., \& Tarrant, S. (2011). How many flowering plants are pollinated by animals? Oikos, 120(3), 321-326.

Osborne, S. E., Iturbe-Ormaetxe, I., Brownlie, J. C., O'Neill, S. L., \& Johnson, K. N. (2012). Antiviral protection and the importance of Wolbachia density and tissue tropism in Drosophila simulans. Applied and Environmental Microbiology, 78(19), 6922-6929.

Osborne, S. E., San Leong, Y., O'Neill, S. L., \& Johnson, K. N. (2009). Variation in antiviral protection mediated by different Wolbachia strains in Drosophila simulans. PLoS Pathogens, 5(11), e1000656.

Otvos, L., Bokonyi, K., Varga, I., OTVOS, B. I., Hoffmann, R., Ertl, H. C., . . Bulet, P. (2000). Insect peptides with improved protease-resistance protect mice against bacterial infection. Protein Science, 9(4), 742-749.

Pan, X., Pike, A., Joshi, D., Bian, G., McFadden, M. J., Lu, P., . . Xi, Z. (2017). The bacterium Wolbachia exploits host innate immunity to establish a symbiotic relationship with the dengue vector mosquito Aedes aegypti. The ISME Journal, 12(1), 277.

Pan, X., Zhou, G., Wu, J., Bian, G., Lu, P., Raikhel, A. S., \& Xi, Z. (2012). Wolbachia induces reactive oxygen species (ROS)-dependent activation of the Toll pathway to control dengue virus in the mosquito Aedes aegypti. Proceedings of the National Academy of Sciences, 109(1), E23-E31.

Panaram, K., \& Marshall, J. L. (2007). F supergroup Wolbachia in bush crickets: what do patterns of sequence variation reveal about this supergroup and horizontal transfer between nematodes and arthropods? Genetica, 130(1), 53-60.

Parker, B. J., Barribeau, S. M., Laughton, A. M., de Roode, J. C., \& Gerardo, N. M. (2011). Nonimmunological defense in an evolutionary framework. Trends in Ecology \& Evolution, 26(5), 242-248. 
Pattabhiramaiah, M., Brueckner, D., Witzel, K. P., Junier, P., \& Reddy, M. (2011). Prevalence of Wolbachia in the European Honeybee, Apis mellifera carnica. World Applied Sciences Journal, 15(11), 1503-1506.

Pattabhiramaiah, M., Brueckner, D., Witzel, K. P., \& Reddy, M. (2011). Wolbachia Endosymbiont in the workers of European honeybee, Apis mellifera carnica. Electronic Journal of Biology, 7(4).

Peng, Y.-S., Fang, Y., Xu, S., \& Ge, L. (1987). The resistance mechanism of the Asian honey bee, Apis cerana Fabr., to an ectoparasitic mite, Varroa jacobsoni Oudemans. Journal of Invertebrate Pathology, 49(1), 54-60.

Pike, N., \& Kingcombe, R. (2009). Antibiotic treatment leads to the elimination of Wolbachia endosymbionts and sterility in the diplodiploid collembolan Folsomia candida. BMC Biology, $7(1), 54$.

Poinsot, D., \& Merçot, H. (1997). Wolbachia infection in Drosophila simulans: does the female host bear a physiological cost? Evolution, 51(1), 180-186.

Potts, S. G., Biesmeijer, J. C., Kremen, C., Neumann, P., Schweiger, O., \& Kunin, W. E. (2010). Global pollinator declines: trends, impacts and drivers. Trends in Ecology \& Evolution, 25(6), 345-353.

Prout, T., \& Clark, A. G. (2000). Seminal fluid causes temporarily reduced egg hatch in previously mated females. Proceedings of the Royal Society of London B: Biological Sciences, 267(1439), 201-203.

Pyles, R. B., Vincent, K. L., Baum, M. M., Elsom, B., Miller, A. L., Maxwell, C., . . Nusbaum, R. J. (2014). Cultivated vaginal microbiomes alter HIV-1 infection and antiretroviral efficacy in colonized epithelial multilayer cultures. PLoS one, 9(3), e93419.

Rasgon, J. L., Gamston, C. E., \& Ren, X. (2006). Survival of Wolbachia pipientis in cell-free medium. Applied and Environmental Microbiology, 72(11), 6934-6937.

Rasgon, J. L., \& Scott, T. W. (2003). Wolbachia and cytoplasmic incompatibility in the California Culex pipiens mosquito species complex: parameter estimates and infection dynamics in natural populations. Genetics, 165(4), 2029-2038.

Rashed, A., Hamilton, B., \& Polak, M. (2008). Ectoparasite resistance is correlated with reduced host egg hatch rate in the Drosophila-Macrocheles system. Environmental Entomology, 37(5), 1099-1104.

Rath, W., \& Drescher, W. (1990). Response of Apis cerana Fabr towards brood infested with Varroa jacobsoni Oud and infestation rate of colonies in Thailand. Apidologie, 21(4), 311-321.

Raychoudhury, R., Baldo, L., Oliveira, D. C., \& Werren, J. H. (2009). Modes of acquisition of Wolbachia: horizontal transfer, hybrid introgression, and codivergence in the Nasonia species complex. Evolution, 63(1), 165-183.

Rembold, H., Kremer, J.-P., \& Ulrich, G. M. (1980). Characterization of postembryonic developmental stages of the female castes of the honey bee, Apis mellifera L. Apidologie, 11(1), 29-38. 
Rinderer, T. E., de Guzman, L. I., Delatte, G., Stelzer, J., Lancaster, V., Kuznetsov, V., . . Harris, J. (2001). Resistance to the parasitic mite Varroa destructor in honey bees from far-eastern Russia. Apidologie, 32(4), 381-394.

Rinkevich, F., Margotta, J., Pokhrel, V., Walker, T., Vaeth, R., Hoffman, W., . . Aldridge, R. (2017). Limited impacts of truck-based ultra-low-volume applications of mosquito adulticides on mortality in honey bees (Apis mellifera). Bulletin of Entomological Research, 107(6), 724-733.

Rolain, J.-M., Franc, M., Davoust, B., \& Raoult, D. (2003). Molecular detection of Bartonella quintana, B. koehlerae, B. henselae, B. clarridgeiae, Rickettsia felis, and Wolbachia pipientis in cat fleas, France. Emerging Infectious Diseases, 9(3), 339.

Ros, V. I., Fleming, V. M., Feil, E. J., \& Breeuwer, J. A. (2009). How diverse is the genus Wolbachia? Multiple-gene sequencing reveals a putatively new Wolbachia supergroup recovered from spider mites (Acari: Tetranychidae). Applied and Environmental Microbiology, 75(4), 1036-1043.

Ros, V. I., Fleming, V. M., Feil, E. J., \& Breeuwer, J. A. (2012). Diversity and recombination in Wolbachia and Cardinium from Bryobia spider mites. BMC Microbiology, 12(1), S13.

Ross, P. A., Wiwatanaratanabutr, I., Axford, J. K., White, V. L., Endersby-Harshman, N. M., \& Hoffmann, A. A. (2017). Wolbachia infections in Aedes aegypti differ markedly in their response to cyclical heat stress. PLoS Pathogens, 13(1), e1006006.

Roth, O., Sadd, B. M., Schmid-Hempel, P., \& Kurtz, J. (2009). Strain-specific priming of resistance in the red flour beetle, Tribolium castaneum. Proceedings of the Royal Society of London B: Biological Sciences, 276(1654), 145-151.

Rottschaefer, S. M., \& Lazzaro, B. P. (2012). No effect of Wolbachia on resistance to intracellular infection by pathogenic bacteria in Drosophila melanogaster. PLoS one, 7(7), e40500.

Royet, J. (2004). Infectious non-self recognition in invertebrates: lessons from Drosophila and other insect models. Molecular Immunology, 41(11), 1063-1075. doi:https://doi.org/10.1016/j.molimm.2004.06.009

Ruttner, F., \& Hänel, H. (1992). Active defense against Varroa mites in a Carniolan strain of honeybee (Apis mellifera carnica Pollmann). Apidologie, 23(2), 173-187.

Saikaly, S. K., \& Khachemoune, A. (2017). Honey and wound healing: an update. American Journal of Clinical Dermatology, 18(2), 237-251.

Salmela, H., Amdam, G. V., \& Freitak, D. (2015). Transfer of immunity from mother to offspring is mediated via egg-yolk protein vitellogenin. PLoS Pathogens, 11(7), e1005015.

Salunke, B. K., Salunkhe, R. C., Dhotre, D. P., Khandagale, A. B., Walujkar, S. A., Kirwale, G. S., . . Shouche, Y. S. (2010). Diversity of Wolbachia in Odontotermes spp.(Termitidae) and 
Coptotermes heimi (Rhinotermitidae) using the multigene approach. FEMS Microbiology Letters, 307(1), 55-64.

Santorum, J. M., Darriba, D., Taboada, G. L., \& Posada, D. (2014). jmodeltest. org: selection of nucleotide substitution models on the cloud. Bioinformatics, 30(9), 1310-1311.

Schmid-Hempel, P. (2003). Variation in immune defence as a question of evolutionary ecology. Proceedings of the Royal Society of London B: Biological Sciences, 270(1513), 357-366.

Schmid-Hempel, P. (2005). Evolutionary ecology of insect immune defenses. Annual Review of Entomology, 50, 529-551.

Schroeder, D. C., \& Martin, S. J. (2012). Deformed wing virus: The main suspect in unexplained honeybee deaths worldwide. Virulence, 3(7), 589-591.

Scocchi, M., Lüthy, C., Decarli, P., Mignogna, G., Christen, P., \& Gennaro, R. (2009). The proline-rich antibacterial peptide Bac7 binds to and inhibits in vitro the molecular chaperone DnaK. International Journal of Peptide Research and Therapeutics, 15(2), 147-155.

Sekirov, I., Russell, S. L., Antunes, L. C. M., \& Finlay, B. B. (2010). Gut microbiota in health and disease. Physiological reviews, 90(3), 859-904.

Sinkins, S. P., Walker, T., Lynd, A. R., Steven, A. R., Makepeace, B. L., Godfray, H. C. J., \& Parkhill, J. (2005). Wolbachia variability and host effects on crossing type in Culex mosquitoes. Nature, 436(7048), 257.

Siozios, S., Sapountzis, P., Ioannidis, P., \& Bourtzis, K. (2008). Wolbachia symbiosis and insect immune response. Insect Science, 15(1), 89-100.

Soroker, V., Hetzroni, A., Yacobson, B., Voet, H., Slabezki, S., Efrat, H., \& Chejanovsky, N. (2009). Colony losses in Israel: incidence of viral infection and beehive populations. Paper presented at the Proceedings of the 41st Apimondia Congress, Mointpellier, France.

Spivak, M., \& Reuter, G. S. (2001). Resistance to American foulbrood disease by honey bee colonies Apis mellifera bred for hygienic behavior. Apidologie, 32(6), 555-565.

Stoic, M., Yoshiyama, M., \& Kimura, K. (2016). Potential Antibacterial Activity of Chestnut Honey against Paenibacillus larvae. Journal of Apiculture, 31(4), 351-358.

Stouthamer, R., Breeuwer, J. A., \& Hurst, G. D. (1999). Wolbachia pipientis: microbial manipulator of arthropod reproduction. Annual Reviews in Microbiology, 53(1), 71-102.

Stouthamer, R., \& Mak, F. (2002). Influence of antibiotics on the offspring production of the Wolbachiainfected parthenogenetic parasitoid Encarsia formosa. Journal of Invertebrate Pathology, 80(1), 41-45.

Sutton, E. R., Harris, S. R., Parkhill, J., \& Sinkins, S. P. (2014). Comparative genome analysis of Wolbachia strain w Au. BMC genomics, 15(1), 928. 
Tamarozzi, F., Halliday, A., Gentil, K., Hoerauf, A., Pearlman, E., \& Taylor, M. J. (2011).

Onchocerciasis: the role of Wolbachia bacterial endosymbionts in parasite biology, disease pathogenesis, and treatment. Clinical Microbiology Reviews, 24(3), 459-468.

Tamarozzi, F., Wright, H. L., Johnston, K., Edwards, S. W., Turner, J., \& Taylor, M. (2014). Human filarial Wolbachia lipopeptide directly activates human neutrophils in vitro. Parasite Immunology, 36(10), 494-502.

Tamura, K., \& Nei, M. (1993). Estimation of the number of nucleotide substitutions in the control region of mitochondrial DNA in humans and chimpanzees. Molecular Biology and Evolution, 10(3), 512-526.

Taur, Y., Jenq, R. R., Perales, M.-A., Littmann, E. R., Morjaria, S., Ling, L., . . Dahi, P. B. (2014). The effects of intestinal tract bacterial diversity on mortality following allogeneic hematopoietic stem cell transplantation. Blood, 124(7), 1174-1182.

Taylor, M., Bandi, C., Hoerauf, A., \& Lazdins, J. (2000). Wolbachia bacteria of filarial nematodes: a target for control? Parasitology Today, 16(5), 179-180.

Team, R. D. C. (2008). R: A Language and Environment for Statistical Computing. Vienna, Austria: Foundation for Statistical Computing.

Teixeira, L., Ferreira, Á., \& Ashburner, M. (2008). The bacterial symbiont Wolbachia induces resistance to RNA viral infections in Drosophila melanogaster. PLoS Biology, 6(12), e1000002.

Terenius, O., Papanicolaou, A., Garbutt, J. S., Eleftherianos, I., Huvenne, H., Kanginakudru, S., . . . Barthel, A. (2011). RNA interference in Lepidoptera: an overview of successful and unsuccessful studies and implications for experimental design. Journal of Insect Physiology, 57(2), 231-245.

Terenius, O., Papanicolaou, A., Garbutt, J. S., Eleftherianos, I., Huvenne, H., Kanginakudru, S., . . . Barthel, A. (2011). RNA interference in Lepidoptera: an overview of successful and unsuccessful studies and implications for experimental design. Journal of Insect Physiology, 57(2), 231-245.

Terradas, G., Joubert, D. A., \& McGraw, E. A. (2017). The RNAi pathway plays a small part in Wolbachia-mediated blocking of dengue virus in mosquito cells. Scientific Reports, 7, 43847.

Therneau, T. (2015). A package for survival analysis in S. R package version 2.38. Retrived from http://CRAN. R-project. org/package= survival.

Thomas, P., Kenny, N., Eyles, D., Moreira, L. A., O’Neill, S. L., \& Asgari, S. (2011). Infection with the wMel and wMelPop strains of Wolbachia leads to higher levels of melanization in the hemolymph of Drosophila melanogaster, Drosophila simulans and Aedes aegypti. Developmental \& Comparative Immunology, 35(3), 360-365.

Timmermans, M. J., \& Ellers, J. (2009). Wolbachia endosymbiont is essential for egg hatching in a parthenogenetic arthropod. Evolutionary Ecology, 23(6), 931. 
Tomoyasu, Y., Miller, S. C., Tomita, S., Schoppmeier, M., Grossmann, D., \& Bucher, G. (2008). Exploring systemic RNA interference in insects: a genome-wide survey for RNAi genes in Tribolium. Genome biology, 9(1), R10.

Turner, R. J. (1994). Immunology: a comparative approach. Britain John Wiley Sons Ltd.

Valette, V., Essono, P.-Y. B., Le Clec'h, W., Johnson, M., Bech, N., \& Grandjean, F. (2013). Multiinfections of feminizing Wolbachia strains in natural populations of the terrestrial isopod Armadillidium vulgare. PLoS One, 8(12), e82633.

Van Meer, M. M., \& Stouthamer, R. (1999). Cross-order transfer of Wolbachia from Muscidifurax uniraptor (Hymenoptera: Pteromalidae) to Drosophila simulans (Diptera: drosophilidae). Heredity, 82(2), 163.

vanEngelsdorp, D., Hayes Jr, J., Underwood, R. M., \& Pettis, J. S. (2010). A survey of honey bee colony losses in the United States, fall 2008 to spring 2009. Journal of Apicultural Research, 49(1), 714.

vanEngelsdorp, D., \& Meixner, M. D. (2010). A historical review of managed honey bee populations in Europe and the United States and the factors that may affect them. Journal of Invertebrate Pathology, 103, S80-S95. doi:https://doi.org/10.1016/j.jip.2009.06.011

Vásquez, A., Forsgren, E., Fries, I., Paxton, R. J., Flaberg, E., Szekely, L., \& Olofsson, T. C. (2012). Symbionts as major modulators of insect health: lactic acid bacteria and honeybees. PLoS one, 7(3), e33188.

Vavre, F., Fleury, F., Lepetit, D., Fouillet, P., \& Boulétreau, M. (1999). Phylogenetic evidence for horizontal transmission of Wolbachia in host-parasitoid associations. Molecular Biology and Evolution, 16(12), 1711-1723.

Wade, M. J., \& Chang, N. W. (1995). Increased male fertility in Tribolium confusum beetles after infection with the intracellular parasite Wolbachia. Nature, 373(6509), 72.

Walker, T., Johnson, P., Moreira, L., Iturbe-Ormaetxe, I., Frentiu, F., McMeniman, C., . . Kriesner, P. (2011). The wMel Wolbachia strain blocks dengue and invades caged Aedes aegypti populations. Nature, 476(7361), 450.

Wang, G.-H., Jia, L.-Y., Xiao, J.-H., \& Huang, D.-W. (2016). Discovery of a new Wolbachia supergroup in cave spider species and the lateral transfer of phage WO among distant hosts. Infection, Genetics and Evolution, 41, 1-7.

Wang, Z., Su, X. M., Wen, J., Jiang, L. Y., \& Qiao, G. X. (2014). Widespread infection and diverse infection patterns of Wolbachia in Chinese aphids. Insect Science, 21(3), 313-325. 
Weinert, L. A., Araujo-Jnr, E. V., Ahmed, M. Z., \& Welch, J. J. (2015). The incidence of bacterial endosymbionts in terrestrial arthropods. Proceedings of the Royal Society of London B, 282(1807), 20150249.

Werren, J. H., Baldo, L., \& Clark, M. E. (2008). Wolbachia: master manipulators of invertebrate biology. Nature Reviews Microbiology, 6(10), 741.

Werren, J. H., Windsor, D., \& Guo, L. (1995). Distribution of Wolbachia among neotropical arthropods. Proceedings of the Royal Society of London B: Biological Sciences, 262(1364), 197-204.

Whitworth, T., Dawson, R., Magalon, H., \& Baudry, E. (2007). DNA barcoding cannot reliably identify species of the blowfly genus Protocalliphora (Diptera: Calliphoridae). Proceedings of the Royal Society of London B: Biological Sciences B: Biological Sciences, 274(1619), 1731-1739.

Williams, I. H. (1994). The dependence of crop production within the European Union on pollination by honey bees. Agricultural Zoology Reviews (United Kingdom).

Winston, M. L. (1991). The biology of the honey bee: harvard university press.

Wong, Z. S., Hedges, L. M., Brownlie, J. C., \& Johnson, K. N. (2011). Wolbachia-mediated antibacterial protection and immune gene regulation in Drosophila. PLoS One, 6(9), e25430.

Wong, Z. S., Hedges, L. M., Brownlie, J. C., \& Johnson, K. N. (2011). Wolbachia-mediated antibacterial protection and immune gene regulation in Drosophila. PLoS One, 6(9), e25430.

Woolfit, M., Iturbe-Ormaetxe, I., Brownlie, J. C., Walker, T., Riegler, M., Seleznev, A., . . Pavlides, J. (2013). Genomic evolution of the pathogenic Wolbachia strain, w MelPop. Genome Biology and Evolution, 5(11), 2189-2204.

Wu, M., Sugimura, Y., Taylor, D., \& Yoshiyama, M. (2013). Honeybee gastrointestinal bacteria for novel and sustainable disease control strategies. Journal of Developments in Sustainable Agriculture, $8(2), 85-90$.

Wu, M., Sun, L. V., Vamathevan, J., Riegler, M., Deboy, R., Brownlie, J. C., . . Ahmadinejad, N. (2004). Phylogenomics of the reproductive parasite Wolbachia pipientis wMel: a streamlined genome overrun by mobile genetic elements. PLoS Biology, 2(3), e69.

Wu, M., Sun, L. V., Vamathevan, J., Riegler, M., Deboy, R., Brownlie, J. C., . . Ahmadinejad, N. (2004). Phylogenomics of the reproductive parasite Wolbachia pipientis wMel: a streamlined genome overrun by mobile genetic elements. PLoS Biology, 2(3), e69.

Xi, Z., \& Dobson, S. L. (2005). Characterization of Wolbachia transfection efficiency by using microinjection of embryonic cytoplasm and embryo homogenate. Applied and Environmental Microbiology, 71(6), 3199-3204.

Xu, P., Shi, M., \& Chen, X.-x. (2009). Antimicrobial peptide evolution in the Asiatic honey bee Apis cerana. PLoS One, 4(1), e4239. 
Yañez, O., Gauthier, L., Chantawannakul, P., \& Neumann, P. (2016). Endosymbiotic bacteria in honey bees: Arsenophonus spp. are not transmitted transovarially. FEMS Microbiology Letters, 363(14).

Yeap, H. L., Mee, P., Walker, T., Weeks, A. R., O'Neill, S. L., Johnson, P., . . Endersby, N. M. (2011). Dynamics of the "popcorn" Wolbachia infection in outbred Aedes aegypti informs prospects for mosquito vector control. Genetics, 187(2), 583-595.

Yue, C., \& Genersch, E. (2005). RT-PCR analysis of Deformed wing virus in honeybees (Apis mellifera) and mites (Varroa destructor). Journal of General Virology, 86(12), 3419-3424.

Zabalou, S., Apostolaki, A., Pattas, S., Veneti, Z., Paraskevopoulos, C., Livadaras, I., . . Bourtzis, K. (2008). Multiple rescue factors within a Wolbachia strain. Genetics, 178(4), 2145-2160.

Zhang, S., Wang, S., Li, H., \& Li, L. (2011). Vitellogenin, a multivalent sensor and an antimicrobial effector. The International Journal of Biochemistry \& Cell Biology, 43(3), 303-305.

Zheng, Y., Wang, J.-L., Liu, C., Wang, C.-P., Walker, T., \& Wang, Y.-F. (2011). Differentially expressed profiles in the larval testes of Wolbachia infected and uninfected Drosophila. BMC Genomics, 12(1), 595.

Zhong, Y., \& Li, Z.-X. (2014). Bidirectional cytoplasmic incompatibility induced by cross-order transfection of Wolbachia: Implications for control of the host population. Microbial Ecology, $68(3), 463-471$

Ziegelmann, B., Abele, E., Hannus, S., Beitzinger, M., Berg, S., \& Rosenkranz, P. (2018). Lithium chloride effectively kills the honey bee parasite Varroa destructor by a systemic mode of action. Scientific Reports, 8(1), 683.

Zioni, N., Soroker, V., \& Chejanovsky, N. (2011). Replication of Varroa destructor virus 1 (VDV-1) and a Varroa destructor virus 1-deformed wing virus recombinant (VDV-1-DWV) in the head of the honey bee. Virology, 417(1), 106-112.

Zug, R., \& Hammerstein, P. (2012). Still a host of hosts for Wolbachia: analysis of recent data suggests that $40 \%$ of terrestrial arthropod species are infected. PLoS One, 7(6), e38544. 


\section{APPENDIX 1}

\section{Protocol for the rearing of Apis melliera larvae from eggs through to pupation}

\section{BACKGROUND}

\section{Honey bee development}

Apis mellifera is a eusocial colonial hymenopteran, with three definitive caste divisions. These castes are divided into the reproductive queen, female workers and male drones (Winston, 1991; Matherson \& Reid, 2011). Their development, regardless of caste, is fully holometabolous (undergoes full metamorphosis) and is broken down into egg, larvae, pupae and adult stages, but development time varies between caste (Fig 1). All bees, irrespective of caste, take three days to hatch out of their eggs, but from hatching vary from 16 days in queens, to 19 in workers to up to 23 days for drones. This time is split between larval and pupal stages. Larvae go through four moults, coinciding with transition from first instar larva through to $4^{\text {th }}$ instar, when their cell is capped. They then spend up to nine days as pupae before chewing through the capped cell and emerging as adults (Mathieson \& Reid, 2011).

Honey bee eggs are laid vertically in the comb well (Figure 2, cell 2). The posterior end of the egg is narrower than the top and is connected to the wax by a glue-like substance secreted by the queen during oviposition. The egg is positioned with the anterior (head) end facing upward. Over the course of approximately three days (which is somewhat dependent on temperature), the egg slowly tilts onto its side on comb cell's base. The embryo is nourished by yolk within the egg package, made up of vitellogenin (Salmela, et al. 2015). To hatch, the larvae flexes within the egg, releasing fluid along the dorsal midline which begins the digestion of the egg shell.

During their development, honey bee larvae undergo five instars, each lasting varying lengths of time (Bertholf, 1925). Larvae hatch from their eggs 66-93 hours after oviposition (Collins, 2004). There are a number of morphological features by which to characterize the age of the five instars of larval development, all viewable under a dissecting microscope (Human, et al., 2013). These include the head diameter, development of the wing buds, leg buds, mouth pieces and gonapophyses. It is important to be aware that the first instar lasts between 14-20 hours. Once the larvae has reached the age of one day (24 hours post hatching from the egg), it has already reached the second instar (Bertholf, 1925; Rembold, et $a l ., 1980)$. In a case where eggs rather than larvae are desired, it is important to frequently check when 
oviposition has begun and to check regularly over the next few hours until the queen has laid enough eggs for the given experimental design. The honey bee embryonic germline develops 48 hours post-oviposition (Dearden, 2006). Therefore, egg age will need to be considered for experiments where this is a crucial component, such as embryological studies.

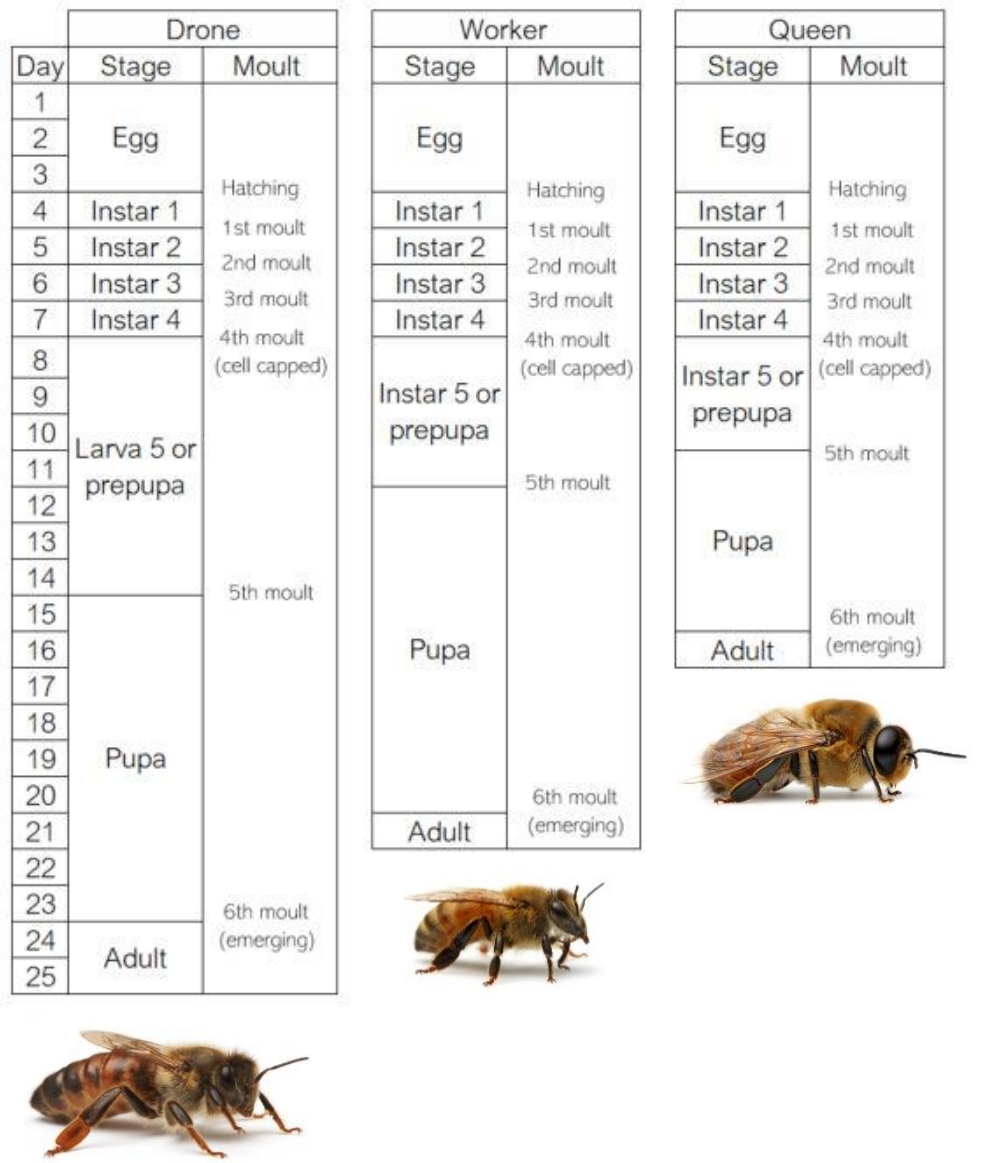

Figure 3 Honey bee (Apis mellifera) developmental stages per caste. Photos: Alexander Wild

\section{PROTOCOL}

\section{Obtaining eggs}

Naturally, eggs are not laid in chronological order along the comb, so eggs and larvae within the comb are not ordered by age and must be visually identified (Figure 2). To streamline this process, the queen can be manipulated to oviposit eggs on comb that is convenient to access, remove from the hive and handle in the laboratory. To obtain eggs (or $1^{\text {st }}$ instar larvae), a queen should be confined using a queen excluder cage (where workers can pass through the cage grid while the queen remains in the matrix) for 24-36 hours on worker comb. The queen excluder should be placed towards the centre of the hive to ensure the queen is 
well fed by nurse bees (Crailsheim, et al., 2013). The length of time the queen remains in the excluder box is dependent on the age of eggs or larvae desired and the speed of oviposition initiation, duration and continuation which are dependent on the given queen. The first instar lasts 14-20 hours after hatching from the egg, which occurs approximately three days after ovideposition (Winston, 1987; Matherson \& Reid, 2011). Queens do not start oviposition immediately after being placed in an excluder and this needs to be confirmed visually after a few hours of caging (Crailsheim, et al., 2013).

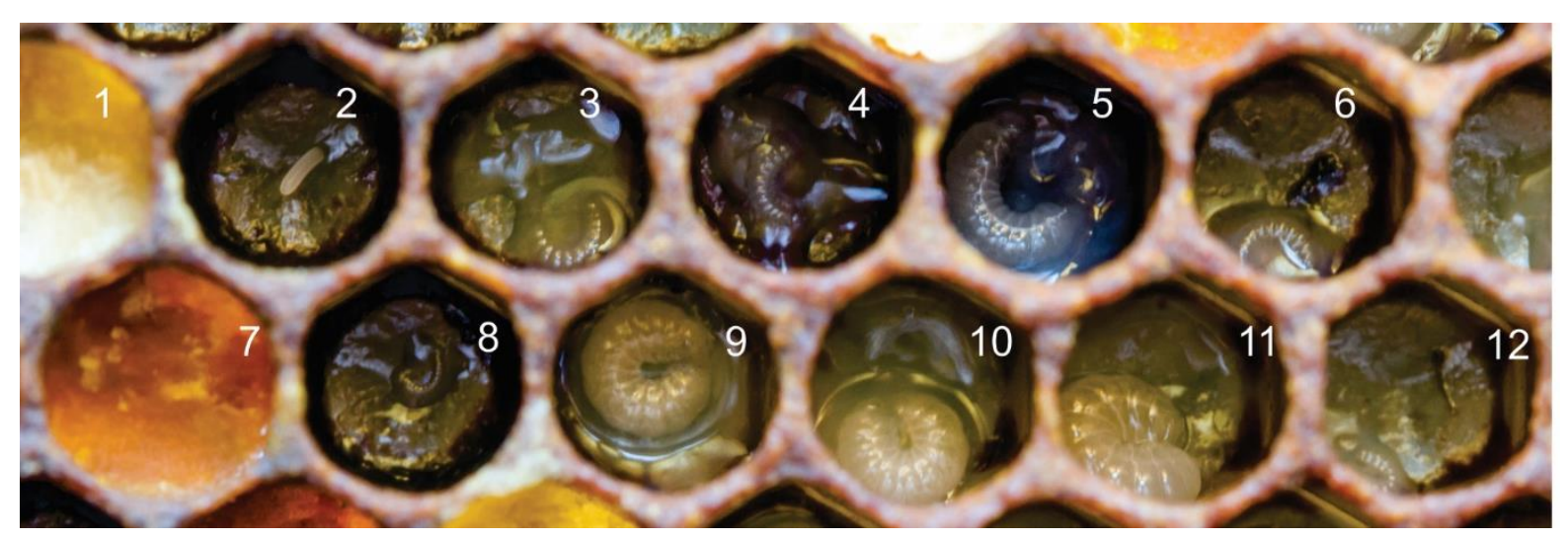

Figure 4 Honey bee eggs and larvae laid in-situ. Egg laying is not chronological by cell within the comb and so larvae found is not ordered by age. By cell: 1 and 7, bee bread - honey and pollen; 2, egg between 1-2 days old; 3-4, 6 and 12 , early $2^{\text {nd }}$ instar larvae; $5,3^{\text {rd }}$ instar larvae; $8,1^{\text {st }}$ instar larvae, recently hatched; 9-10, early $3^{\text {rd }}$ instar larvae; 11 , late $3^{\text {rd }}$ instar larvae.

Collins (2002) found that young eggs are incredibly sensitive to disturbance and that any handling can reduce their hatch rate by up to $50 \%$. Deviations in relative humidity can cause shriveling of the eggs and significantly reduce the proportion of eggs that hatch into healthy larvae. The movement of comb to plate or petri dish is precarious and in order to reduce impact it is advisable to keep eggs within the comb until hatching. Microinjection applications can often be conducted with eggs remaining on the comb if the excess height of the wax walls is cut down with a sharp scalpel or scissors.

If eggs are to hatch successfully, they need to be grafted from the comb onto the desired plate in the same position. That is, the end of the egg in contact with the wax comb will develop into the anus-end of the larvae and to promote healthy hatching, the end of the egg that comes into contact with the plate needs to be consistent with that in contact with the wax in-situ. 


\section{Incubation environment}

The inside of a beehive is regulated to vary between no more than $2^{\circ} \mathrm{C}$ in brood frames ( $\mathrm{Li}$, et al., 2016) and the relative humidity (RH) is retained at approximately 90-95\% RH during egg oviposition and larval development up to pupation. Reduced RH can result in the shriveling of eggs and reduced hatch rate. A drop from $90 \%$ to $80 \%$ RH has been shown to lower healthy larvae production by $30 \%$ (Collins, 2002)

Honey bee larvae may be kept in air tight plastic containers (such as Tupperware) and placed inside incubators to facilitate humidity regulation. It is important to maintain an optimum temperature of $34.5^{\circ} \mathrm{C}$ with minimal variation $\left( \pm 1^{\circ} \mathrm{C}\right)$ as suboptimal temperatures have been shown to affect adult bee longevity and can induce malformed wings (Vojviodic, et al. 2010). Humidity can be maintained and adjusted by including a dish of saturated $\mathrm{K}_{2} \mathrm{SO}_{4}$ solution to maintain $95 \% \mathrm{RH}$. After the $6^{\text {th }}$ day with the onset of pupation, the $\mathrm{K}_{2} \mathrm{SO}_{4}$ may be replaced with a saturated $\mathrm{NaCl}$ solution to achieve $80 \% \mathrm{RH}$. This adjustment has proved to be appropriate in a number of studies (eg. Rembold \& Lackner (1981) Vandenberg \& Shimanuki (1987), Peng et al. (1992), Aupinel, et al. (2005)) but was not found to have any noticeable effect during this protocol. Alternatively, if using a separated container with a ventilated division (eg Sistema deli storers) the bottom of the tray can be lined with sterile tissues dampened with autoclaved distilled water. However, if this technique is chosen, it is important to avoid saturation of the tissues as this causes the moisture in the air to condense and drown the larvae. During the egg stage, the effect of humidity is related to the ability of an egg to maintain its membrane integrity. Therefore, inadequate humidity will cause disruption of the chorion/vitelline membrane within the eggs and cause damage or leakage and therefore a lowered hatch rate.

\section{Preparation of diet}

There are many diet recipes used by different labs and they vary in their ratios of sugars, water and royal jelly. In general, it is important that the larval diet does not contain less than $50 \%$ (v/v) royal jelly or more than $33.3 \%(\mathrm{v} / \mathrm{v})$ aqueous solutions. If these requirements are not met, the larval diet will contain too much water and young larvae will drown in the diet or have problems with digestion (Crailsheim, 2013). Studies

by Kaftanoglu et al. (2010a, 2010b) have shown that variation in sugar ratios (glucose : fructose) had impact on the number of adults emerged, and on the number of queens and intercastes produced. Lower quantities of sugars enable growth but cause death during pupation, while higher sugar quantities increase the chance of queens and intercastes. 
The diet used in this protocol used the following recipe ratio:

$$
\begin{aligned}
& -6 \% \text { D-glucose } \\
& -6 \% \text { D-frucotse } \\
& -1 \% \text { yeast extract } \\
& -53 \% \text { royal jelly } \\
& -33 \% \text { distilled } \mathrm{H}_{2} \mathrm{O}
\end{aligned}
$$

It is recommended to make the diet in bulk for ease of labour. Diet stored at $4{ }^{\circ} \mathrm{C}$ should be kept and used for 3 days only. Alternatively, diet made for the whole exposure period may be prepared at rearing initiation, aliquoted, and stored at $-20^{\circ} \mathrm{C}$ for the duration.

Keep royal jelly frozen at $-20^{\circ} \mathrm{C}$ and thaw by placing it at $4{ }^{\circ} \mathrm{C}$ overnight or at room temperature for an hour dependent on the size of the container. Make up the aqueous solution (glucose, fructose, yeast and distilled $\left.\mathrm{H}_{2} \mathrm{O}\right)$ in a beaker with warm water cool enough for hands to touch $\left(45-55^{\circ} \mathrm{C}\right)$ and ensure everything is dissolved before decanting into the royal jelly and mixing with a spatula. This solution can then be aliquoted for daily feeding dependent on the number of larvae being reared. It is important to warm the diet to $35.4^{\circ} \mathrm{C}$ before feeding to avoid chilling the larvae.

\section{Mortality}

The presence of dead larvae in the feeding plates increases the likelihood of bacterial or fungal infection and increases the risk of mortality in the rest of larval cohort. Therefore, it is vital to remove dead larvae as soon as possible to prevent decomposition by bacterial or fungal saprophytes and contamination of the rest of the larvae. Dead larvae can be recognized by the following symptoms, either by eye or under a dissecting microscope: absence of movement (particularly in older instars), lack of turgidity, flattened body, discolouration or necrosis of tissue (Genersch et al., 2005, 2006). (Figure 3B) Additionally, any eggs that have not hatched after 90 hours post-oviposition should be removed. 


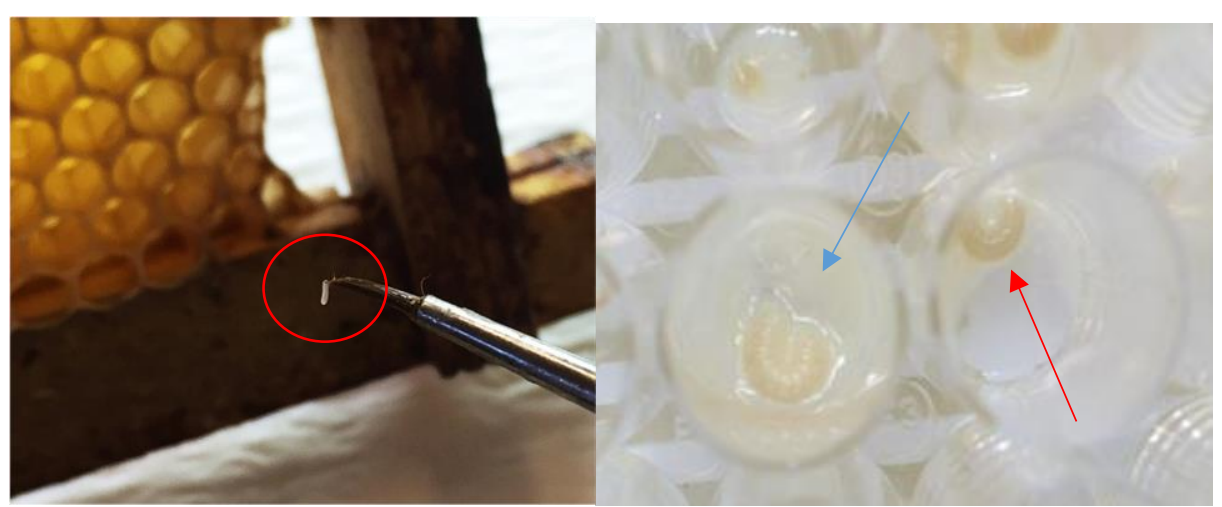

Figure $5 \mathrm{~A}$, honey bee egg removed from comb using a size 0 paint brush with damp bristles tapered to a point. B, Visual difference between alive larvae (blue arrow) and dead larvae (red), distinguishable by discolouration.

\section{Customized protocol}

- Honey bee eggs are kept in-comb until hatching. If using a removable queen excluder comb, the excluder should be kept upright in a large air tight container, as occurs in the hive. The eggs must be checked multiple times per day, and once a few eggs are seen to be hatching, the comb should be placed flat so there is no sliding of the first instar larvae.

- If the eggs are required to be moved prior to hatching, eggs should be grafted as groups of 3 into the wells of 24-well cell culture plates using the end of a size 1 paint brush with dampened and tapered bristles (Fig 4a). A light dissecting microscope may help with this. Alternatively, resting the comb with the light source positioned behind the wax frame may help to visualize the eggs. Eggs are very easily damaged (Collins, 2004) and are prone to being bent, squashed and pierced. In order to minimize trauma, eggs should be placed into their respective wells by rotating the paint brush during the placement to reduce pressure or smearing of the egg. Wegner, et al. (2009) provide additional options for moving eggs.

- Dependent on the frequency of visits affordable each day, if the eggs are close to hatching ( $<48$ hours since ovideposition) a small quantity of diet (see section 'Preparation of diet' above) can be placed below the eggs to ensure adequate food for the larvae upon hatching. This is done ad lib using a small spatula, placed in the centre of the well and spread to the base of the eggs in a thin layer to prevent potential drowning of the larvae upon hatching. Larvae should be placed with the same side up as they hatched, as their spiracles used for respiration are found here. Turning them will result in suffocation, and in the presence of liquid food, drowning.

- Once hatched, $1^{\text {st }}$ instar larvae are transferred with a paint brush in the same manner as eggs, with a thick smear of diet placed near the head using a paintbrush. Alternatively, the diet can be aliquoted onto the plate and the larvae gently placed on top. This increases the risk of drowning but there is a 
smaller likelihood of the diet drying out, so the larvae need to be checked less frequently during this stage.

- Larvae below instar three should be fed using a paint brush. The diet should be smeared in the well with the majority of diet placed near the larva's head. If the head is unable to be determined from the posterior end of the larvae (as young larvae are relative homogenous looking, and mouthparts are difficult to distinguish without microscopy), equal amounts can be placed on each end.

- Larvae should be checked preferably every 4 hours to replace food. It is important to provide adequate diet when the larvae are being left unattended overnight.

- In general, the larvae should receive approximately $10 \mu \mathrm{L}$ of diet each on the first day (Aupinel, et al., 2005), and increase as development continues. However, as long as a balance can be reached between providing adequate quantities of food without drowning, the exact quantities of food does not matter. This can be measured by eye within reason. If they have eaten their allotted food, provide more.

- If there is diet remaining from the previous day, siphon it away using a pipette before supplying fresh diet as the water component of the diet will eventually separate and increasing the risk of drowning.

- As the larvae grow and moult, they can have their food carefully pipetted next to their mouthparts. As the larva grows the risk of drowning decreases.

\section{Pupation}

- On the $6^{\text {th }}$ day the larvae may start depositing uric acid crystals on the dorsal side of the body. This is an indication of their reaching the defecation stage and predicts the beginning of the spinning stage. The larvae should now be removed from the feeding dishes and transferred to larger petri dishes (100 x $15 \mathrm{~mm}$ ), lined with Kimwipes ${ }^{\oplus}$ tissue paper.

- The next day, the old Kimwipes ${ }^{\circledast}$ tissue paper containing feces should be removed and the larvae should be moved to fresh tissue and transferred to $80 \% \mathrm{RH}$. Once defecation ends, spinning will begin and the larval will initiate pupation. For workers, pupation lasts approximately 9 days.

- Any dead or non-pupated larvae should be removed after 24 hours. 


\section{REFERENCES}

Aupinel, P., Fortini, D., Dufour, H., Tasei, J., Michaud, B., Odoux, J., \& Pham-Delegue, M. (2005). Improvement of artificial feeding in a standard in vitro method for rearing Apis mellifera larvae. Bulletin of Insectology, 58(2), 107.

Bertholf, L. (1925). The moults of the honeybee. Journal of Economic Entomology, 18(2), 380-384.

Collins, A. M. (2002). Collection of honey bee eggs for cryopreservation. Journal of Apicultural Research, 41(3-4), 89-95.

Collins, A. M. (2004). Variation in time of egg hatch by the honey bee, Apis mellifera (Hymenoptera: Apidae). Annals of the Entomological Society of America, 97(1), 140-146.

Collins, A. M., \& Mazur, P. (2006). Chill sensitivity of honey bee, Apis mellifera, embryos. Cryobiology, 53(1), 22-27.

Crailsheim, K., Brodschneider, R., Aupinel, P., Behrens, D., Genersch, E., Vollmann, J., \& RiessbergerGallé, U. (2013). Standard methods for artificial rearing of Apis mellifera larvae. Journal of Apicultural Research, 52(1), 1-16.

Dearden, P. K. (2006). Germ cell development in the Honeybee (Apis mellifera); Vasa and Nanos expression. BMC Developmental Biology, 6(1), 6.

Genersch, E., Ashiralieva, A., \& Fries, I. (2005). Strain-and genotype-specific differences in virulence of Paenibacillus larvae subsp. larvae, a bacterial pathogen causing American foulbrood disease in honeybees. Applied and Environmental Microbiology, 71(11), 7551-7555.

Genersch, E., Forsgren, E., Pentikäinen, J., Ashiralieva, A., Rauch, S., Kilwinski, J., \& Fries, I. (2006). Reclassification of Paenibacillus larvae subsp. pulvifaciens and Paenibacillus larvae subsp. larvae as Paenibacillus larvae without subspecies differentiation. International Journal of Systematic and Evolutionary Microbiology, 56(3), 501-511.

Human, H., Brodschneider, R., Dietemann, V., Dively, G., Ellis, J. D., Forsgren, E., . . Jaffé, R. (2013). Miscellaneous standard methods for Apis mellifera research. Journal of Apicultural Research, 52(4), 1-53.

Kaftanoglu, O., Linksvayer, T. A., \& Page Jr, R. E. (2010). Rearing honey bees (Apis mellifera L.) in vitro: effects of feeding intervals on survival and development. Journal of Apicultural Research, 49(4), 311-317.

Kaftanoglu, O., Linksvayer, T. A., \& Page Jr, R. E. (2011). Rearing honey bees, Apis mellifera, in vitro 1: effects of sugar concentrations on survival and development. Journal of Insect Science, 11(96), 110. 
Matheson, A., \& Reid, M. (2011). Practical Beekeeping in New Zealand: The Definitive Guide: Completely Revised and Updated: Exisle Publishing.

Peng, Y.-S. C., Mussen, E., Fong, A., Montague, M. A., \& Tyler, T. (1992). Effects of chlortetracycline of honey bee worker larvae reared in vitro. Journal of Invertebrate Pathology, 60(2), 127-133.

Rembold, H., Kremer, J.-P., \& Ulrich, G. M. (1980). Characterization of postembryonic developmental stages of the female castes of the honey bee, Apis mellifera L. Apidologie, 11(1), 29-38.

Rembold, H., \& Lackner, B. (1981). Rearing of honeybee larvae in vitro: Effect of yeast extract on queen differentiation. Journal of Apicultural Research, 20(3), 165-171.

Salmela, H., Amdam, G. V., \& Freitak, D. (2015). Transfer of immunity from mother to offspring is mediated via egg-yolk protein vitellogenin. PLoS Pathogens, 11(7), e1005015.

Vandenberg, J., \& Shimanuki, H. (1987). Technique for rearing worker honeybees in the laboratory. Journal of Apicultural Research, 26(2), 90-97.

Vojvodic, S., Jensen, A. B., James, R., Boomsma, J. J., \& Eilenberg, J. (2011). Temperature dependent virulence of obligate and facultative fungal pathogens of honeybee brood. Veterinary Microbiology, 149(1-2), 200-205.

Wegener, J., Al-Kahtani, S., \& Bienefeld, K. (2009). Collection of viable honey bee (Apis mellifera) larvae after hatching in vitro. Journal of Apicultural Research, 48(2), 115-120. 


\section{APPENDIX 2}

\section{Phylogenetic analysis accession numbers}

Table S1 Accession numbers for taxa examined in the phylogenetic analysis in Figure 2. Ordered by host species in alphabetical order for all available sequences for $16 S$, gltA, groEL, ftsZ, and wsp for each species.

\begin{tabular}{|c|c|c|c|c|c|c|c|}
\hline \multirow[b]{2}{*}{$\begin{array}{l}\text { Wolbachia host } \\
\text { species }\end{array}$} & \multirow[b]{2}{*}{ Order } & \multirow[b]{2}{*}{ Supergroup } & \multicolumn{5}{|c|}{ Accession numbers } \\
\hline & & & $16 S$ & gltA & groEL & $f t s Z$ & $w s p$ \\
\hline Aphis fabae & Hemiptera & M & JX296462 & JN316248 & JN316284 & HQ843854 & EU822302 \\
\hline Apis mellifera & Hymenoptera & A & EF032158 & - & - & - & - \\
\hline $\begin{array}{l}\text { Apis mellifera } \\
\text { capensis }\end{array}$ & Hymenoptera & $\mathrm{B}$ & - & - & - & - & FJ438823 \\
\hline $\begin{array}{l}\text { Apis mellifera } \\
\text { scutellata }\end{array}$ & Hymenoptera & B & - & - & - & - & AF510085 \\
\hline $\begin{array}{l}\text { Armadillidium } \\
\text { vulgare }\end{array}$ & Isopod & $\mathrm{B}$ & AJ133196 & FJ390331 & FJ390366 & DQ778102 & AJ419987 \\
\hline Asobara tabida & Hymenoptera & A & FJ603467 & - & AY714809 & - & AY581189.1 \\
\hline Bemisia tabaci & Lepidoptera & $\mathrm{O}$ & KF454771 & KF587270 & KF452543 & - & KX650070 \\
\hline $\begin{array}{l}\text { Brevicoryne } \\
\text { brassicae }\end{array}$ & Hemiptera & M & JX296429 & JN316250 & JN316284 & $\mathrm{JN} 316233$ & - \\
\hline Brugia malayi & Spirurida & $\mathrm{D}$ & AJ010275 & AJ609643 & AF373870 & AJ010269 & AY52702 \\
\hline Brugia pahangi & Spirurida & $\mathrm{D}$ & AJ012646 & AJ609642 & AJ609654 & AJ010270 & - \\
\hline Bryobia sp. & Spider mite & $\mathrm{K}$ & EU499316 & EU499326 & EU499331 & EU499321 & JN572881 \\
\hline $\begin{array}{l}\text { Coptotermes } \\
\text { acinaciformis }\end{array}$ & Dictyoptera & $\mathrm{F}$ & DQ837197 & - & AJ627384 & - & AJ833931 \\
\hline $\begin{array}{l}\text { Coptotermes } \\
\text { lacteus }\end{array}$ & Dictyoptera & $\mathrm{F}$ & DQ837199 & - & AJ627385 & - & AJ833930 \\
\hline $\begin{array}{l}\text { Cordylochernes } \\
\text { scorpioides }\end{array}$ & Pseudoscorpian & $\mathrm{O}$ & - & FJ390336 & FJ390370 & AY916134 & AY916133 \\
\hline $\begin{array}{l}\text { Ctenocephalides } \\
\text { felis }\end{array}$ & Siphonaptera & I & AY157504 & AJ609650 & AJ609659 & AJ628415 & KY363325 \\
\hline Culex pipiens & Diptera & B & KJ512994 & AY714785 & - & - & - \\
\hline $\begin{array}{l}\text { Culex } \\
\text { quinquefasciatus }\end{array}$ & Diptera & $\mathrm{B}$ & KX611381 & AY714789 & AY714804 & - & - \\
\hline $\begin{array}{l}\text { Dipetalonema } \\
\text { gracile }\end{array}$ & Spirurida & $\mathrm{J}$ & KY255233 & AJ609648 & AJ609658 & - & - \\
\hline $\begin{array}{l}\text { Dirofilaria } \\
\text { immitis }\end{array}$ & Spirurida & $\mathrm{C}$ & Z49261 & AJ609641 & AJ558023 & AJ010272 & KF359767 \\
\hline
\end{tabular}




\begin{tabular}{|c|c|c|c|c|c|c|c|}
\hline $\begin{array}{l}\text { Dirofilaria } \\
\text { repens }\end{array}$ & Spirurida & $\mathrm{C}$ & $\mathrm{AJ} 276500$ & - & AJ609653 & AJ010273 & AJ232176 \\
\hline $\begin{array}{l}\text { Drosophila } \\
\text { melanogaster }\end{array}$ & Diptera & A & AB360385 & AE017260 & AE017257 & U28189 & KX650072 \\
\hline $\begin{array}{l}\text { Drosophila } \\
\text { simulans }\end{array}$ & Diptera & A & DQ235280 & AY714792 & AY714807 & AY227739 & DQ235409 \\
\hline $\begin{array}{l}\text { Drosophila } \\
\text { simulans }\end{array}$ & Diptera & A & DQ235279 & AY714790 & AY714805 & AY508998 & AF020068 \\
\hline $\begin{array}{l}\text { Drosophila } \\
\text { simulans }\end{array}$ & Diptera & A & DQ235278 & AY714791 & AY714806 & U28178 & AF020070 \\
\hline $\begin{array}{l}\text { Drosophila } \\
\text { simulans }\end{array}$ & Diptera & B & DQ235288 & AY714787 & AY714800 & AY509001 & AF020074 \\
\hline $\begin{array}{l}\text { Encarsia } \\
\text { formosa }\end{array}$ & Hymenoptera & A & AF045189 & AY714783 & AY714797 & U28196 & FJ222455 \\
\hline $\begin{array}{l}\text { Folsomia } \\
\text { candida }\end{array}$ & Collembola & $\mathrm{E}$ & KU255239 & AJ609649 & - & AJ344216 & KT799615 \\
\hline $\begin{array}{l}\text { Kalotermes } \\
\text { flavicollis }\end{array}$ & Dictyoptera & $\mathrm{F}$ & Y11377 & AJ609651 & AJ609660 & AJ292345 & - \\
\hline $\begin{array}{l}\text { Leptopilina } \\
\text { australis }\end{array}$ & Hymenoptera & B & - & - & AY714802 & - & AF071920 \\
\hline $\begin{array}{l}\text { Litomosoides } \\
\text { brasiliensis }\end{array}$ & Spirurida & $\mathrm{D}$ & KU255241 & AJ609646 & AJ609655 & - & AF409112 \\
\hline $\begin{array}{l}\text { Litomosoides } \\
\text { hamletti }\end{array}$ & Spirurida & $\mathrm{D}$ & KU255244 & - & AJ609656 & - & - \\
\hline $\begin{array}{l}\text { Litomosoides } \\
\text { sigmodontis }\end{array}$ & Spirurida & $\mathrm{D}$ & FR827944 & AJ609645 & AF409113 & AJ010271 & - \\
\hline $\begin{array}{l}\text { Mansonella } \\
\text { ozzardi }\end{array}$ & Spirurida & $\mathrm{F}$ & AJ279034 & AJ609647 & AJ609657 & - & - \\
\hline Mansonella sp. & Spirurida & $\mathrm{F}$ & AJ279034 & AJ628413 & AJ628412 & AJ628414 & - \\
\hline $\begin{array}{l}\text { Mellitobia } \\
\text { digitata }\end{array}$ & Hymenoptera & A & - & - & AY714808 & - & KS308227 \\
\hline $\begin{array}{l}\text { Mesaphorura } \\
\text { italica }\end{array}$ & Isoptera & $\mathrm{H}$ & AJ575104 & - & - & AJ575103 & - \\
\hline $\begin{array}{l}\text { Microcerotermes } \\
\text { sp }\end{array}$ & Dictyoptera & $\mathrm{F}$ & AJ292347 & - & AJ628411 & AJ292346 & - \\
\hline Nasonia giraulti & Hymenoptera & A & M84690 & AY714793 & AY714810 & U28182 & AY622512 \\
\hline $\begin{array}{l}\text { Nasonia } \\
\text { longicornis }\end{array}$ & Hymenoptera & B & M84692 & AY714794 & AY714811 & - & AF448385 \\
\hline $\begin{array}{l}\text { Nasonia } \\
\text { vitripennis }\end{array}$ & Hymenoptera & A & - & AY714795 & AY714812 & U28188 & DQ508544 \\
\hline $\begin{array}{l}\text { Nasutitermes } \\
\text { nigriceps }\end{array}$ & Isoptera & $\mathrm{H}$ & DQ837204 & FJ390333 & - & FJ390318 & - \\
\hline $\begin{array}{l}\text { Onchocerca } \\
\text { gibsoni }\end{array}$ & Spirurida & $\mathrm{C}$ & - & AJ609639 & AJ609652 & AJ010267 & AJ 252178 \\
\hline $\begin{array}{l}\text { Onchocerca } \\
\text { gutturosa }\end{array}$ & Spirurida & $\mathrm{C}$ & AF172401 & - & - & AJ010268 & - \\
\hline $\begin{array}{l}\text { Onchocerca } \\
\text { ochengi }\end{array}$ & Spirurida & $\mathrm{C}$ & AJ276499 & AJ609640 & - & AJ010266 & AJ 252178 \\
\hline $\begin{array}{l}\text { Onchocerca } \\
\text { volvulus }\end{array}$ & Spirurida & $\mathrm{C}$ & AJ276498 & - & Y09416 & AJ276501 & - \\
\hline $\begin{array}{l}\text { Protocalliphora } \\
\text { sialia }\end{array}$ & Hymenoptera & $\mathrm{B}$ & X62247 & AY714788 & AY714801 & U28202 & AY622511 \\
\hline $\begin{array}{l}\text { Radopholus } \\
\text { similis }\end{array}$ & Spirurida & $\mathrm{L}$ & & - & EU833484 & EU833483 & - \\
\hline $\begin{array}{l}\text { Syringophilopsis } \\
\text { turdi }\end{array}$ & Parasitiformes & $\mathrm{F}$ & KP114103 & KP114117 & - & - & - \\
\hline $\begin{array}{l}\text { Torotrogla } \\
\text { carduelia }\end{array}$ & Parasitiformes & Q & KP114100 & - & - & - & -- \\
\hline
\end{tabular}




\begin{tabular}{|c|c|c|c|c|c|c|c|}
\hline $\begin{array}{l}\text { Torotrogla } \\
\text { lusciniaea }\end{array}$ & Parasitiformes & $P$ & & KP114118 & KP114120 & - & - \\
\hline $\begin{array}{l}\text { Torotrogla } \\
\text { merulaea }\end{array}$ & Parasitiformes & $\mathrm{P}$ & KP114099 & - & KP114119 & KP114113 & - \\
\hline $\begin{array}{l}\text { Torotrogla } \\
\text { rubeculia }\end{array}$ & Parasitiformes & $P$ & AY764280 & AY714784 & KP114123 & - & - \\
\hline $\begin{array}{l}\text { Toxoptera } \\
\text { aurantii }\end{array}$ & Hemiptera & $\mathrm{N}$ & JN384094 & - & - & - & - \\
\hline $\begin{array}{l}\text { Tribolium } \\
\text { confusum }\end{array}$ & Coleoptera & A & LO2883 & AY714784 & AY714798 & U28194 & KJ152796 \\
\hline $\begin{array}{l}\text { Trichogramma } \\
\text { cordubensis }\end{array}$ & Hymenoptera & B & AJ292347 & - & AY714803 & - & AF245164 \\
\hline $\begin{array}{l}\text { Wuchereria } \\
\text { bancrofti }\end{array}$ & Spirurida & D & AF093510 & AJ609644 & - & AF081198 & DQ235409 \\
\hline $\begin{array}{l}\text { Zootermopsis } \\
\text { angusticollis }\end{array}$ & Isoptera & $\mathrm{H}$ & AY764280 & AY764281 & AY764278 & AY764283 & - \\
\hline $\begin{array}{l}\text { Zootermopsis } \\
\text { nevadensis }\end{array}$ & Isoptera & $\mathrm{H}$ & - & AY764282 & AY764278 & AY764284 & - \\
\hline \multicolumn{8}{|l|}{ Outgroup } \\
\hline $\begin{array}{l}\text { Ehrlichia } \\
\text { chaffeensis }\end{array}$ & Rickettsiales & & СР007480 & AF304142 & - & AF221944 & - \\
\hline $\begin{array}{l}\text { Ehrlichia } \\
\text { ruminantium }\end{array}$ & Rickettsiales & & NR074155 & DQ513390 & DQ647013 & DQ647000 & - \\
\hline
\end{tabular}




\section{APPENDIX 3}

\section{Primers}

Table S2 Primers used throughout this thesis

\begin{tabular}{|c|c|c|c|c|}
\hline Locus & Primer (F/R) & Primer sequence (5'-3') & PCR type & Reference \\
\hline \multirow{2}{*}{$16 \mathrm{~S}$} & \multirow{2}{*}{ Wspecf/Wspecr } & CATACCTATTCGAAGGGATAG & \multirow{2}{*}{ Standard } & \multirow{2}{*}{$\begin{array}{l}\text { Werren et al., } \\
2000\end{array}$} \\
\hline & & AGCTTCGAGTGAAACCAATTC & & \\
\hline \multirow{2}{*}{ FtsZ } & \multirow{2}{*}{ ftsZ_F1/ftsZ_R1 } & ATYATGGARCATATAAARGATAG & \multirow{2}{*}{ Standard } & \multirow{2}{*}{$\begin{array}{l}\text { Baldo et al., } \\
2006\end{array}$} \\
\hline & & TCRAGYAATGGATTRGATAT & & \\
\hline \multirow{2}{*}{ groEL } & \multirow{2}{*}{ WgroF1/ WgroRev1 } & CAACRGTRGSRRYAACTGCDGG & \multirow{2}{*}{ Standard } & \multirow{2}{*}{$\begin{array}{l}\text { Casiraghi et } \\
\text { al., } 2005\end{array}$} \\
\hline & & GATADCCRCGRTCAAAYTGC & & \\
\hline \multirow{2}{*}{$\mathrm{FbpA}$} & \multirow{2}{*}{ FbpA_F1/fbpA_R1 } & GCTGCTCCRCTTGGYWTGAT & \multirow{2}{*}{ Standard } & \multirow{2}{*}{$\begin{array}{l}\text { Baldo et al., } \\
2006\end{array}$} \\
\hline & & CCRCCAGARAAAAYYACTATTC & & \\
\hline \multirow{2}{*}{ wsp } & \multirow{2}{*}{$81 \mathrm{~F} / 691 \mathrm{R}$} & TGGTCCAATAAGTGATGAAGAAAC & \multirow{2}{*}{ Standard } & \multirow{2}{*}{$\begin{array}{l}\text { Zhou et al., } \\
1998\end{array}$} \\
\hline & & AAAAATTAAACGCTACTCCA & & \\
\hline \multirow{2}{*}{$\begin{array}{l}\text { Deformed wing } \\
\text { virus }\end{array}$} & \multirow{2}{*}{ DWV_F/DWV_R } & TCCATCAGGTTCTCCAATAACGGA & \multirow{2}{*}{ RT-PCR } & \multirow{2}{*}{$\begin{array}{l}\text { Yue \& } \\
\text { Genersch, } \\
2005\end{array}$} \\
\hline & & CCACCCAAATGCTAACTCTAAGCG & & \\
\hline \multirow{2}{*}{ abaecin } & \multirow{2}{*}{ Abaec_F1/Abaec_R1 } & CAGCATTCGCATACGTACCA & \multirow{2}{*}{ RT-qPCR } & \multirow{2}{*}{ Evans, 2004} \\
\hline & & GACCAGGAAACGTTGGAAAC & & \\
\hline \multirow{2}{*}{ apidaecin } & \multirow{2}{*}{ apidF1/ApidR1 } & TAGTCGCGGTATTTGGGAAT & \multirow{2}{*}{ RT-qPCR } & \multirow{2}{*}{$\begin{array}{l}\text { Evans et al } \\
2006\end{array}$} \\
\hline & & TTTCACGTGCTTCATATTCTTCA & & \\
\hline \multirow{2}{*}{ defensin 1} & \multirow{2}{*}{ Defen1F/DefenR } & TGCGCTGCTAACTGTCTCAG & $\mathrm{PT} A \mathrm{PCP}$ & Franc 2004 \\
\hline & & AATGGCACTTAACCGAAACG & KI-qPCR & Evans, 2004 \\
\hline 1. & 1 & CTCTTCTGTGCCGTTGCATA & DT & Evans et al \\
\hline nymenoptaecin & 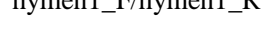 & GCGTCTCCTGTCATTCCATT & К1-qPCK & \\
\hline Mel & w $f / w 1$ & GCTCCTCTGGTTGCTACTGG & TRD & Lee, et al., \\
\hline wMlel & WI_t/WI_R & ACTATGCCATCGCGTTTTGC & RI-qPCR & 2012 \\
\hline Pros 54 & nros54 F/nros54 P & TCGAACCAAGATGGTACTGGAA & $\mathrm{PT} A \mathrm{PCP}$ & Cameron et \\
\hline 110554 & piOs 34 _T/PIOSJ4_K & TTGTTGTGCTTGCAGTCGTG & К1-पРСК & al., 2013 \\
\hline
\end{tabular}

